\title{
Copyright
}

by

Amy Elizabeth Coren

2007 
The Dissertation Committee for Amy Elizabeth Coren Certifies that this is the approved version of the following dissertation:

\section{Bridging the WTA-WTP gap: Ownership, bargaining, and the endowment effect}

\section{Committee:}

Randy L. Diehl, Supervisor

Matthew McGlone

Jeffrey Lowenstein

Robert Josephs

Lynn Blais

Frank Cross 
Bridging the WTA-WTP gap: Ownership, bargaining, and the endowment effect

\author{
by
}

Amy Elizabeth Coren, B.A; M.A.

\author{
Dissertation \\ Presented to the Faculty of the Graduate School of \\ The University of Texas at Austin \\ in Partial Fulfillment \\ of the Requirements \\ for the Degree of \\ Doctor of Philosophy
}

The University of Texas at Austin

August 2007 


\section{Dedication}

This dissertation is dedicated to my popa, who first inspired in me a love of learning,

and

David, who told me to “just keep swimming” 


\section{Acknowledgements}

I have been so fortunate to have had the support of a number of amazing individuals throughout the development of this dissertation. First and foremost, I would like to thank my graduate advisor, Dr. Randy Diehl, for his unwavering support in my many endeavors over my graduate career and all of the warm advice and engaging conversations. I would also like to acknowledge Dr. Diehl's support for the inter-disciplinary Ph.D. program, without which I might never have completed the current dissertation.

I am also tremendously grateful to Dr. Jeffrey Loewenstein, who became my adopted advisor over the course of this dissertation and whose guidance has helped refine and shape many of the ideas in the current document. Dr. Loewenstein unselfishly devoted many hours to discussion of my dissertation and whose suggestions and criticisms have led to great improvements in my own scholarship. In addition, his support was integral to getting the data collected for this dissertation.

The members of my dissertation committee, Dr. Randy Diehl, Dr. Jeffrey Loewenstein, Dr. Matt McGlone, Dr. Robert Josephs, Lynn Blais, and Frank Cross, provided wonderful comments that have greatly improved the quality of this dissertation and also inspired a number of future projects. My sincerest thanks to all of you.

I wouldn't have made it through any of this without the support of friends and family. I would like to say thank you to Dr. Sarah Hill, Chris Henry, and Dr. Nicolle Matthews for their tremendous support over the last few years. Sarah, thank you for all of the advice and help with the dissertation, the formatting issues, and the final defense. Chris, what would I have done with you and your conference room? I am eternally grateful! I would also like to thank Amy, Bill, Shari, Jean, and the rest of the FAA for all of their support and patience as I have gone through 
this process. I am blessed to count you as my friends. Amy, thank you for ensuring I got up on Saturday mornings so I could write on the dissertation later in the day. You provided much needed support on many occasions.

I would also like to thank my parents, Lance and Sue Coren, and my cousin cum little brother, Max for everything. They provided endless love and support through my many years of graduate school. I would also like to especially thank my nanny, Jayne Hodges, who graciously proofread this dissertation twice for spelling.

Lastly, I would like to thank my fiancé, David Gamage, for all his support and encouragement and especially for his patience during some of the more difficult times during the course of this dissertation. Thank you for everything. 


\title{
Bridging the WTA-WTP gap: Ownership, bargaining, and the endowment effect
}

Publication No.

\author{
Amy Elizabeth Coren, Ph.D. \\ The University of Texas at Austin, 2007
}

Supervisor: Randy L. Diehl

\begin{abstract}
Numerous studies have shown a discrepancy between how much an individual will accept to give up an object and how much an individual will pay to acquire the same good. This discrepancy is more commonly known as the endowment effect. Although scholars have generated a vast literature demonstrating the existence of the endowment effect, the underlying psychological mechanisms that account for this phenomenon remain a source of controversy. In the following dissertation, two different psychological processes are proposed to account for the WTP/WTA discrepancy: the use of a bargaining script and cognitive engagement through object interaction. Experiment 1 explores how the use of a bargaining schema affects buyers' and sellers' valuations of a mug. Experiment 2 examines the role object interaction plays in an individual's decisions
\end{abstract}


about an object's value. Each of these studies presents new data that provide novel insights into the potential psychological processes that underlie the endowment effect. 


\section{Table of Contents}

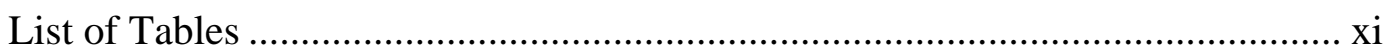

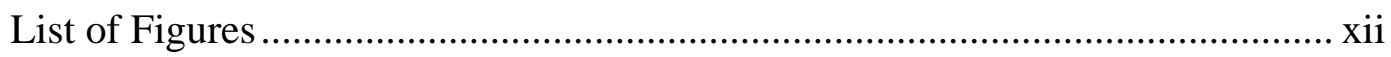

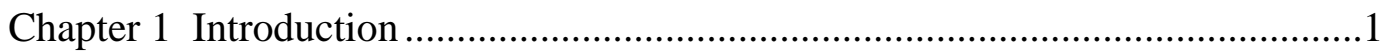

Chapter 2 Background and Literature Review.......................................................11

Prospect theory and the Origins of loss aversion...................................11

Recent developments in the literature.................................................16

Implications for Law and Policy..........................................................26

Chapter 3 Bargaining Behaviors ..............................................................................31

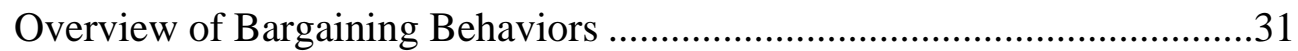

Bargaining experience, endowment, and the role of loss aversion.................34

Bargaining scripts and the source of the WTP/WTA values ..........................35

Buyer/Seller roles, experience, and the WTP/WTA disparity .........................38

Testing the bargaining script theory: Study 1 ..................................................46

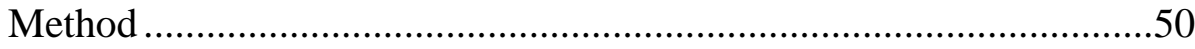

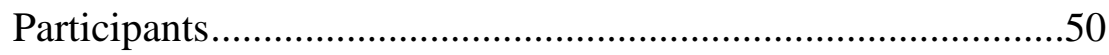

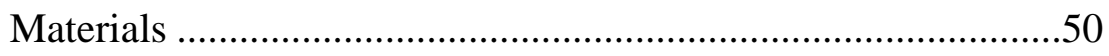

Procedure ………………………………………………..... 51

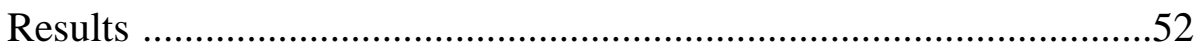

Role within Condition................................................................52

Role between Condition ..............................................................54

Language and Role ……………………………………….....57

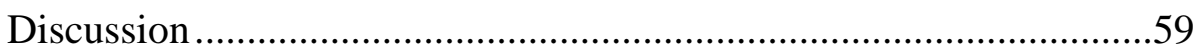

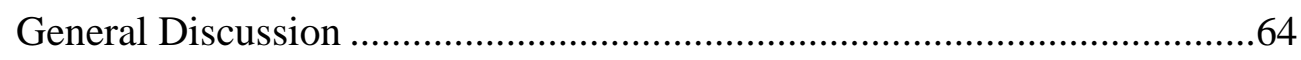

Limitations and future directions ..................................................................68

Chapter 4 Ownership and Engagement..............................................................70

Ownership, Identity, and Possessions ............................................................70 
Time, attachment, and the WTA/WTP disparity .......................................72

Cognitive Investment and the Instant Endowment Effect .........................74

Testing a theory of cognitive investment................................................77

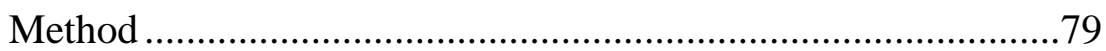

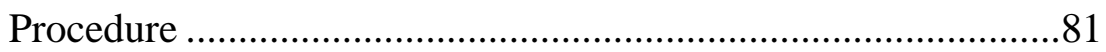

Results and Discussion .............................................................82

General discussion, limitations, and final considerations ..........................90

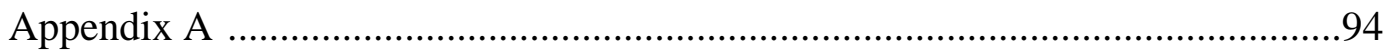

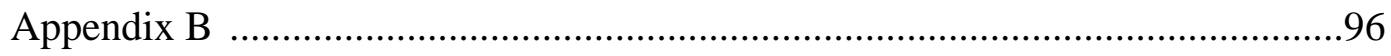

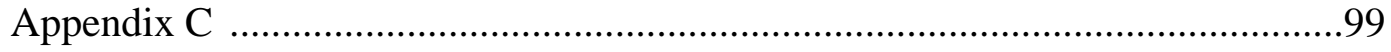

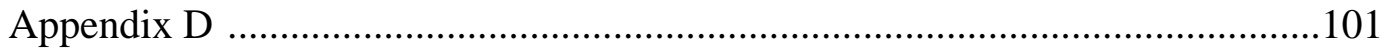

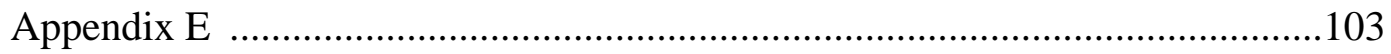

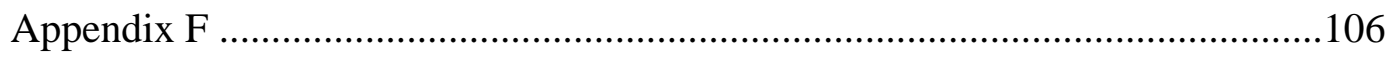

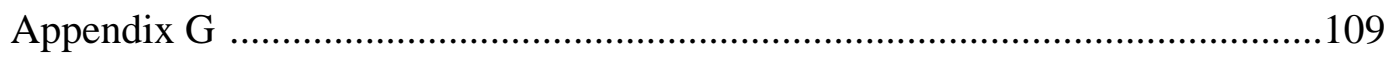

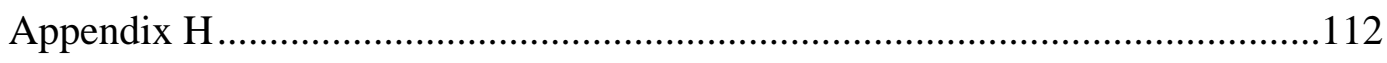

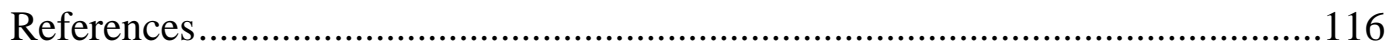

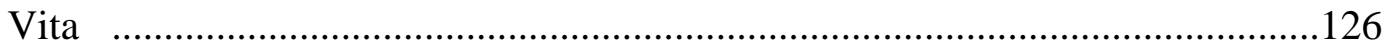




\section{List of Tables}

Table 1: $\quad$ Summary of predictions for Study 1 .................................................49

Table 2: Comparison of WTP/WTA means......................................................52

Table 3: Comparison of Buyers' WTP values (by Condition)...........................55

Table 4: $\quad$ Comparison of Sellers’ WTA values (by Condition) .........................56

Table 5: $\quad$ Summary of predictions for Study 2 .................................................79

Table 6: Mean pen valuation as a function of Ownership and Engagement...83

Table 7: Comparison of mean pen values by evaluation and ownership

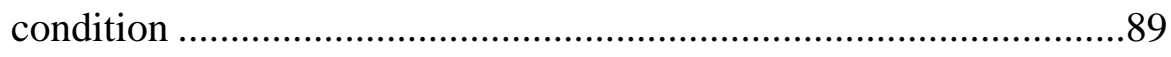




\section{List of Figures}

Figure 1: $\quad$ Standard economic utility curve .................................................11

Figure 2: $\quad$ Utility curve under a theory of loss aversion .................................14

Figure 3: $\quad$ WTP/WTA error bars for conditions in Study 1.............................54

Figure 4: $\quad$ Interaction between WTP/WTA values and Language ......................58

Figure 5: Histogram of pen valuations responses by condition ......................84

Figure 6: $\quad$ Price change as a function of ownership........................................85

Figure 7: $\quad$ Mean pen values for Engagement by Ownership ..........................87

Figure 8: Number of Positive vs. Negative Evaluations as a function of

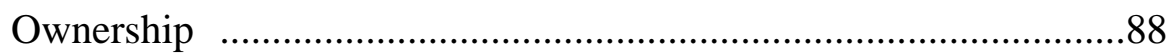

Figure 9: Comparison of mean pen values as a function of evaluation............89 


\section{Chapter One - Introduction}

"When we stand back and examine the literature on the endowment effect, it is difficult not to be impressed by how much attention the phenomenon has attracted in terms of number of publications. At the same time, it is surprising to observe how little is known about the psychology that underlies the phenomenon." (Ariely et al. 2005)

After twenty five years of research and a prolific number of publications on the subject, the behavioral phenomenon whereby ownership of an object appears to affect an individual's subjective value of that object is still the center of significant controversy. Although numerous studies have observed this phenomenon - known as the "endowment effect" (Thaler 1980) - over the past several decades, only modest progress (beyond Kahneman \& Tversky's 1979 theory of loss aversion) has been made toward understanding the psychology underlying this phenomenon. This dissertation provides two distinct approaches for understanding the source of the endowment effect (here characterized as the willingness-to-pay/willingness-to-accept gap): (1) a theory of bargaining scripts and (2) a theory of cognitive investment. The main contributions of these two theories will be to further our understanding of the psychological processes underlying how we place a subjective value on a given object and why these processes may contribute to the willingness-to-pay/willingness-to-accept disparity.

According to neoclassical economic theory, ownership of a good or object should not affect its valuation ${ }^{1}$. In other words, owners of a mug should not require a higher

\footnotetext{
${ }^{1}$ Following the assumptions of the utility theory in neoclassical economics, preferences should be independent of endowment (or ownership).
} 
price to give up their mug than buyers would be willing to pay to acquire the same mug. However, extensive research has shown that the price at which individuals will agree to give up a good or entitlement they are endowed with is considerably higher than the price the individuals would be willing to pay to obtain the same good or entitlement (Adamowicz et al. 1993, Hanemann 1991). For example, people were willing to pay up to \$31 to obtain a hunting permit, but were not willing to accept less than \$143 to give up the same permit already in their possession (Heberlein \& Bishop 1985). The implication of this willingness-to-pay/willingness-to-accept price gap (hereafter WTP/WTA gap), is that an item is more valuable to its owner than to its potential buyer. However, the question still remains: how and (more importantly) why does ownership of a good apparently affect its value?

To provide answers to these questions, the dominant paradigm relies on the theory of loss aversion as an explanatory mechanism for the endowment effect (Kahneman \& Tversky 1979, Thaler 1980, Tversky \& Kahneman 1991, Van Boven et al. 2000, Jolls et al. 1998). Loss aversion -that losses loom larger than equivalent gains (Kahneman \& Tversky 1984, Tversky \& Kahneman 1991) - suggests that owners who lose a good (through either trade or sale) experience that loss more acutely than they would experience the gain of an equivalent item. Thus, the higher prices demanded by owners (in the form of higher WTA values) reflect the greater impact of the losses they experience from having to give up their good, compared to the gains they would receive from acquiring the same good they did not already own (Bar-Hillel \& Neter 1996).

Although loss aversion continues to be the dominant explanation for the source of the WTP/WTA gap, the findings of several recent studies have cast some doubt as to 
whether or not loss aversion can provide satisfactory insight regarding the psychological phenomena underlying the endowment effect (Plott \& Zeiler 2005, Roth 2005, Strahilevitz \& Loewenstein 1998, Novemsky \& Kahneman 2005). For example, one recent criticism of loss aversion is that it fails to address the variability in the size of the WTP/WTA gap across studies (Korobkin 2003). If loss aversion provided a complete explanation for the source of this phenomenon, we would expect that the size of the endowment effect (expressed as the ratio of WTA/WTP) would be roughly equivalent for all goods and entitlements. However, a large number of studies have shown that there is considerable variability in the size of the WTA/WTP gap, and that the size of the gap is correlated with the type of good or entitlement (e.g. environmental goods create a larger endowment effect - expressed as a larger WTA/WTP gap - than do more traditional consumer goods) (Horowitz \& McConnell 2002).

Perhaps more problematic for the theory of loss aversion are more recent findings that a WTA/WTA gap is not always present under the circumstances that loss aversion would predict. The theory of loss aversion implies that the endowment effect should be present whenever a loss is incurred by an individual, regardless of the identity of the person experiencing the loss. For example, when faced with a situation where they may have to give up an object, all individuals should react roughly the same regardless of the situational circumstances or the identity of the individual. Yet, studies have shown that professional traders do not demonstrate an endowment effect (List 2003), nor do subjects situated within agency relationships (Arlen et al. 2001), or buyer's agents (Van Boven et al. 2003). Additionally, several recent experiments have failed to produce a WTA/WTA gap in numerous different experimental scenarios, contrary to the predictions of the 
theory of loss aversion (Singh 1991, Ortona \& Scacciati 1992, Shogren et al. 1994, Van Dijk \& Van Knippenberg 1996, Morrison 1997, Schmidt \& Traub 2003, Lerner et al. 2004, Blondel \& Lévy-Garboua 2005, Van de Ven et al. 2005, Plott \& Zeiler 2005, Roth 2006).

One of the most influential critiques of the theory of loss aversion was launched by Plott and Zeiler (2005) who recently proposed that the WTA/WTP gap is the result of study participants misunderstanding the instructions contained within endowment effect experiments (Plott \& Zeiler 2005). Under their theory of subject misconceptions, Plott and Zeiler argue that, "any observed WTP-WTA gap is not a reflection of a fundamental feature of human preferences" (pp 16), but rather, "the existence of such phenomenon is symptomatic of subjects' misconceptions about the nature of the experimental task" (pp 17).

In contrast to the theory of loss aversion, Plott and Zeiler's (2005) theory of subject misconceptions claims that the gaps between expressed willingness-to-pay and willingness-to-accept valuations do not represent the participants' actual valuations of the objects in question. Rather, these discrepant values result from the experimental participants mistakenly adjusting their reported values due to strategic behavior:

"[I]f a subject is asked to provide a 'selling price' that reflects his valuation for a good he owns, natural instincts might persuade him to announce an amount higher than his actual valuation. In fact, given bargaining instincts of sellers to inflate ask and buyers to deflate bids, those endowed with a good likely will ask for more than their non-strategic 
valuations while those not endowed with a good likely will bid less than their nonstrategic valuations." (Plott \& Zeiler 2005, pp. 11).

In other words, ownership only causes owners to increase their publicly expressed WTA valuations, while causing non-owners to lower their publicly expressed WTP valuations true private valuations, however, are not affected by ownership. Plott and Zeiler (2005) further argue that the previous literature has not adequately controlled for these strategic misrepresentations of public WTP and WTA valuations, and that the literature has consequently erred in assuming that the observed gap in publicly expressed WTA and WTP valuations indicates anything about the subjects' true private valuations.

The theory of bargaining scripts proposed in chapter three of this dissertation takes up Plott and Zeiler's (2005) theme of strategic valuation behavior and proposes that this behavior results from the use of bargaining scripts in situations which call for an individual to assign value to an object. Similar to Plott and Zeiler's (2005) theory of subject misconceptions, the proposed theory of bargaining scripts explains the source of the WTA/WTP disparity as the result of strategic motives on the part of experimental subjects. Whereas Plott and Zeiler claim that subjects misunderstand the instructions of the experiments they are engaged in and thus answer the experimental questions with strategically biased valuations for the objects in question rather than with their true valuations, the theory of bargaining scripts hypothesizes that the subjects' valuations of the objects are derived from the behavioral expectations specified through a "buy-low", "sell-high" bargaining script. When placed in a situation where they need to place a value on an object, the theory of bargaining scripts states that individuals activate this type of 
bargaining script to guide them in processing the incoming information (i.e. what values they should mark on a valuation sheet in an experiment).

As such, the theory of bargaining scripts posits a more developed psychological framework for understanding Plott and Zeiler's (2005) results. The theory of bargaining scripts is broadly compatible with Plott and Zeiler's (2005) theory of subject misconceptions, but represents a substantial elaboration on the internal psychological processes underlying experimental subjects" "misconceptions."

In addition to Plott and Zeiler (2005), the use of strategic behavior as underlying the source of the WTP/WTA disparity has also been examined in a number of studies by evolutionary theorists (Kirchsteiger \& Oechssler 1997, Carmon \& Ariely 2000, Jones 2001, Heifetz \& Segev 2001, Carmichael \& Macleod 2002, Friedman 2003, Huck et al. 2005). However, none of the evolutionary-based studies has adequately addressed the underlying psychological processes behind the evolutionary drives discussed in the studies. Instead, these studies relied on more formal evolutionary models to explain strategic valuation behavior in individuals (Huck et al. 2005), and speculating that expressions of strategic behavior were "hard-wired" rather than learned processes. Although the theory of bargaining scripts proposed in this dissertation acknowledges the contribution of these earlier studies and is broadly compatible with their results, it does not rest its assumptions on previous evolutionary models.

The second theory proposed in this dissertation is the theory of cognitive investment. Outlined in detail in chapter four, the theory of cognitive investment speculates that the source of the WTA/WTP disparity results from increased attachment with an object resulting from an individual's increased interaction (both physical and 
mental) with that object. That is, when an individual engages with an object - regardless of whether ownership is present - the individual will come to value the object higher than an individual who has not had the opportunity to interact with the object.

The theory of cognitive investment also provides an explanation for how the processes by which individuals form identification with an object and/or attachment to an object affects the value the individuals assign to the object. To illustrate, consider the following example: upon winning a turkey, the recipient (of the turkey) might start mentally planning a dinner involving the turkey and accompanying side dishes. Before winning the turkey, the recipient might have been indifferent between turkey and ham. Nevertheless, after winning the turkey, the recipient might demand a premium before exchanging her turkey for a ham, as she has already invested cognitive resources (i.e. mental energy) in the turkey by thinking of future uses for it (assuming the side dishes she was thinking of serving with the turkey would not be appropriate for ham). The higher price she demands reflects both the price of this "cognitive investment" and the cost to her of having to "rethink" her dinner plans to accommodate replacing the turkey with a ham.

Attachment and its effects on object value has been discussed in several earlier studies. Strahilevitz and Loewenstein (1998) demonstrated that the magnitude of the WTA/WTP gap increases the longer an object is owned. They hypothesize that this occurs due to the owner forming greater identification and/or attachment to the object in other words, becoming more cognitively invested. Indeed, numerous previous studies have documented that individuals become "invested" in their possessions over time in the form of increased attachment, and that this increased attachment and/or identification is 
the reason individuals place a greater value on their owned objects (Korobkin 2003, Ariely et al. 2005).

Nevertheless, the importance of attachment as an explanation for the source of the WTA/WTP disparity has been downplayed by the existing literature mainly due to the fact that the gap between owners' and non-owners' valuations shown by the endowment effect experiments arises nearly instantaneously (over a period of minutes or less). In light of these findings, Kahneman et al. (1990) used the term "instant endowment effect" to distinguish between the increased valuation they hypothesized was due to loss aversion from a more gradual increase in valuation that might result from identification and/or attachment. As Korobkin (2003) describes the prevailing view, "attachment seems a far less plausible explanation of the endowment effect in experiments in which subjects are asked to value consumer items just moments after they are randomly given the items" (pp.1251-52).

If the adherents of the theory of loss aversion are correct in claiming that attachment cannot occur quickly, then they are likely also correct in believing that attachment (or cognitive investment) cannot be a significant cause of the WTA/WTP disparity. However, none of these previous studies has directly tested whether or not attachment might occur quickly enough to motivate the WTA/WTP gap observed in the endowment effect experiments. The theory of cognitive investment proposed in this dissertation hypothesizes that a degree of attachment can develop rapidly enough to motivate observed WTA/WTP disparities. Although a complete process of attachment or cognitive investment may take significant time, it is proposed that a substantial degree of attachment can develop immediately upon engagement with an object. 
The process by which an individual comes to understand that she owns an object necessarily entails at least some degree of engagement with the object ${ }^{2}$. For example, Beggan \& Brown (1994) found that current users of an object had stronger claims of ownership than former users. Hence, the observed gaps between the WTA valuations assigned by owners and the WTP valuations assigned by non-owners may result from the owners having engaged more with the object as a result of the process by which they were assigned ownership. Returning to the turkey example, upon being informed that she now owns a turkey an individual might immediately begin mentally conceptualizing herself as a possessor of the turkey and thinking of potential future uses for the turkey. If the same individual was merely shown a turkey without any indication of ownership, she might not engage with the turkey to the same degree as she would have no reason to begin planning future uses for the turkey.

Any experiment which bestows experimental subjects with ownership of a good must necessarily cause the subjects to engage with that good through the process by which the state of ownership is conveyed. If - as the theory of cognitive investment predicts - engagement with an object increases the subjective value one assigns to the object, even over a period of minutes, then the WTA/WTP disparity may be caused by the engagement that results from the bestowal of ownership.

The remainder of this dissertation is organized as follows: Chapter two outlines the previous literature on the WTP/WTA disparity and the implications of this disparity for law and policy. Chapter three discusses the proposed theory of bargaining scripts and presents empirical evidence for this theory derived from study 1 . Chapter four details the

${ }^{2}$ Heider (1985) proposed that ownership could be conceptualized as the association between an object and an individual. 
proposed theory of cognitive investment and presents evidence for this theory derived from study 2. 


\section{Chapter Two - Background / Literature Review}

\section{Prospect Theory and the Origins of Loss Aversion}

The foundation of modern (neo-classical) economics is based on the assumption that people's behaviors (choices) are guided by instrumental reason; that is, people will behave in a manner that maximizes their utility according to their preferences. This is known as Rational Choice Theory (RCT) (Pyndick \& Rubinfeld 2001). Under RCT, choices are rational if they are utility maximizing - that among a set of feasible alternatives individuals choose whatever they most prefer. "Utility" is simply a way of indicating how preferences are ranked by an individual. It is not a substantive object of choice, and indeed it makes no sense to describe an individual as seeking or preferring utility. These preferences can be represented by a continuous 'utility function' such that $\mathrm{U}_{\mathrm{P}}(A)>\mathrm{U}_{\mathrm{P}}(B)$ if and only if an individual $P$ prefers $A$ to $B$ (Figure 1). Preferences are considered rational if they are complete and transitive. ${ }^{3}$

Figure 1. Standard utility curve

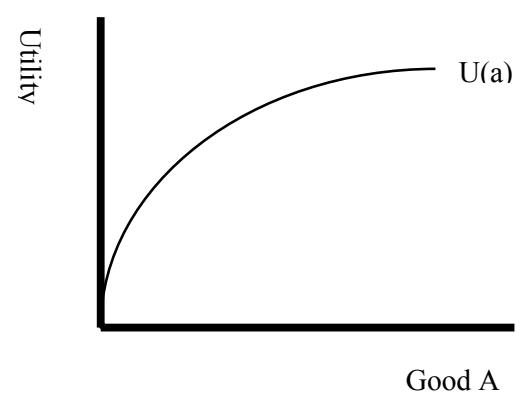

3 These descriptions of people's preferences are derived from fundamental axioms in economics. 
Using the principles of RCT as a foundation, Van Neumann and Morgenstern (1944) developed Expected Utility Theory (EUT) ${ }^{4}$ as a model to explain choice under uncertainty. More formally, EUT states that people's preferences for lotteries ${ }^{5}$ precede their preferences for outcomes. In other words, rather than be concerned for the utility derived from picking a particular lottery (distributional outcome), individuals' preferences are established over lotteries and from these preferences for certain lotteries (over others) that an individual's underlying utility can be deduced.

Despite the many contributions EUT has made as a model of decision making, discrepancies between the descriptive behavior predicted by EUT and the actual behavior observed in decision making under risk and uncertainty ${ }^{6}$ led to the development of alternative accounts to EUT. The most famous of these alternative accounts is Prospect Theory developed by Daniel Kahneman and Amos Tversky in 1979.

Kahneman and Tversky's Prospect Theory (PT) (1979) was intended as a descriptive account of decision making in response to mounting evidence that contradicted the following axioms of EUT: that (a) people's preferences are orderly and conform to a general law of diminishing returns, and (b) the assumption of rationality: that human behavior is "rational" in that choices can reasonably be expected to accomplish the decision-maker's goals. ${ }^{7}$ PT classifies these contradictions to EUT (and the underlying assumption of economic rationality) into the following categories:

\footnotetext{
${ }^{4}$ Daniel Bernoulli was actually the first person to develop the concept of expected utility in his solution to the St. Petersburg Paradox (1738). However, Bernoulli's work was not widely cited until the development of EUT by Van Neumann and Morgenstern in 1944.

5 The term "lottery" is defined here as a set of uncertain outcomes with their respective probabilities.

${ }^{6}$ E.g. the Allias Paradox (Allias, 1952).

${ }^{7}$ See appendix A at the end of this chapter for specifics on which contradictory evidence was most important.
} 
1. Framing - People make different choices depending on whether the same problem is presented as a loss or a gain. In more formal terms framing effects are viewed as preferences for differing perceived values, based on the assumption that losses are weighed more heavily than equivalent gains.

2. Nonlinear preferences - Explains the violation of axiom of transitivity in observable behavior. The axiom of transitivity states: if $X \rightarrow Y$ and $Y \rightarrow Z$, then $X \rightarrow Z$. Empirical evidence to the contrary has shown that people often make choices that are inconsistent with this axiom, violating the assumption of rationality.

3. Risk aversion and risk seeking - Some individuals will simultaneously and knowingly take unfair bets to avoid risk (e.g., by buying life insurance) and unfair bets that increase risk (e.g., betting at casinos).

4. Source - The mechanism may matter even if the probable outcomes of activities are identical. People may pay more for a good because of the way it is packaged than they will an item that they know to be identical but packaged differently, even if they intend to immediately discard the packaging.

5. Loss aversion - potential losses loom greater than relatively equal potential gains. The observed asymmetry in these differences is far too large to be explained solely by income effects. ${ }^{8}$

This dissertation will focus primarily on the last of the listed aspects of Prospect Theory - loss aversion. Under the framework of Prospect Theory, loss aversion refers to the tendency for people to prefer to avoid a loss more than they would prefer to acquire an equivalent gain (Kahneman and Tversky 1979, Tversky and Kahneman 1991). More

\footnotetext{
${ }^{8}$ The relationship between income effects and the WTA/WTP gap is discussed in more detail in section II of this chapter.
} 
formally, loss aversion states that there is a kink in individual utility functions at the reference point, such that utility results from changes in wealth rather than from absolute states and that decreases in wealth (losses) have larger impacts on utility than do increases in wealth (gains) (Figure 2).

\section{Figure 2. Utility curve under a theory of loss aversion}

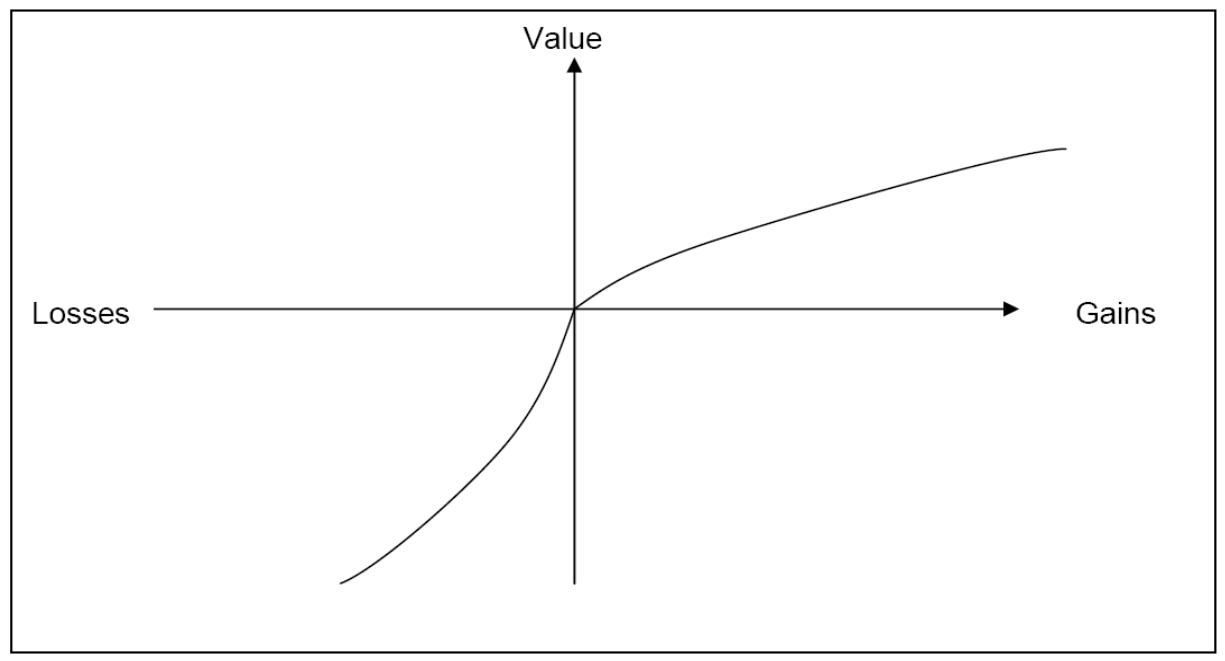

In 1980, Richard Thaler's paper, Toward a Positive Theory of Consumer Choice, drew on loss aversion as an explanation for choice in riskless decision making. Thaler noted that the values for a good already in the possession of a consumer were significantly higher than the values for a good on the shelf. He termed this discrepancy in buying and selling prices the "endowment effect," hence coining the term:

"... a certain degree of inertia is introduced into the consumer choice process since goods that are included in the individual's endowment will be more highly valued than those not held in the endowment... This follows because removing a good from the 
endowment creates a loss while adding the same good (to an endowment without it) generates a gain. Henceforth, I will refer to the underweighting of opportunity costs as the endowment effect." (Thaler 1980:44).

The "endowment effect," or the willingness-to-pay (WTP) willingness-to-accept (WTA) gap ${ }^{9}$, was initially reported in studies of contingent valuation (Cummings, Brookshire, Schultz 1986, Loomis, J. 1987) and in an early experimental setting by Knetsch (1989) who found WTP-WTA discrepancies for the buying and selling of chocolate bars. However, the most well-known endowment effect experiments are the famous mug studies by Kahneman, Knetsch, and Thaler (1990) (hereafter KKT). In these experiments, it was found that subjects provided a higher WTA value when the mug was in their possession and a lower WTP value when they were asked to purchase a mug.

KKT's results have been replicated by numerous other experiments, using a wide variety of goods, including: pens, movie tickets, hunting licenses, visibility, nuclear waste repositories, nasty-tasting liquids, sandwiches, etc. (Horowitz \& McConnell 2002). In comparing the various studies, Horowitz \& McConnell (2002) found that the WTP/WTA ratios revealed by laboratory experiments were not significantly different from those found in real world data - such as from contingent valuation studies. Although the various studies finding a WTA/WTP gap were met with widespread skepticism throughout the 1980's and 1990's, these results are now part of the standard canon.

\footnotetext{
${ }^{9}$ There is some argument as to whether these terms are actually interchangeable (Plott \& Zeiler 2005). For the purposes of this paper, endowment effect will be defined as the discrepancy between an individual's WTP-WTA prices for a good (the WTP-WTA gap).
} 
According to Huck et al. (2005), the existence of the WTA/WTP disparity "must by now be accepted as stylized fact."

\section{Recent Developments in the Literature}

Whereas the main focus of the first couple decades of research on the WTA/WTP gap was to prove the existence of the gap despite resistance and skepticism from mainstream economists, more recently the focus has shifted to showing that (1) the WTA/WTP disparity is context dependant and (2) attempting to explain the nature of this context dependency (Arlen et al. 2001, Korobkin 2003). Loss aversion remains the dominant theoretical explanation for the WTA/WTP gap; in the words of Novemsky and Kahneman (2005:120), "Most researchers accept loss aversion as both a description and an explanation of the phenomenon being studied [the WTA/WTP disparity]". Nevertheless, many scholars have interpreted some of the more recent empirical evidence on the WTA/WTP gap as being incompatible with the predictions of loss aversion. Although loss aversion continues to function as the dominant paradigm, an increasing number of scholars have begun promoting alternative theories in order to challenge the validity of loss aversion as a satisfactory and complete explanation for the WTA/WTP disparity (Brown 2005, Plott \& Zeiler 2005, Roth 2005, Gal 2006).

The theory of loss aversion states that the WTA/WTP gap arises from an inherent property of individual utility functions - that losses loom larger than gains (Kahneman \& Tversky 1979, 1991). Hence, loss aversion is generally interpreted as predicting that the magnitude of the WTA/WTP disparity should not vary significantly depending on the type of good being valued or the individual's relationship with the good to be valued 
(Korobkin 2003). Yet these predictions are inconsistent with much of the recent empirical evidence (Roth 2005).

For example, the WTA/WTP gap has been shown to increase in magnitude when a good is obtained as a result of skill or effort and to decrease in magnitude when a good is obtained as a result of chance (Loewenstein \& Issacharoff 1994) or as a gift (Klein, Klein, \& Allen 1995). It has also been demonstrated that the WTA/WTP gap can increase with length of ownership, such that a longer duration of ownership leads to an enhanced WTA/WTP disparity (Strahilevitz \& Lowenstein 1998). These results cannot easily be explained by a theory - such as loss aversion - that views the WTA/WTP gap entirely as a property inherent to individual utility functions (Plott \& Zeiler 2005, Roth 2005) and exogenous from outside features.

In addition, some studies have found that valuations conducted by agents - rather than by principles (i.e. buyer's agents) - do not demonstrate a WTA/WTP disparity. Arlen et al. (2002) found no gap for mugs when the subjects were told that the mugs were to be used as part of a business scheme and were to be valued based on their potential use in this money-making venture, even though the authors did find a gap for the same mugs when the subjects were told the mugs were theirs to keep and use (as a replication of the famous KKT (1990) study). The authors (Arlen et al. 2002) concluded that these results were "likely due to the fact that the agency context induces subjects to view property rights principally for their exchange value, thereby causing them to 'dis-endow' their initial legal entitlements."

However, despite the conclusions of Arlen et al. (2002), the evidence is still somewhat mixed as to whether agents display a WTA/WTP gap. Marshall et al. (1986) 
also found that subjects did not display a gap when asked to advise a friend about making purchases, but Korobkin (1998) did find a gap when law students were asked to advise hypothetical corporate clients on their purchasing decisions. Korobkin (2003) speculated that the difference between his results and the Marshall et al. (1986) results may be due to the fact that Korobkin's experiment instructed the subjects that their future job prospects partially depended on the success of the advice - thus giving them more of a personal stake in the outcome of the transaction - whereas instructions in Marshall et al. (1986) involved no personal stake for the experimental subjects.

Another interesting result from more recent studies is that the WTA/WTP disparity is larger for goods that are intended to be used by the individual making the valuation and smaller - or even nonexistent - for goods that are intended for resale (Adamowicz et al. 1993). According to Arlen et al. (2002:8), "the evidence does suggest that whether an object is viewed primarily for its consumption value or its exchange value does affect the endowment effect, although this can depend as much on the context of the exchange as on the attributes of the asset." These results are consistent with the studies of valuation by agents, as agents valuing a good on behalf of their principles operate in a similar fashion to individuals who value a good solely for its market - as opposed to use - potential. In both cases, the agent-individual making the valuation is looking not to their own subjective preferences, but to their best guesses as to the subjective preferences of others, with the others being either the specific principle or the generalized pool of market buyers. Regardless, other studies have shown that individuals (including buyer's agents) are not good at estimating the preferences of others. (Van Boven, Dunning, \& Loewenstein 2002) 
Similar to the studies of agency and use value, a number of studies have shown that the magnitude of the WTA/WTP gap alters depending on the type of good being studied and that the gap can even disappear for some types of goods (Roth 2005). In particular, a series of studies has shown that the WTA/WTP disparity diminishes for commodity-type goods and increases for more unique goods (Horowitz \& McConnell 2002). On the extreme condition, Van Dijk \& van Knippenberg (1996) found no gap whatsoever for money and for bargaining chips with fixed monetary values. In contrast, Samuelson and Zeckhauser (1988) did find a gap in studying the relative valuations subjects placed on a variety of securities and other financial instruments. Apparently, whereas money is viewed as completely fungible, financial instruments with different risk properties have sufficient non-commodity properties for a WTA/WTP gap to manifest.

In a related instance where the WTA/WTP disparity failed to manifest for a category of goods, Ortona and Scacciati (1992) did not find the disparity in valuations of "necessary goods" such as books students were required to purchase for their classes. Necessary goods appear to function much like cash and tokens with fixed monetary value in that the value of necessary goods is strictly equal to their purchase price and contains no subjective element. Were the individuals to give up the necessary goods, they would simply have to repurchase them at market value, thus making the gaining or losing of necessary goods essentially equivalent to the gaining or losing of pure cash.

Along similar lines, numerous studies have found that larger WTA/WTP disparities exist whenever subjects find it more difficult to compare between the goods they are "endowed" with and the goods they are instructed to evaluate (Ariely et al. 
2005). For instance, Van Dijk and van Knippenberg (1998) found that more subjects traded a bottle of wine they were endowed with for an alternative bottle of wine when the bottles were from the same wine region than when the bottles were from different wine regions. Bar-Hillel and Neter (1996) reported similar findings for experiments involving pens and lottery tickets. As the results of these studies suggest, larger WTA/WTP gaps are reported for goods that lack close substitutes than for goods where equivalent substitutes are readily available (Horowitz and McConnell 2002). As an example of the many experiments supporting this finding, Adamowicz et al. (1993) found a much smaller gap for sporting tickets when it was possible to see the games on television than when the games were not televised - thus limiting the alternative means for seeing the games without using the tickets.

It may be possible to reconcile these studies on agency, use value, substitutability, and commodity goods with the theory of loss aversion. Indeed, Kahneman et al. (1990) predicted that no gap would be found for "exchange goods" - objects held solely for the purpose of later selling or trading them - as far back as 1990. Novemsky and Kahneman (2005) reemphasized this belief and supported it with experiments involving goods that were instructed as being held for exchange purposes and other goods that were instructed as being given for the experimental subjects' own use. In explaining how these results might be compatible with loss aversion, Novemsky and Kahneman (2005) concluded that the mechanisms behind loss aversion simply do not apply "when all the benefits of the good that is given up are present in the acquired good." Extrapolating this idea into a theoretical extension to loss aversion, they argued: 
"In other words, we believe that loss aversion operates on benefits rather than on attributes of goods. Thus, goods with different attributes that provide the same benefits can be exchanged without loss aversion. For example, there is no loss aversion for an old car that is traded in as part of the purchase of a new car if the new car is perceived as having all the benefits of the old one." (Novemsky \& Kahneman 2005:123-24).

Although their attempt at reconciling the more recent studies, which show that the WTA/WTP gap is context dependent with loss aversion has merit, a number of scholars continue to argue that the recent empirical results are incompatible with even this extended theory of loss aversion (Plott \& Zeiler 2005, Roth 2005). Novemsky and Kahneman's (2005) extension of loss aversion strikes many scholars as being too much of a post-hoc explanation. Their view is that if any study that fails to show a WTA/WTP gap can be explained by the individuals viewing the objects they were endowed with as having similar characteristics to the objects they were not endowed with, then perhaps the adherents of loss aversion need a theory to account for what object characteristics individuals view as being similar with regard to loss aversion. Moreover, Novemsky and Kahneman's (2005) extension of loss aversion does not seem to account for what is actually going on in at least some of the experiments that have challenged the explanatory powers of loss aversion (Brown 2005).

Another area of controversy over recent empirical studies is whether individuals' experience with valuing the types of goods in question affects the magnitude of the WTA/WTP gap. In the earliest of these studies, Shogren et al. (1994) found that subjects' WTA and WTP values converged through multiple rounds of Vickrey auctions. Shogren 
et al. (1994) thus concluded that experience attenuates the WTA/WTP disparity. But in commentating on these results, Korobkin (2003) points out that the use of multiple round Vickrey auctions might serve to convince the subjects that there are substitutes to purchasing the goods in any single round - since the subjects learn that the goods will also be available in subsequent rounds - and might also train subjects into viewing the goods as being valued at the market prices revealed through the auction mechanisms. Korobkin (2003) thus concludes that the use of Vickrey auctions creates an environment unrepresentative of real world market transactions. Yet similar to Shogren et al. (1994), List (2003) also found that market experience can serve to eliminate the WTA/WTP gap in experiments looking at professional traders of sports memorabilia. Although there is still some controversy over the role of experience, the balance of evidence does seem to suggest that experience attenuates the magnitude of the WTA/WTP gap (Roth 2005).

It is important to note, however, that the WTA/WTP disparity is not entirely context dependent. The disparity is fairly robust to a wide variety of circumstances that might have been expected to affect the magnitude of the WTA/WTP gap. For instance, subjects of different age groups have been shown to exhibit the disparity without significant differences in their reported magnitudes (Harbaugh et al. 2001).

In addition, actual legal entitlement is not required for the WTA/WTP disparity to manifest. The mere physical possession of an object or previous enjoyment of a condition is enough (Beggan \& Brown 1994). For example, Hartman et al. (1991) found a significant WTA/WTP gap with regard to changes in the quality of the power service enjoyed by their experimental subjects - when acting as power service customers, the subjects were far more averse to a diminution in the quality of the service that they had 
previously enjoyed as compared to an increase in this quality of service. Kahneman and Tversky (1984) found a similar result when experimental subjects were asked how much they would benefit from being promoted to a better job as opposed to how much they would suffer from being demoted to a worse job. Likewise, the WTA/WTP gap has been found with regard to physical goods even before the goods were actually possessed or enjoyed by the subjects (Carmon et al. 2003). For instance, both studies by Ariely and Simonson (2003) and by Heyman et al. (2004) found that auction participants who believed they had entered a winning bid, exhibited a WTA/WTP disparity for the goods bid upon even before the goods have actually been won.

Ultimately, the balance of evidence from recent empirical studies does seem to cast at least some doubt on the explanatory power of the theory of loss aversion for the WTP/WTA disparity (Plott \& Zeiler 2005, Roth 2005). Yet it is not clear that anyone has offered a superior theoretical explanation. For instance, as one of the early theories trumpeted as an alternative to loss aversion, Loomes and Sundgin (1982) developed what they labeled "regret theory." Regret theory stated that individuals make choices so as to avoid the possibility of later regretting their choices and that action is more likely to produce regret than inaction, thus causing the WTA/WTP gap. However, later experiments (Loomes et al. 1992) did not uphold the predictions of regret theory and the authors eventually abandoned the theory as an alternative to loss aversion.

It is also worth discussing one other early alternative explanation for the WTA/WTP gap which was forwarded as an alternative to loss aversion and that draws on standard (neo-classical) economic theory - an explanation for the WTA/WTP disparity based on wealth and income effects. It has long been a precept of traditional neo-classical 
economics that there are diminishing marginal returns to money, such that a gift of two thousand dollars produces less than twice as much utility as a gift of one thousand dollars (Pindyck \& Rubinfeld 2001). Coombs \& Avrunin (1977) argue that virtually all conceivable goods exhibit diminishing marginal returns in this fashion. Hence, losses can be expected to result in greater negative utility as compared to the positive utility that would be created by equivalently sized gains. Wealth effects make losses more dire (since one is less wealthy after a loss) and gains less valuable (as one is more wealthy after a gain).

Yet, although wealth and income effects might explain some portion of the WTA/WTP gap in a manner consistent with neo-classical economic theory, wealth and income effects are unable to explain gaps of the magnitude commonly observed in experimental and real world settings (Ariely et al. 2005). Neoclassical economic theory would predict a substantial WTA/WTP gap for a house valued in the thousands of dollars (or hundreds of thousands of dollars), but not for mugs and candy bars worth less than ten dollars. Losing or gaining cheap consumer goods like mugs or candy bars simply does not affect overall wealth to the degree necessary to produce more than a minimal wealth effect. Additionally, there are several studies that have controlled for wealth and income effects through a variety of mechanisms and still found a significant WTA/WTP disparity (Boyce et al. 1992, Franciosi et al. 1996, Morrison 1997).

Perhaps the most important recent assault on the theory of loss aversion was launched by Plott and Zeiler (2005). By altering the controls used in their replications of KKT's classic endowment effect experiments, Plott and Zeiler (2005) were able to turn the WTA/WTP disparity off and on. Plott and Zeiler (2005) thus concluded that the 
WTA/WTP disparity is an artifact of subject misconceptions and of experimental design procedures, and "that any observed WTP-WTA gap is not a reflection of a fundamental feature of human preferences."

Although Plott and Zeiler's (2005) results are somewhat problematic for the theory of loss aversion, their experiments do not provide sufficient evidence to justify their conclusion that the WTA/WTP gap results entirely from subject misconceptions. Johnson et al. (2006), for one, criticized Plott and Zeiler's (2005) results by noting that their experimental procedures involved giving their subjects an "extraordinary level of instruction" on the nature of the valuation task. Similar to Korobkin's (2003) argument against Shogren et al.'s (1994) findings discussed previously, it is entirely possible that Plott and Zeiler's (2005) procedures in effect trained their subjects out of exhibiting the WTA/WTP disparity. Ultimately, Plott and Zeiler's (2005) experiments do succeed in casting doubt on the explanatory power of loss aversion - if aversion to losses were an inherent feature of individual utility functions, then it should not be possible to train individuals out of exhibiting this feature. However, Plott and Zeiler (2005) do not succeed in justifying "subject misconceptions" as an entirely alternative theory to loss aversion. There is significant ambiguity inherent in how Plott and Zeiler (2005) use the term subject misconceptions and it might be possible to expand on the concept of subject misconceptions in order to develop a more satisfactory theoretical explanation for the WTA/WTP gap.

The recent empirical studies on the WTA/WTP disparity have revealed that the WTP/WTA disparity could be context dependant. Despite Novemsky and Kahneman's (2005) attempt to reconcile this context dependency with loss aversion, and the attempts 
by scholars such as Plott and Zeiler (2005) to formulate alternative theories to loss aversion, the literature still lacks a satisfactory theoretical explanation for the WTA/WTP gap. If the literature on the WTA/WTP disparity is to be used as a guide for debates in law and policy, significant future work will need to be undertaken in order to develop a more complete understanding of the various phenomena which may be associated with the WTA/WTP gap.

\section{Implications for Law and Policy}

The lack of a complete theoretical explanation for the WTA/WTP disparity has obstructed the use of the psychological literature on the phenomenon in its applications to law and policy (Korobkin 2003, Epstein 2007). Within several areas of law, courts and administrative agencies need to determine the preferences and valuations of individuals. Yet the behavioral literature on the WTA/WTP gap has demonstrated that the value an individual will assess an object as having changes depending on whether or not the individual owns the object. The mere fact of ownership increases assessment of value. Thus, one problem becomes how to objectively determine whether estimates of WTP values or estimates of WTA values are the more appropriate valuations for use in law and policy (Korobkin 2003).

Despite over 20 years of research on the subject, legal scholars remain baffled about how to cope with the WTA/WTP disparity (Epstein 2007). For instance, within the law of remedies, controversy rages as to whether juries should be instructed to award damages based on the market value of whatever was lost or destroyed or whether damages should be calculated based on an estimate of what amount of compensation the 
victim would have demanded before parting with the object that was lost or destroyed (McCaffery, Kahneman, \& Spitzer 1995). By its very definition, the existence of a WTA/WTP disparity means that there is a difference between willingness to pay and willingness to accept values. Thus, when tort victims' properties are wrongfully destroyed, the question becomes: should they be compensated based on the amount they would be willing to pay to reacquire the property (WTP) or the amount they would have demanded to part with the property in a voluntary exchange (WTA)?

A similar problem results when courts need to award compensation for eminent domain suits within property law. Should the award be based on the amount similar buyers pay for like property or the amount sellers demand to part with like property? Also, when assessing benefit and harm within regulatory cost-benefit analysis (i.e., when the EPA decides whether to approve an industrial practice that creates pollution), should the benefits of allowing the practice be measured against the amount nearby citizens would pay to avoid the pollution before they are affected or the amount citizens would pay to clean up the pollution after they are affected? (Cohen \& Knetsch 1992, Williams 1995, Knetsch 1997). In these and other domains, legal scholars need to know whether willingness-to-pay or willingness-to-accept valuations represent an individual's true preferences (i.e. an individual's actual value). Unfortunately, existing theoretical explanations for the WTA/WTP disparity are inadequate for determining which of these values represents a true preference, and not just a biased valuation.

Legal scholars sometimes need to look beyond the existence of the WTA/WTP gap in order to determine what motivates the disparity. The difference between willingness-to-pay and willingness-to-accept values presents a dilemma in areas of the 
law that require a single valuation number (Rachlinksi \& Jourden 1998). Unfortunately for the needs of the legal academy, the psychological literature has mostly avoided the question of whether a willingness-to-pay value or a willingness-to-accept value more truly represents an individual's actual and non-biased preference.

The lack of a complete theoretical explanation for the WTA/WTP gap has also hindered those areas of law and policy that need to prescribe solutions for the problem of allocating initial entitlements (Hovenkamp 1991). This problem lies at the heart of a number of important legal and regulatory areas including intellectual property, land use and zoning (Yen 1990, Poindexter 1998). One of the most foundational concepts in law and economic analysis is the Coase Theorem (Coase 1960). The Coase Theorem states that - in the absence of transaction costs and under other stylized conditions - initial entitlements are irrelevant to outcomes. In other words, it does not matter who starts with a good or entitlement, because the parties will always negotiate so that the good or entitlement ends up with whichever party values it the most. The only effect of initial entitlements is to change wealth distribution as the entitled party is paid off by the nonentitled party.

Contrary to the conclusions of the Coase Theorem, the existence of the WTA/WTP disparity means that many desirable transactions will not take place (Schweizer 2002). Whoever starts with a good or entitlement will demand more to give up the good or entitlement based on the fact of mere ownership. Since initial entitlements seem to play an important role in the valuation of a good, it is thus very important for the law to get the initial entitlements right. 
Reflecting on this predicament, legal scholars have reached very different conclusions about how to allocate initial entitlements. Hovenkamp (1991) has argued that distributions should be based on WTA valuations, but Korobkin (2003) has countered this by arguing that the appropriate valuation depends on what we think is the causal explanation for the WTA/WTP gap and that the theory of regret avoidance calls for using WTP valuations. Sunstein (1986) takes the argument a step further and concludes that the State should no longer consider market-mimicking analyses when assigning initial entitlements. Without a better understanding of the causal processes behind the WTA/WTP gap, legal scholars will continue to lack the tools needed to resolve these debates.

In numerous areas such as tort damages, eminent domain suits, and the initial allocation of entitlements; courts, legislatures, and/or administrative agencies need to decide between using either WTA valuations, WTP valuations, or some hybrid of the two valuations. Since it is possible to form estimates for both WTA and WTP valuations, and these two types of valuations predictably differ by significant magnitudes, the existence of the WTA/WTP gap poses a serious dilemma for law and policy. Unfortunately, our current theoretical explanations for the cause of the WTA/WTP disparity are still inadequate for determining which type of valuation is closer to the true preferences of individuals.

The theories explored in the subsequent chapters of this dissertation have different implications for this debate. If the WTA/WTP disparity is a result of the use of bargaining scripts, then both WTA and WTP valuations are biased due to the application 
of a buy-low/sell-high script. If both values (WTP and WTA) are biased, then this suggests that a hybrid approach to valuing goods and entitlements may be necessary,

In contrast, if the source of the WTA/WTP is a result of cognitive investment devoting mental resources into an object through engagement with the object - then WTA values should be seen as representing the value of the object plus the cost of the investment to the individual. As such, this would argue for prioritizing the use of WTA valuations in most areas of law and policy.

The experiments carried out in this dissertation are not capable of fully resolving the debates over how various areas of law and policy should cope with the WTA/WTP disparity. At most, the experiments may increase our understanding of the psychological processes underlying the WTA/WTP gap and further the ongoing conversations about the implications of these processes for law and policy. 


\section{CHAPTER 3 - BARgAining BEHAVIORS}

\section{Overview of Bargaining Behaviors}

From personal decision making with a spouse (e.g., where should we go to dinner?) to informal consumer transactions (flea markets), negotiating with others is something almost everyone is familiar with. As with many other types of social interaction, bargaining has its own unique scripts, or behaviors. Consider the following description from a travel guide describing appropriate "bargaining behavior":

"If a shopkeeper asks "What will you pay?" you should ask again "What's the price?" The shopkeeper's price will be higher than what he expects you to pay. There's no fixed formula for making your counter-offer but it should be substantially less than you expect or want to pay; a half or even a quarter of the shopkeeper's price (depending on how inflated that is). However, if your counter-offer is way too low, the shopkeeper will know he's dealing with someone who doesn't get what bargaining is all about." (Brosnahan 2004)

At first glance, this carefully choreographed "dance" between a buyer and a seller may seem like a very inefficient way of determining a fair price. However, amid all the subterfuge and affectation, a very common form of bargaining behavior is played out: the buy-low, sell-high bargaining strategy (Korobkin 2003). This form of strategic bargaining behavior is considered to be proper behavior in a bargaining environment (Goodpaster 1996) and is typified by a buyer's understatement of their willingness-to-pay (WTP) value and a seller's overstatement of their willingness-to-accept (WTA) value for the good or service under negotiation. 
Previous literature has noted the connection between the buy-low, sell-high form of bargaining behavior and the WTP/WTA disparity (Korobkin 2003, Brown 2005, Roth 2006). Brown (2005) noted that even when an individual was asked to provide both their WTP (buying) price and their WTA (selling) price for the same object in their possession, that there was still an endowment effect. When asked to explain these differences in their WTP/WTA prices, "getting a good deal" was consistently used by subjects as an explanation.

"Although a few subjects were obviously cognizant of the opportunity cost of failing to sell the item, most indicated that they were primarily concerned with not giving up the item for less than some meaningful portion of what it was worth in a sale situation...[o]verall, most subjects seemed primarily concerned with getting a good deal (or conversely, avoiding a bad deal) in the transaction.” (Brown 2005, pg. 9).

Brown's findings suggest that individuals' value assigning behavior may be at least partially influenced by the role they will be playing in respect to their object. Rather than assigning value to the good based solely on what it is actually worth to them, individuals perceive that they need to assign a "correct" value in relation to the underlying goals of their role as a buyer or seller.

In the remainder of this chapter, I explore the extent to which the source of the WTP/WTA disparity can be explained in terms of a bargaining script and how specific scripts may guide an individual's behavior when they assign value to a particular object. I hypothesize that the discrepancy in WTP/WTA values for a given good may result from the use of a bargaining script where certain features, such as behavioral expectations and 
internal justifications for the pricing of the good, are influenced by an adaptive buy-low, sell-high strategy.

To summarize in advance of the more in-depth analysis provided later in this chapter, the bargaining script hypothesis begins with the assumption that individuals enter bargaining situations with the self-interested motivation of either maximizing the amount they obtain for the bargained-over good (in the case of sellers) or of minimizing the amount they pay for the bargained-over good (in the case of buyers). The nature of the motivation depends on the role an individual has adopted, as each role (either a buyers/sellers) has its own unique goals.

In order to achieve these goals, buyers must be able to approximate the lowest offer that the seller will accept, while sellers must be able to approximate the highest price that a buyer will be willing to pay. As previous studies have demonstrated, this form of valuation can be quite difficult (Slovic 1995, Bettman et al. 1998, Gal 2006). Hence, both buyers and sellers may rely on a bargaining script as an aid for performing these difficult valuation tasks.

As bargaining situations are ubiquitous in our society, individuals are likely to make use of bargaining scripts in a wide variety of valuation tasks, even when the motivations behind the development of the bargaining scripts do not apply to the valuation task in question. This explains Brown's (2005) findings where experimental subjects explained why they awarded higher WTA valuations than WTP valuations by reference to their desire "to get a good deal" despite experimental procedures which made this strategic bargaining behavior irrational within the context of the experiment. Having learned how to perform valuations using bargaining scripts, individuals may 
employ these scripts outside of the contexts in which they originated, thus causing the WTA/WTP disparity.

\section{Bargaining experience, endowment, and the role of loss aversion}

The source of the WTP/WTA discrepancy has generally been attributed to loss aversion vís a vís the endowment effect (Kahneman \& Tversky 1979, Knetsch 1989). Under the framework of loss aversion, the endowment effect relies on the idea that buying is mentally accounted as a gain and selling is mentally accounted as a loss (Thaler 1980). The different willingness-to-pay/willingness-to-accept values provided by buyers versus sellers are said to reflect this type of loss/gain mental accounting. If the pain of giving up a good is greater than the pleasure of receiving a good, then logically any seller's WTA value would be higher than any buyer's WTP value.

Despite the parsimoniousness of these theories, the results of several more recent studies suggest that the source of the WTP/WTA discrepancy may be in fact more complicated than suggested by the theory of loss aversion. For example, List (2003) found that experience in bargaining situations (i.e. buying and selling or trade experiences) is an important moderator of the WTP/WTA disparity. Shogren et al. (1994) found that substitutability of a good can also drive the WTP/WTA disparity along with experience. For example, when a good is readily available in the marketplace (e.g. candy bars or coffee mugs), WTP and WTA values for the good will converge over time. However, when the good is not easily substitutable, e.g. reduced health risk, WTP/WTA values do not converge and persist despite gained experience in bargaining transactions. ${ }^{10}$

\footnotetext{
${ }^{10}$ Hanemann's (1991) models of utility and substitutability of different goods, on which Shogren et. al's work is based, predict exactly this.
} 
Both of these studies provide evidence that losing or gaining a good does not completely account for the source of the WTP/WTA discrepancy and that other factors such as bargaining experience may have moderating effects. List (2003) concludes that learning and experience in bargaining may help to attenuate the WTP/WTA disparity by shifting an individual's perceptions about a good, but does not provide any further explanation as to exactly what this shift in perception involves or how it moderates the discrepancy. A potential explanation for what a perceptual shift might entail and how it may attenuate the WTP/WTA disparity is discussed in the following sections of this chapter.

\section{Bargaining scripts and the source of WTP/WTA values}

Individual behavior is often guided by sets of behavioral rules that prescribe a particular course of action for a given situation. When faced with a novel situation, individuals search for cues about how to interpret the situation and for what the appropriate behavior is within the situation (Lamberts and Shanks 1997). This process of using habitual arrangements of mental categories in order to understand new situations involves finding relevant comparisons between the current situation and other past instances or situations stored in memory and leads to the activation of the appropriate behavioral rules. These habitually organized mental categories that individuals use to process new information are known as schemata (or, alternatively, as schemas).

First proposed by Bartlett $(1932,1958)$, schemata can be thought of as cognitive structures that contain knowledge about people, events, roles, etc., and that are used by individuals to categorize and sort items stored in memory (i.e. past experiences, 
knowledge, etc.). In other words, a schema provides an individual with a knowledge base that can serve as a guide for the interpretation of actions, events, or information (Rumelhart \& Ortony 1977). I propose that the behavior witnessed in many of the studies where WTP/WTA values are elicited comes as a result of the activation of a particular type of schema of bargaining behavior known as a bargaining script.

Schank and Abelson (1977) introduced the concept of scripts as a method to describe schemata concerned with an individual's behavioral repertoire. A script is a way of structuring knowledge concerning conventional or frequently encountered situations and can be categorized into strong or weak scripts (Abelson 1981). Weak scripts organize expectations about the behaviors of others (or oneself). Strong scripts are similar to weak scripts but also specify a temporal component for the expected behaviors. ${ }^{11}$ A bargaining script therefore, is defined as a weak script into which has been placed knowledge concerning previous transactional encounters (i.e. buying or selling of goods or services). ${ }^{12}$

A bargaining script is formed from numerous encounters involving transactions with others and includes features often associated with marketplace transactions (e.g. prices, goods, etc.). Although these transactions may be very different in their form and location, e.g. bartering on the street versus selling one's possessions at an auction, they both possess certain similar fundamental features: interaction with another person, a good

\footnotetext{
11 A classic example of a script would be for expected behavior at a restaurant. For example, a typical restaurant script would assumes when we enter, we will be seated, then a waiter should come by for the order, etc. (c.f. Schank \& Abelson 1977, Schank 1982a).

12 I define a bargaining script in terms of a weak, rather than a strong script, as I do not feel there is enough temporal structure to bargaining transactions (under the definitions of a strong script) to define it as a strong script. This is a matter of opinion and is thus debatable; but is beyond the focus of this dissertation.
} 
or service for which a "price" has been determined, and an agreement on payment. Each of these features forms an element of the bargaining script.

Of these features, one of the most important (and complex) elements is the interaction with another person. Although a part of the larger bargaining script, the expectations and structures of this interaction fall under the province of role theory (Biddle 1986, Stryker \& Statham 1985). Roles' focus on interactive social phenomenon and complementary roles (e.g. buyers and sellers) are necessary for a role-governed behavior to be activated. Although normally differentiated from scripts (Sarbin \& Allen 1968, Solomon et al. 1985), roles function as a special case of sub-script ${ }^{13}$ in the case of a bargaining meta-script, where role-specified behaviors constitute only a part of the individuals' bargaining behavior repertoire. ${ }^{14}$ For example, the bargaining script for an individual in the role of a seller will not only contain general structural information about the situation, but will also contain a different set of behavioral expectations for interpersonal interactions than if that individual was in the role of a buyer.

If a bargaining script is activated for a situation involving marketplace transactions, what characteristics of this script lead to the observed discrepancy in WTP/WTA values for a given good between buyers and sellers? One answer is that the WTP/WTA disparity reflects the difference in the goals of a bargaining script for a buyer versus a bargaining script for a seller. For example, a buyer and a seller may both structure their behavior in the same situation according to a bargaining script, but their goals depend on the behavioral expectations of their role. As such, individuals develop

\footnotetext{
${ }^{13}$ Roles are usually thought of as distinct from scripts, since scripts also provide understanding of the situation, not just expectations that guide behavior in the situation (Solomon et al. 1985).

14 There are also role-specific scripts, where the roles completely define the relationship between individuals, rather than just constitute a part of the behavioral repertoire (Tompkins 1978).
} 
two separate bargaining scripts that function according to the behavioral expectations of each role. What these behavioral expectations entail, how they are developed, and how they may ultimately lie at the source of the WTP/WTA discrepancy are discussed in the next section.

\section{Buyer/Seller roles, experience, and the WTP/WTA disparity}

If the ultimate reason for the WTP/WTA disparity lays in the simple explanation that sellers and buyers differ in the behavioral expectations specified by their bargaining scripts, several questions still remain: 1) how and why do individuals acquire and develop different scripts for buyers and sellers and 2) how is this difference ultimately manifested in a WTP/WTA discrepancy?

As mentioned earlier in this chapter, scripts are cognitive shortcuts by which individuals can more efficiently reconcile the information stored in their memory with the information coming in from the surrounding environment. Scripts operate in a top-down direction to help individuals interpret the bottom-up flow of information from their surroundings. Generally speaking, scripts are acquired when individuals break down information into general chunks which are then categorically stored in memory for later recall (Gagné, 1993). As new knowledge is perceived, it is coded into either a preexisting schema (assimilation) or organized into a new script (accommodation) (Gagné, 1993, Piaget 1952). Rumelhart \& Norman (1978) elaborated on these concepts with the addition of three additional elements to the process of schema development: accretion, tuning, and restructuring. Accretion is the coding of new information in terms of one's existing knowledge (e.g. adding new information about auction mechanisms to one's 
existing bargaining script). Restructuring is the process of creating new schemata (e.g. creating an entirely new script from the point of view as a buyer). Tuning is the gradual modification of a schema as a result of experience with the knowledge/skills necessary to that situation (e.g. completing several practice trials in an experiment before participating in a real trial).

Buyer and seller bargaining scripts are acquired through the same processes as any other script or schema: through interaction, knowledge acquisition, and experience. Most individuals are provided with ample opportunity in which to participate in transactional situations as either a buyer or a seller. For example, an individual may use a buyer-oriented bargaining script when shopping for produce at a market, whereas she will use a seller-oriented bargaining script when deciding what price to ask for when selling an old couch on the internet. The key difference in the two scripts is the underlying strategic behavior influencing the perception of the situation. Although both the buyer and the seller scripts are ultimately motivated by self-interest, this drive manifests in sellers wanting to obtain as much money (or other trade resources) as possible in exchange for the sale good and in buyers wanting to give up as little money (or other trade resources) as possible in order to obtain the sale good. More specifically, buyer- and seller-oriented scripts are influenced by a "buy-low, sell-high" strategy, respectively, whereby buyers understate their willingness-to-pay price and sellers overstate their willingness-to-accept price (Korobkin 2003, Knez et al. 1985).

Since the underlying motivations of bargaining strategy differ according to role, individuals create two different bargaining scripts, one for a buyer and one for a seller. To understand how the differences between these bargaining scripts lay at the source of 
the WTA/WTP discrepancy, it is necessary to elaborate on how a buy-low, sell-high strategy differentially manifests in the buyer/seller roles.

The concept of "buy-low, sell-high" is one form of strategic heuristic for determining one's subjective valuations or preferences (Korobkin 2003). Historically, theories regarding individuals' preferences have taken their cue from rational choice theory, which states that preferences are complete (Pyndick \& Rubinfeld 2004, Von Neumann \& Morgenstern 1944); that is individuals know both the value they derive from every good or object in their possession and the value they would derive from every good or object they might conceivably obtain. However, in recent years, a number of studies have largely challenged this theory (Camerer 1995, Rabin 1998) and given rise to theories of preferences that take into account the influence of psychological factors, such as framing (Mandler 2005). Regarding the valuation of goods, several studies have shown that even when asked to provide an entirely subjective value, accurately assessing the value of a good is not an easy task for individuals (Slovic 1995, Bettman et al. 1998, Gal 2006). As a result, it is safe to assume that individuals may use some kind of heuristic for efficiently determining their preferences. For example, a heuristic for determining the value of good may take the form "buy-low, sell-high" for some situations. This strategic heuristic would have different effects, depending on if one was determining value from a seller's or a buyer's point of view.

Consider the situation of an individual who seeks to purchase an item from a shopkeeper in an environment where bargaining is to be expected. Assuming the individual is motivated primarily by self-interest (that the individual does not view the shopkeeper as a friend or as some other deserving recipient of altruism), the individual 
will seek to offer the minimum amount in exchange for the good that the shopkeeper is willing to accept. Only this offer will maximize the buyer's surplus from the transaction the difference between the value the individual buyer receives from obtaining the good and the value of what is given up in exchange for the good.

In other words, upon entering the barganing situation, the individual will follow the behavioral expectations for the role of a buyer. If a buy-low strategic heuristic is, in fact, influencing the buyer's behavior and preferences, the following issues will be considered by the buyer before making an offer: (1) if the buyer offers too high a price in exchange for the item, the seller will accept the trade, but the buyer will worry that too much has been offered in exchange for the item. ${ }^{15}$ (2) On the other hand, the buyer also understands that if too little is offered in exchange for the item, then the seller will walk away and the trade will not take place. This last point has a particularly strategic element; the buyer must offer a low price in order to maximize their value, but not so low an offer that a transaction will not occur.

The buyer also expects the seller to make counteroffers and again considers the same issues mentioned in points 1\&2: the buyer knows that if an excessively high counteroffer is offered and accepted, too much will have been paid for the item. However, the buyer also knows that if a seller's counteroffers are consistently refused, the seller will walk from the trade. The delicate practice of determining the smallest appropriate price to offer and highest counteroffer to accept is the buy-low sell-high strategy influencing the behavioral expectations of the buyer role.

\footnotetext{
15 Note that the buyer will reach this understanding based on process elements rather than the outcome e.g., the seller accepts the trade too readily.
} 
The seller's behavioral expectations are also similarly influenced by a buy-low, sell high strategy. This role of seller is the mirror-image of the buyer role described above. Just as the buyer must learn to determine the offers that would result in paying too much and the offers that would result in no transaction taking place, the seller must similarly learn that asking too high a price will result in the buyer walking away and in no transaction will take place. However, if the seller offers too low a price, then she risks losing value from the exchange.

It is also worth noting that a bargaining script can be activated in circumstances in which there is not explicit bargaining, like the offer-counteroffer situation described above. For instance, if a buyer goes to a grocery store where the price for milk is $\$ 2.99$, the buyer must decide whether to purchase the milk for the listed price or else leave and try to find a better price at another grocery store. Although there isn't a "seller" per se, the buyer's motivations and resulting strategic behaviors still correspond with the buyeroriented bargaining script role and the behavioral expectations therein. Despite the lack of an individual seller, the buyer must still determine whether the listed price is acceptable, or whether the listed price is too high and thus walk away from the transaction. ${ }^{16}$

So how do these aforementioned differences between sellers' bargaining scripts and buyers' bargaining scripts act as a source of the WTP/WTA disparity? The buy-low sell-high strategy underpinning the buyer/seller roles comprising an individual's bargaining script leads to individuals 1) ascribing lower prices to a good if they are told

\footnotetext{
16 There are transaction costs associated with completing a trade. Hence, abandoning a trade that is near completion generates opportunity costs due to the transaction costs that must be reoccurred in order to find a new potential trade and to bring that new trade to near completion.
} 
they are a buyer and 2) ascribing higher prices to a good if they are told they are a seller. A bargaining script theory of WTP/WTA values makes current endowment relatively unnecessary to value assignment, in the sense that endowment (or ownership) is relevant only in that it serves as a cue that one is in the role of a seller and should classify the situation according to the behavioral expectations of that role.

A bargaining script theory is also consistent with the findings of previous studies that are incompatible with a theory of loss aversion as the source of the WTP/WTA discrepancy (List 2003, Plott \& Zeiler 2005, Roth 2006) ${ }^{17}$. As previously mentioned, experience seems to play an important role in moderating the WTP/WTA disparity (List 2003, Shogren et al. 1994). Inexperienced (novice) bargainers are shown to have larger discrepancies in their WTP/WTA values than experienced bargainers. This is incompatible with a theory of loss aversion, under which ownership, regardless of experience, should be the influencing factor in value assignments. However, as an individual becomes more experienced in buying, selling, and trading behaviors, the less a buyer's value diverges from a seller's value for a particular good. ${ }^{18}$ List (2003) theorized that learning and experience in bargaining may help to attenuate the WTP/WTA disparity by shifting an individual's perceptions about a good, but did not elaborate as to how this might occur or what it is that shifts in perception. I hypothesize that it is the tuning and

\footnotetext{
${ }^{17}$ Several studies from the evolutionary psychology and biology literature provide some independent support for a bargaining script theory (c.f. Huck et al. 2005, Carmichael \& Macleod 2002). These studies all start with the economic logic for why it is rational for seller's to provide higher WTA valuations and for buyers to provide lower WTP valuation - similar to the Heifetz et al (2007) paper discussed at the end of this section - and then proceed to argue that since the use of a buy-low/sell-high strategy is advantageous for individuals, that it must have been hardwired as a result of natural selection. The studies do not discuss any psychological mechanisms for how the buy-low/sell-high strategy could be hardwired into individual decision making, such as the bargaining script hypothesis.

18 This experience is carried over to other similar situations, despite suggestions of limited transfer of learning across tasks (Loewenstein 1999).
} 
restructure of an individual's bargaining script that is responsible for the attenuation of the WTP/WTA gap. Experience moderates the WTP/WTA disparity by modifying an individual's set of behavioral rules for bargaining - by modifying their bargaining script. As individuals become familiar with a new system of value elicitation that is not based on strategic behaviors (such as the auction mechanisms employed in many of these studies), they adapt their bargaining script, placing less emphasis on buy-low, sell high strategies when deciding what value to assign to an object. This adaptation could occur either through individuals becoming more accustomed to valuation environments in which strategic bargaining behavior is not rational, through individuals becoming more familiar with the plausible valuations of the goods studied and thus reducing the scope of the bargaining zone, or through a combination of both of these mechanisms. In support of this explanation for how expertise can mitigate the WTA/WTP disparity, research on novice versus expert performance (e.g., Chi et al., 1988) suggests that the nature of expertise is largely due to the possession of schemas that guide an individual's perception and problem-solving.

A bargaining script theory is also consistent with the results of Plott \& Zeiler's (2005) theory of subject misconceptions. Plott \& Zeiler show that with practice under certain highly stylized conditions, the WTP/WTA gap is not present. Bargaining script theory is compatible with these findings in that as the participants in the study gain experience in the value elicitation mechanisms, they refine their scripts to incorporate the information learned from participation in the auction context. In essence, the participants in the Plott \& Zeiler (2005) study can be said to have gone from exhibiting novice-like behavior to exhibiting behaviors similar to that of the experienced card traders in List's 
study (2003). What Plott \& Zeiler term subject misconceptions, could also be thought of as the use of non-optimal bargaining scripts. ${ }^{19}$

Finally, a recent paper by three economists has shown that the WTA/WTP disparity can be derived as an economically rational response to the structure of market environments (Heifetz et al. 2007). ${ }^{20}$ The paper presents a model of how the WTA/WTAP disparity may serve as a "benefit [for] private negotiators, effectively transforming them into 'tougher' bargainers than they would be in the absence of bias, thereby augmenting the credibility of their threat to exit without an agreement." (pg. 123) The model focuses on "cognitive distortions" in trade and proposes that a buyer's perception of their valuation is a function of their true, a-contextual value (b), and a distortion component $(\tau)$. The distortion component serves the strategic purpose of signaling to each side the "emotional toughness" of the bargaining partner, which may create a situation for an enhanced payoff (pg. 129).

While providing a compelling economical model, Heifetz et al. (2007) does not attempt to elaborate on the psychological underpinnings of the cognitive distortions, beyond recognizing their role in buyer's determinations of value. Bargaining script theory could provide a more psychologically rich theoretical mechanism behind their results and provide a means to test the assumptions of the economic model through experimental design.

\footnotetext{
19 Although Plott \& Zeiler put forth the theory of subject misconceptions as an alternative explanation for the WTP/WTA disparity, they do not go into detail about what exactly these misconceptions entail. The bargaining script theory explores what mechanisms might lead to these misconceptions and how they are adapted through experience.

20 This result is a more sophisticated version of the theory for source of the WTP/WTA discrepancy put forth by several of the evolutionary papers.
} 


\section{Testing the bargaining script theory: Study 1}

The bargaining script theory states that the source of the discrepancy between WTP/WTA values for a particular good may result from an individual's use of a bargaining script where the behavioral expectations for the set of roles specified by the script are influenced by a buy-low, sell-high strategy. If loss aversion fully accounts for the source of the WTP/WTA gap, then situational context should not affect the magnitude of the gap. If possession of an object alone is what is considered when assigning value, sellers' values should always be significantly higher than buyers' values and there should not be substantial variability between the situational conditions. However, if buyers and sellers are using a bargaining script, then their values will be influenced by the perception of their situation, with the activated script providing a framework for processing the incoming contextual information. As the incoming contextual information is varied, so might the processing framework. This is similar to the "cognitive distortion" component (Heifetz et al. 2007) mentioned in section three.

Study 1 is designed to examine the bargaining script theory through the use of four value elicitation scenarios where, through the choice of semantic cues, the strength of the activation of a bargaining script (as opposed to another type of script) was manipulated. Each manipulation was designed to vary the contextual information provided by the experimental condition. The dependent measure in Study 1 was price. The independent variables and conditions used in Study 1 are discussed in more detail below.

Situational Intensity One of two independent variables used in Study 1, situational intentsity consisted of four levels differing in their amount of bargaining cues (intensity) 
and ranged from a "heightened" bargaining condition to a "null" condition. The intensity of the condition was manipulated by varying the information content of the form to include more or less salient bargaining features, such as words commonly associated with bargaining. ${ }^{21}$ It is predicted that there will be an effect of intensity of the condition on the magnitude of the WTP/WTA disparity. The individual predictions for each condition are discussed below:

\section{$\underline{\text { Heightened Condition }}$}

The heightened condition consisted of a bargaining situation in which the role participants were to play (buyer or seller) was explicitly stressed to participants, along with the instructions that they should treat the situation as they would any serious negotiation (Appendix A). The language and structure of the heightened bargaining condition form was designed so as to strongly activate a bargaining script in the individual. It was predicted that participants in this condition would be more affected by the behavioral expectations of their bargaining scripts, and thus, more likely to rely on a "buy-low, sell-high" strategy when determining their value for an object. Hence, I predict that there should be a larger WTP/WTA gap between buyers and sellers in this condition compared to the other conditions due to the greater influence of a "buy-low, sell-high" strategy.

\section{$\underline{\text { Baseline Condition }}$}

This condition was designed to replicate the classic "endowment effect", using the same value elicitation instructions employed by earlier WTP/WTA experiments (Plott \& Zeiler 2005, Strahilevitz \& Loewenstein 1998) (Appendix B). It was predicted that

\footnotetext{
21 This included words such as buyer, seller, negotiate, price, etc.
} 
participants in this condition should, as in other studies, produce the average WTP/WTA ratio of approximately 2:1.22 This condition also used "bargaining" language (i.e. words such as buy, sell, and trade). However, the language and structure of the situation was not as explicit as that used in the heightened condition, and therefore, might not be as strongly perceived as a "bargaining" context. Although the interpretive framework is still assumed to be a bargaining script, elements of other scripts may be used to interpret the incoming information. It was predicted that the WTP/WTA gap in this condition would be smaller than that in the heightened condition (yet still significant).

\section{Diminished Condition}

The diminished condition was designed to provide as little contextual information as possible to keep the situation ambiguous (see Appendix C). The purpose of diminished condition was to provide a situation where participants would not necessarily rely completely on a bargaining script when determining their value of an object. A smaller WTP/WTA gap is expected in this condition as compared to either the baseline or heightened conditions.

\section{Null or No Condition}

The Null condition was designed with no contextual information (Appendix D).This condition consisted of only one sentence, with a one word change between the instructions eliciting a willingness-to-accept value and those eliciting a willingness-topay value. A WTP/WTA gap was not predicted for this condition.

\footnotetext{
22 A number of studies report an average WTP/WTA discrepancy of 2:1, with seller prices twice as high as buyer prices (Roth 2006, Morrison 1997).
} 


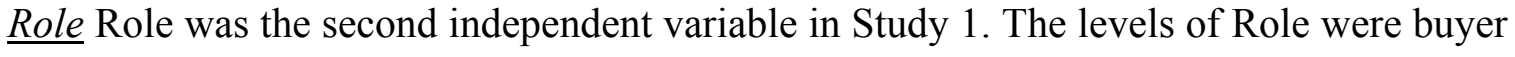
(non-owner) and seller (owner). One of the elements of the bargaining script theory was that the difference between these roles, due to a buy-low, sell-high strategy, was contributing to the WTP/WTA disparity found in numerous studies. It was predicted that buyers and sellers should continue to show differences in values for the same good (the WTP/WTA gap), but that this difference would be attenuated by the situational condition. For example, it is predicted that buyers' mean WTP values should decrease as a function of the strength of the bargaining condition (from No condition $\rightarrow$ Heightened condition), due to buyers' increasing reliance on a "buy-low" strategy. For sellers, their mean WTA values should increase as a function of the strength of the condition, due to sellers' increasing reliance on a "sell-high" strategy. Table 1 summarizes the predictions for Study 1.

Table 1. Summary of predictions for Study 1

\begin{tabular}{|c|c|c|c|}
\hline \multirow{2}{*}{ CONDITION } & PREDICTED & CONDITION & CONDITION \\
& WTP/WTA GAP & RANK BY MEAN & RANK BY MEAN \\
WTP VALUE & WTA VALUE \\
\hline Heightened & Greater than $2: 1$ & Lowest & Highest \\
\hline Baseline & $2: 1$ & $3^{\text {rd }}$ & $2^{\text {nd }}$ \\
\hline Diminished & Less than $2: 1$ & $2^{\text {nd }}$ & $3^{\text {rd }}$ \\
\hline Null & None $(1: 1)$ & Highest & Lowest \\
\hline
\end{tabular}




\section{Methods: Study 1}

\section{Participants}

246 undergraduates from the University of Texas at Austin (113 male and 133 female) participated in this study. Subjects received extra course credit for their participation. All subjects were treated in accordance with the "Ethical Principles of Psychologists and Code of Conduct” (American Psychological Association 2002).

\section{Materials}

Four different value elicitation sheets were used. The instructional set of the value elicitation sheets is similar to that used in previous endowment effect studies (e.g., Plott \& Zeiler 2005; Strahilevitz \& Loewenstein 1998). For each value elicitation sheet, the instructional set was minimally altered to reflect one of the following four situational conditions: a heightened bargaining situation, a baseline condition, a diminished bargaining condition, and a no-bargaining condition (see Appendices A-D). For each situational condition, subjects were also assigned either the role of a buyer or a seller. An example of the instructions for the heightened condition for a buyer is provided below:

You are a buyer. You will be bargaining with one of the other people in this room. The object you will be bargaining over is the mug on the desk. You are expected to bargain with the seller to determine the price that the mug will sell for. You should treat this situation as you would any serious negotiation. 
For each of the prices listed below, please indicate whether you would buy the mug from your partner at that price.

The mugs used in Study 1 were glass coffee mugs with no writing or other visible branding. The mugs retailed for $\$ 3.99$.

Procedure

Subjects $(N=245)$ were randomly assigned to one of the eight conditions (buyer/seller X heightened, baseline, diminished, or no bargaining situation) prior to the beginning of the study. At the beginning of the study, those in the buyer condition were handed a folded value elicitation sheet corresponding to their bargaining condition. Those in the seller condition were also handed a folded value elicitation sheet and a mug. Each seller received the following instructions from the experimenter when given the mug:

"This mug is yours. Here you go. Please take your mug back to the table with you."

Subjects were instructed to keep their sheets folded until told to unfold them. Each subject had no knowledge of the conditions of those around them; however the value elicitation sheets were distributed so that no two sellers or buyers were seated together. Thus, at any one table, there was only one person with a mug. Subjects were told to unfold their sheets and read the instructions carefully. Sellers indicated for every price, on a list of prices that increased in $50 \notin$ increments, whether they would sell their mug or not. Buyers indicated on a similar list whether they would buy the mug or not. Subjects were asked to turn over their sheets when finished. At the end of the study, the sheets were collected and the subjects fully debriefed. 
Results

\section{Role within Condition}

Table 2 presents the mean values for buyers' and sellers' prices within each condition. All conditions showed a difference between the buyers' mean WTP prices and the sellers' mean WTA prices, with the exception of the Diminished condition, where there was no difference between the roles. Mann-Whitney U tests were performed to examine whether or not these WTP/WTA differences were significant within each condition.

\section{Table 2. Comparison of WTP/WTA means}

\begin{tabular}{|c|l|r|r|r|}
\hline $\begin{array}{c}\text { Situational } \\
\text { Condition }\end{array}$ & Role & $\mathrm{N}$ & Mean & Std. Deviation \\
\hline \multirow{2}{*}{ Heightened } & Buyer & 32 & $\$ 2.34$ & $\$ .92$ \\
& Seller & 34 & $\$ 3.29$ & $\$ 1.29$ \\
& Buyer & 31 & $\$ 2.50$ & $\$ 1.67$ \\
Baseline & Seller & 32 & $\$ 2.59$ & $\$ 1.53$ \\
& Buyer & 29 & $\$ 3.81$ & $\$ 1.68$ \\
& Seller & 29 & $\$ 3.81$ & $\$ 1.27$ \\
& Buyer & 29 & $\$ 3.94$ & $\$ 1.50$ \\
& Soller & 29 & $\$ 3.51$ & $\$ 1.37$ \\
\hline
\end{tabular}

Consistent with the predictions, the difference between the WTP/WTA values in the Heightened condition was significant $(Z=3.07, \mathrm{p}<.002)$, with buyers' WTP values $(\mathrm{M}=\$ 2.34)$ lower than sellers' WTA values $(\mathrm{M}=\$ 3.29)$. However, contrary to the 
predictions, the difference between the WTP/WTA values in the Baseline condition was not significant $(\mathrm{Z}=.069$, n.s.) On average, in the Baseline condition, buyer's WTP values $(\mathrm{M}=\$ 2.50)$ were only slightly lower than seller's WTA values $(\mathrm{M}=\$ 2.59)$. Also inconsistent with the predictions, there was no difference between the WTP/WTA values in the Diminished condition $(\mathrm{Z}=.039$, n.s. $)$. Interestingly, in the Diminished condition, the mean WTP/WTA values for buyers and sellers was the same for both roles $(\mathrm{M}=\$$ 3.81), providing a WTP/WTA of 1:1. The WTP/WTA difference in the No condition was not significant $(\mathrm{Z}=1.3, n . s)$. Buyers' mean WTP values $(\mathrm{M}=\$ 3.94)$ were, in fact, higher than the sellers' mean WTA values $(\mathrm{M}=\$ 3.51)$. When presented with virtually no contextual information, buyers consistently placed a higher value on the mug than the sellers in the same condition. Figure 3 displays the error bars for each role by condition. 
Figure 3. WTP/WTA error bars

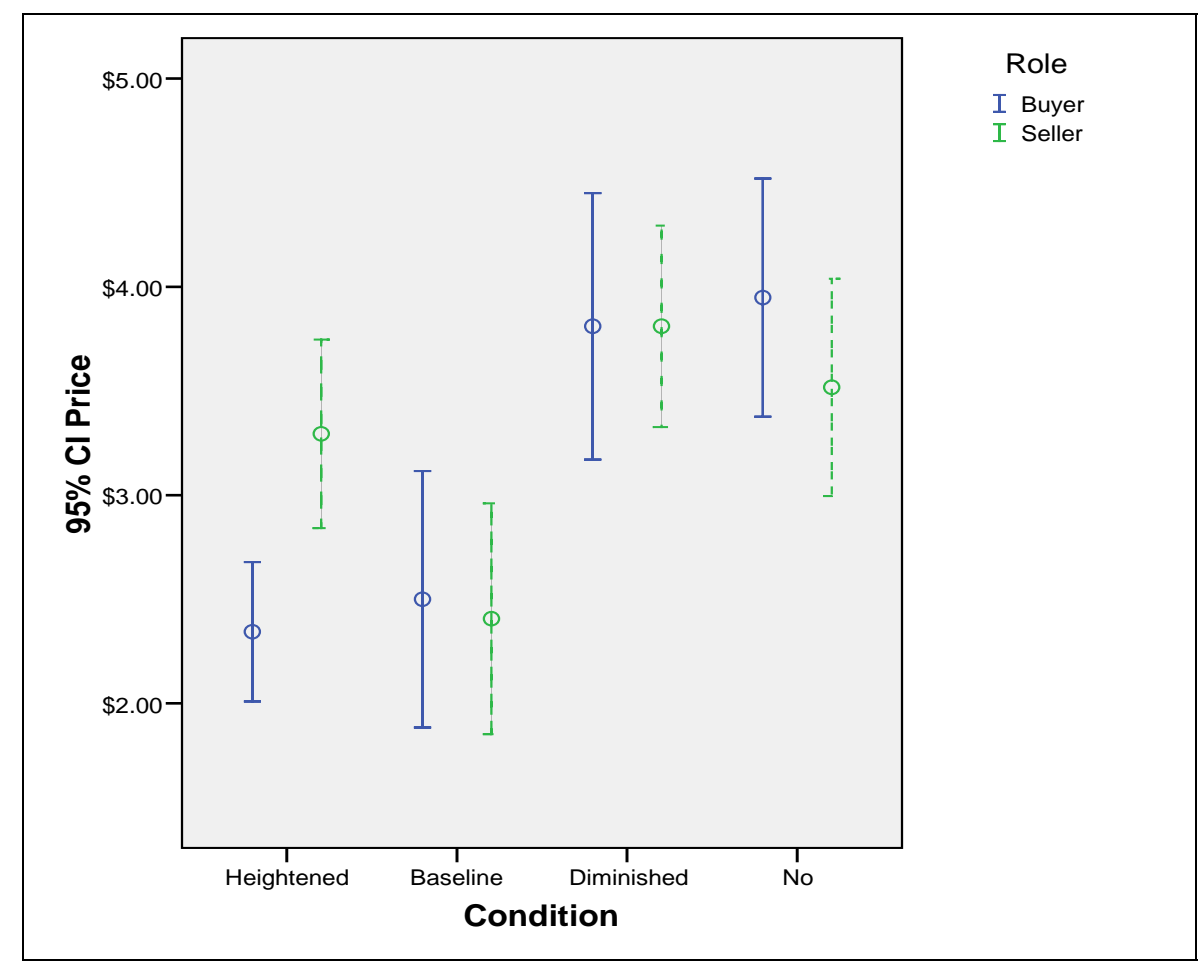

\section{Role between Conditions}

It was predicted that the WTP/WTA values recorded for each role would vary according to condition. A series of Mann-Whitney U tests were conducted to examine the impact of situational condition on Buyers' WTP values (see Table 3) and Sellers' WTA values (see Table 3). 
Table 3. Comparison of Buyers’ WTP values (by Condition)

Situational Condition

Heightened

$\mathrm{M}=\$ 2.34$

Baseline

$\mathrm{M}=\$ 2.50$

Diminished

$\mathrm{M}=\$ 3.81$

\section{Comparison with}

Baseline

$\mathrm{M}=\$ 2.50$

$\mathrm{Z}=.097$

Diminished

$\mathrm{M}=\$ 3.81$

$\mathrm{Z}=3.82 * *$

$\mathrm{Z}=2.93^{*}$

$\mathrm{Z}=3.34^{* *}$

NOTE: $* p \leq .01 .{ }^{* *} p \leq .001$.

As shown in Table 3, the mean value of the buyers' WTP values generally increased as a function of situational condition, which is consistent with the predictions made for the role of buyer. As the intensity of the bargaining situation decreased (from Heightened $\rightarrow$ No condition), the buyers' mean WTP values for their mugs increased $(\mathrm{M}=\$ 2.34 \rightarrow \mathrm{M}$ $=\$ 3.94)$. However, two comparisons that are inconsistent with the predictions are noteworthy:

1) WTP values for the Heightened condition were lower than for the Baseline condition, but not significant so $(\mathrm{M}=\$ 2.34, \$ 2.50$ respectively). Buyers in the Heightened condition placed a similar (although slightly lower) value on their mugs than did buyers in the Baseline condition. This is contrary to the prediction that the "more intense" the bargaining situation, the more likely buyers would be to place a lower value on the mug (part of the "buy low" strategy). 
2) WTP values for the Diminished condition were lower than for the No condition, but not significant so $(\mathrm{M}=\$ 3.81, \$ 3.94$ respectively). Buyers in the Diminished condition placed a similar (although slightly lower) value on their mugs than did buyers in the No condition. The No condition did not provide any contextual information regarding the situation. It was predicted that the lack of information would result in a price that was closer to the median price across all conditions.

\section{Table 4. Comparison of Sellers' WTA values (by Condition)}

\section{Situational \\ Condition}

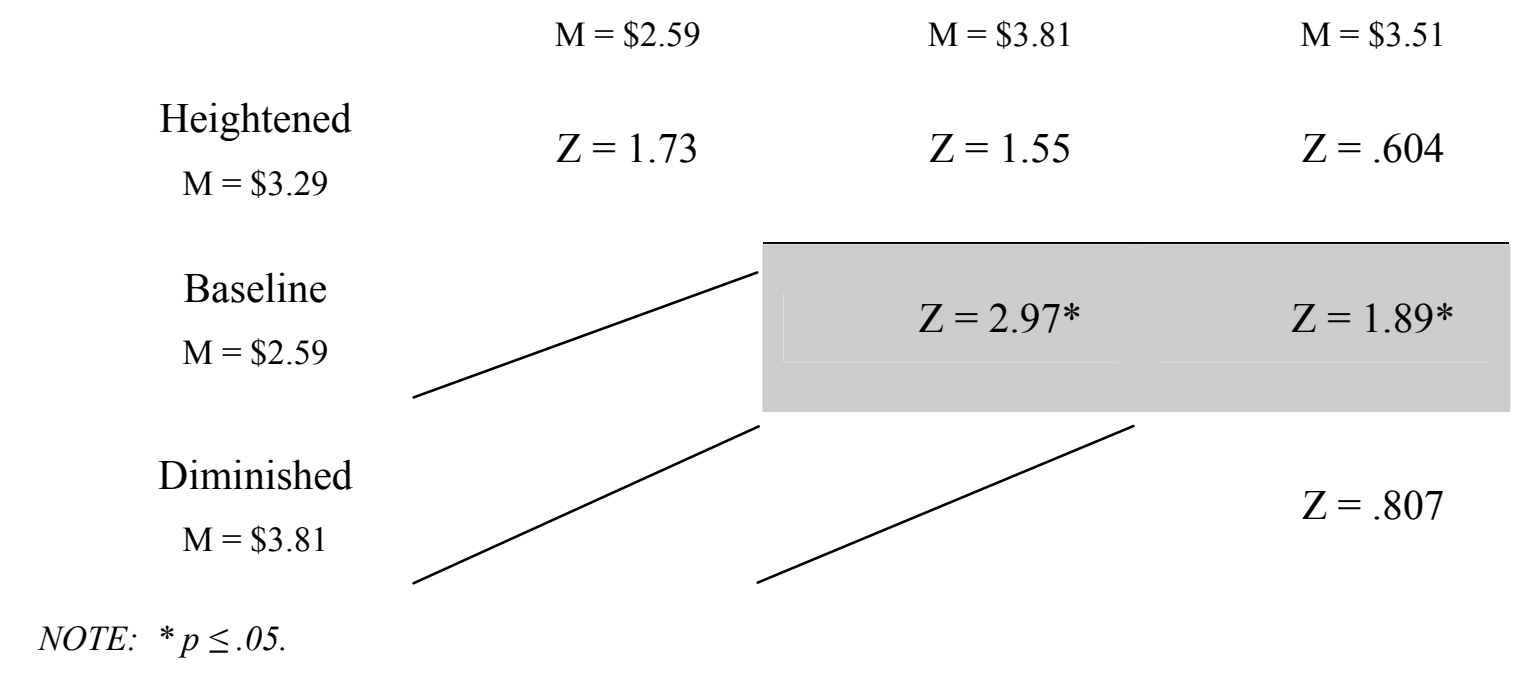

\section{Comparison with}

\begin{abstract}
Baseline
\end{abstract}
Diminished

No

NOTE: $* p \leq .05$.

As shown in Table 4, the mean value of the sellers' WTA values did not show a clear and consistent increase as the intensity of the bargaining situation increased (from No Condition $\rightarrow$ Heightened condition). The mean WTA value in the Heightened condition $(\mathrm{M}=\$ 3.29)$ was significantly higher than the mean WTA value in the Baseline 
condition $(\mathrm{M}=\$ 2.59) ; \mathrm{Z}=2.25, \mathrm{p}<.01$, but was not significantly higher than either of the other two conditions. In addition, contrary to the predictions, the Diminished condition showed higher WTA values than did the No condition $(\mathrm{M}=\$ 3.81, \mathrm{M}=3.51$ respectively), although this difference was not significant $(Z=.807, p<.01)$. Similar to the buyers' WTP values, there are several comparisons between the sellers' WTA values that are worth further mention:

1) The Baseline condition WTA values were the lowest of any of the three groups. Given the rates of WTA values from previous studies, the relatively low WTA values of the Baseline condition were unexpected. Contrary to previous studies, there was not a significant gap between the WTA and WTP values for the baselines condition.

2) The mean WTA values for both the Diminished and No conditions were higher than for the Heightened or Baseline conditions. This split between the conditions was not expected and is further explored in the following subsection.

\section{Language and Role}

Results from the comparisons of WTA/WTA values across conditions showed a surprising split between the two "higher" intensity conditions (Heightened and Baseline) and the "lower" intensity conditions (Diminished and No). Closer examination of the value elicitation sheets revealed a language factor that had not been reported by previous studies: in both the Heightened and Baseline conditions, role was indicated by either the words "buyer" or "seller." In the Diminished and No conditions, role was indicated by either the words "owner" or "non-owner." examination of the data indicated that this 
difference in language may be part of the explanation for the higher values in the Diminished and No conditions.

In order to examine the relationship between language and WTP/WTA values, a 2 (buy/sell vs. own/non-own) X 2 (WTP value vs. WTA value) ANOVA was run. The Heightened and Baseline conditions were collapsed into a single category labeled "buy/sell"; the Diminished and No conditions were likewise collapsed into a single category of "own/non-own".

There was a significant interaction between language category and value, $F(1,241)=3.22$, p. $<.10$ (see Figure 3$)$ and a main effect for language, $F(1,241)=$ $37.90, \mathrm{p}<.001$. The WTP/WTA values in the "own/non-own category" are higher $(\mathrm{M}=$ $\$ 3.87, \$ 3.66$ respectively) than the WTP/WTA values in the "buy-sell" category ( $\mathrm{M}=$ $\$ 2.42,2.86$ respectively). 
Figure 4. Interaction between WTP/WTA values and Language

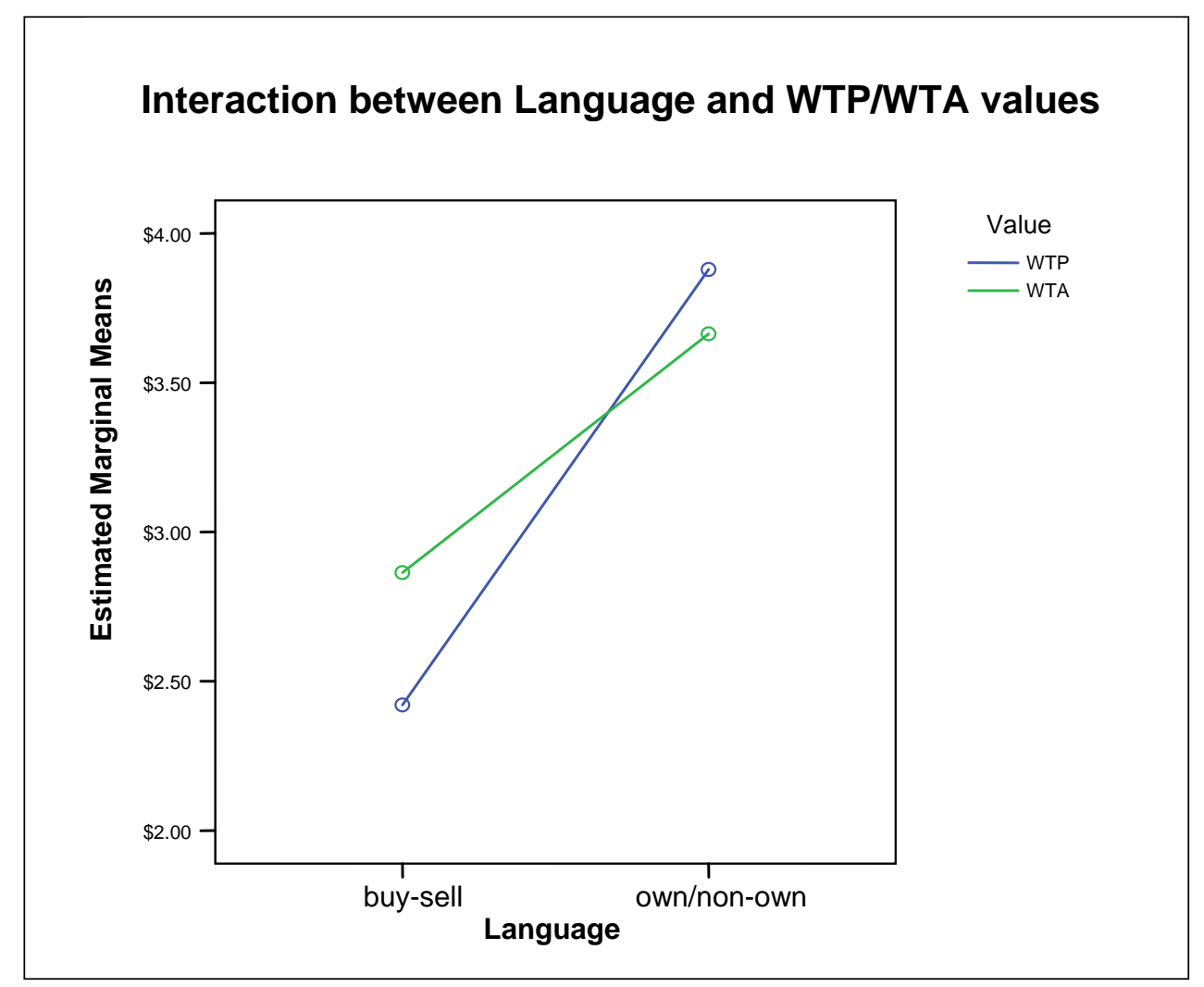

\section{Discussion}

The results from Study 1 provide some evidence for the hypothesis that a bargaining script may be influencing the value an individual assigns to an object, leading to an observed willingness-to-pay/willingness-to-accept gap in object values. Although it was initially predicted that the intensity of the bargaining situation (i.e. how strongly a script was activated) would be the main influence on WTP/WTA values, the results suggest that the language in which the roles are framed has a considerable effect as well. 


\section{The influence of situational intensity on value}

As predicted, the WTP/WTA values in the Heightened condition showed the greatest disparity. This is consistent with a theory of bargaining scripts and the underlying assumption that a "buy-low, sell-high" strategy is part of the expected behavior for the buyer-seller roles in the bargaining script. Individuals in this category showed the lowest WTP values of any of the conditions. This suggests that when placed in a heightened bargaining condition, where a bargaining script is most salient (or strongly activated), individuals are more likely to act in accordance with the behavioral expectation of a buyers' bargaining script. Interpretation of the WTA values for the individuals in the role of seller in the Heighten condition is less clear. Consistent with the predictions for this condition, there was a significant WTP/WTA gap in the Heightened condition. Although this difference was statistically significant, the difference in WTP/WTA values produced a WTP/WTA ratio of only 1.4:1 rather then the approximate 2:1 WTA/WTP ratio that has typically been found in previous studies (Brown \& Gregory 1999). In addition, the WTA values are still lower than the WTA values in the conditions

where the contextual information is diminished and less likely to strongly activate a bargaining script. We must be careful in interpreting this finding as evidence against the theory of bargaining scripts since there seems to be a confound of language which may be driving both the WTP/WTA values. The effects of language are discussed in further detail in the next subsection. 
One of the most surprising results of Study 1 was the failure to replicate the "classic endowment effect" in the Baseline condition. The results from the Baseline condition produced only a small WTP/WTA gap; sellers' mean WTA values were only slightly higher than the buyers' mean WTP values. One explanation for why this result may have occurred could lie in the instructional set that was used to provide the contextual information for the condition. Although used with apparent success in previous studies (Plott \& Zeiler 2004, Strahilevitz \& Loewenstein 1998), it may be that the participants in this study did not understand the instructions or interpreted them in a way that led to sellers providing a lower value than the object was actually worth to them. Finally, it may be that the sample used in this study is simply anomalous and their results, therefore, must be interpreted lightly. On a more positive note, the buyers' WTP values did fit the general predicted pattern for WTA values across condition. Since the "bargaining intensity" of the baseline condition was designed to be "less" than in the Heightened condition, buyers' WTP values should be slightly higher than those in the Heightened condition. This is mainly because a bargaining script (and the behavioral expectations along with that script) should be less strongly activated in the Baseline condition. Rather individuals may not be following a "buyer's script" but using other types of role information to interpret the situational condition.

The Diminished condition was designed to provide an ambiguous context while the No condition provided no context. It was not clearly stated as a bargaining situation or a trade situation, and in the No condition only one word varied in the value sheet instructions. It was predicted that this ambiguity would also lead to ambiguity regarding which script to use to interpret the situation. Since the "appropriate" script was not 
immediately clear from the worded context, it was predicted that individuals in the Diminished condition would display valuation behavior that was consistent with a weak "buy-low, sell-high" strategy. That is, individuals' WTP/WTA values would not show the same amount of disparity as predicted in the "more intense" conditions (although some difference was predicted). For the No condition, WTP/WTA values were expected to be roughly equal and the most "non-strategic" of the valuations (i.e. a bargaining script would not be used at all, but rather some other basic valuation script which did not distinguish between the roles of buyers and sellers).

Surprisingly, the WTP/WTA values in the Diminished condition were exactly equal. Furthermore, these values were both much higher than either the WTP or WTA values in the Heightened or Baseline conditions, with the WTA values in this condition being the highest of all 4 conditions. The No condition also produced higher WTP/WTA values than seen in both the Heightened or Baseline conditions, and the highest WTP value of all four conditions. This last result is in line with prediction in the sense that it may show that buyers in these "less intense" conditions are less constrained by the "buylow" strategy and are using other methods to assess value. The next subsection speculates

as to why these two conditions produced such markedly higher WTP/WTA values and also as to why the WTP values in the Diminished condition were the highest of the conditions.

\section{The influence of language on values}

After examining the results from Study 1, it became apparent that there was a split between the four conditions along a value dimension. The WTP/WTA values in the 
Heightened and Baseline conditions were more similar to one another than to the WTP/WTA values for the Diminished and No conditions. The same held true for the WTP/WTA values from the Diminished and No conditions; these values were more similar to each other than to either the Heightened or Baseline conditions. Further examination revealed that this division paralleled the labels used to indicate role in each of the situational conditions.

When designing the conditions, it was important to gradually decrease the intensity of the bargaining context. One manner in which this was accomplished was via a change in the labels used to indicate role from "buyer/seller" (in the Heightened and Baseline conditions) to "owner/non-owner" (in the Diminished and No conditions). The reasoning behind this change lay in the belief that the latter language was less likely to lead individuals to link their role to a "bargaining script" (with the behavioral expectations that may entail) and the associated "buy-low/sell-high" strategy.

As indicated by the results, this change in role labels had a considerable effect on the WTP/WTA values. However, both roles were not affected equally, with language having a stronger impact on WTP values than WTA values. The increase in WTP values (buyers' and non-owners' values) as situational intensity decreased is consistent with the theory of bargaining scripts. It is reasonable to expect that individuals labeled as "buyers" are more closely adhering to the bargaining script (and a "buy-low" strategy) than nonowners and thus have a correspondingly smaller WTP value. However, this increase was expected to be gradual and relatively consistent across conditions. What was observed was a significant increase between WTP values of individuals in the buyer label groups and those in the non-owner label groups. 
The results also indicate that WTA values (sellers' and owners' values) are affected by language, though not to the same extent that WTP values are. While it was predicted that WTP values should be higher than the WTA values for any given condition, it was not predicted that there would be a significant difference between the WTP values in the "less intense conditions" (Diminished and No conditions) and the "more intense conditions" (Heightened and Baseline conditions). It is indicated that there is a difference between sellers and owners regarding object value. More specifically, the results suggest that when labeled "sellers" individuals value an object less than do individuals labeled "owners" for the same object.

\section{General Discussion}

Understanding the underlying cognitive processes an individual engages in when determining a price for an object is important for our understanding of what lies at the source of the WTP/WTA disparity. Traditional theories, such as loss aversion, explain the valuation process through the lens of utility to the individual - i.e., loss aversion states that individuals have a kink in their utility functions which causes losses to generate more negative utility than gains do positive utility. ${ }^{23}$ In contrast, the theory of bargaining scripts looks to the psychological processes through which individuals assign values to objects. Instead of positing some deep characteristic of individual utility functions, the theory of bargaining scripts states that an individual uses a cognitive shortcut, known as a script, when determining their value for an object. Moreover, this theory hypothesizes

\footnotetext{
${ }^{23}$ Recent studies have looked at other factors that may mitigate the disutility associated with loss and individuals' ability to accurately judge the pain associated with a loss (Mellers \& Ritov 2007, Koszegi \& Rabin 2004, Wilson \& Gilbert 2005).
} 
that different situational cues may activate different scripts, which in turn affect the resulting valuations.

Specifically, a theory of bargaining scripts predicts that individuals are guided in their price determinations by a "bargaining script" where behavioral expectations for the roles in the script are influenced by a "buy-low, sell-high" strategy. This strategy and its influence on the actions in the script may be the source of the WTP/WTA disparity. For example, it was predicted if individuals assume the role of "buyer" and are influenced by the "buy-low" strategy, then they will produce a value that is lower than the value they would produce if they had assumed the role of "seller". Furthermore, a theory of bargaining scripts predicts that the less ambiguous the context (i.e. is it a bargaining situation or is it some other kind of situation), the more likely an individual is to follow the bargaining script.

Four conditions differing in their "bargaining intensity" were used in Study 1 to examine the predictions that role and ambiguity regarding script was appropriate for the situational context would create the WTP/WTA disparity frequently observed in most studies on valuation and the endowment effect. While the results do support the general predictions, not all the hypotheses were confirmed. Furthermore, the importance of role labels on valuation behavior (i.e. buyer vs. non-owners, sellers vs. owners) was underestimated.

The results from Study 1 suggest that individuals are sensitive to the situational cues, with more ambiguity regarding the situation leading to less reliance on a "bargaining script" as a guide to behavior. For example, the most intense condition, the Heightened condition, was the only condition to show a significant difference between 
WTP and WTA values. However, the instructions made it clear that this was a bargaining situation and clearly stated what role the participant was going to play, disambiguating the situation. Since the situation was clear, participants relied on an appropriate bargaining script to guide their behavior.

Interestingly, the Baseline condition failed to show a significant WTP/WTA gap. The valuation form and instruction sheet have been used in previous studies and elicited a significant WTP/WTA gap (Plott \& Zeiler 2005, Strahilevitz \& Lowenstein 1998). It may be that the particular group of participants in this condition was less sensitive to the situational cues, and provided their values using some other script, where buyer and seller roles aren't as discrepant in their prices. Of course, we must allow for the possibility that the failure to replicate a significant WTP/WTA gap was simply an anomaly of this study and that further retesting using the same condition is necessary.

Finally, there was an effect of labeling on WTP/WTA values that was not predicted in the initial hypotheses. Participants labeled as buyers or sellers in the less ambiguous situations (the Heightened and Baseline condition) had significantly lower WTP/WTA values then did participants labeled as owners or non-owners 24 in the situations with less contextual information (Diminished and No). These results suggest that these two types of labels may be involved in the activation of different types of scripts, with the result that individuals will be guided by different strategies when determining an object's value.

\footnotetext{
24 Actually, in the Diminished condition, the non-owners read instructions that they "could become an owner of the pen" followed by the valuation sheet.
} 
Recent research suggests that labels are "critical influence mechanisms" and can help disambiguate a situation, often changing the behavior an individual will engage in (Zhong, Loewenstein, \& Murnighan 2007):

“...[L]abels nonetheless provide cues that can evoke a variety of applicable norms by suggesting socially agreed upon solutions to otherwise difficult choice dilemmas. In other words, the labels themselves, almost regardless of their content, can be psychologically assuring because they reduce ambiguity and uncertainty within complex social relationships." (Zhong et al. 2007, pg. 48)

In the case of Study 1, the labels of owner vs. seller may be prompting an individual to a certain scripted path of action based by disambiguating the situational condition. This would be especially true for the No condition, where very little contextual information was given, outside of the language indicating role.

As stated earlier, the WTP/WTA values were significantly higher for participants in the conditions with the role labels owner/non-owner, than those participants in the conditions with the role labels buyer/seller. What psychological cues might these roles provide that accounts for the difference in WTP/WTA values?

One possibility is that the bargaining scripts elicited by the labels buyer/seller in the Heightened and Baseline conditions invoke more market-oriented behavior and lead participants to view the object more as a tradable commodity. In contrast, owner/nonowner labels in the Diminished and No conditions may invoke scripts that are more tied to self-identification and future uses. This may affect the valuation of the object, since the nature of the object (as a commodity or as a possession tied to self) has changed. 
Previous studies have indicated that experimental subjects consider objects they view as tradable commodities as different from objects that they value as possessions (List 2004, Klein \& Baker 2004). In the case of this experiment, it may be that values assigned using a bargaining or market-oriented script are generally lower than the values assigned using scripts involving possession or material object attachment, as the marketoriented scripts lead to the individual's having greater sensitivity to price and value.

\section{Limitations and future directions}

An important aspect of the theory of bargaining scripts that was not adequately addressed in the design of the experiment was the influence that the role labels had on cuing the appropriate behavior. In future studies, it would be interesting to focus on the behavior invoked by different labels. For example, the label "trader" might invoke valuation behavior that is different from that of a "seller" or "owner" label. Additionally, a cursory review of the WTP/WTA disparity literature reveals that the influence of labels is a question that has not been adequately addressed by the existing literature. Given the results of this study, mixing labels (i.e. using combinations like owner and buyer, instead of seller and buyer) may be creating an artificial WTP/WTA disparity. For example, Strahilevitz and Loewenstein (1998), reported a \$3.84 difference between owners' WTA values and buyers' WTP values. This difference may not be due to aspects of ownership, but may instead be a result of the different scripts cued by the dissimilar labels. More research on the effects that labels have on value is necessary.

Another limitation of Study 1 is that sex differences in valuation were not examined. It could be that men and women may respond to bargaining script and label 
cues differently. The behavior specified by gender roles could influence the behavioral expectations of the script. For example, women are more likely to give up something in their endowment than men (Eckel \& Grossman 1998) and men's proposals in a dictator game are more sensitive to prices than women's (Andreoni \& Vesterlund 2001). Furthermore, there is evidence to suggest that sellers may be sensitive to these gender differences in bargaining behavior. Ayres and Siegelman (2001) found that car salesmen routinely quoted higher prices to women than men. Along similar lines, age differences may also play a part. As all the subjects of this study were undergrads at a university, age was not taken into account as a factor. Future research might look at how bargaining scripts change and adapt over the lifetime.

In conclusion, Study 1 offered a thought provoking approach to further our understanding of what the source of the WTP/WTA disparity might be. The current findings go beyond the traditional explanation of loss aversion and attempt to explore the psychological aspects that are involved with ownership and how they may affect an object's value. The current research thus enters into the growing body of literature examining psychological aspects of ownership and object valuations and provides additional information about the various factors that guide us in our determination of an object's value. 


\section{Chapter Four - Cognitive Investment}

\section{Ownership, Identity and Possessions}

When the term "endowment effect" was coined over 25 years ago by Richard Thaler (1980) to describe the WTA/WTP gap, the importance of the role of ownership in how individuals assign value to goods was just being realized. Since then, a multitude of experiments has repeatedly shown that people are more reluctant to give up a good that they own as compared to how eager they would be to obtain a similar good were it unowned (Kahneman et al. 1990, Knetsch \& Sinden 1984, Knetsch 1989). Furthermore, this reluctance is often manifested in the tendency for individuals to demand far more to give up an object that is owned than they would be willing to spend to acquire the same object were it un-owned -in other words, a WTA/WTP disparity. However, despite a robust body of scholarship on the WTA/WTP disparity, there is still significant debate over what the causal processes behind the disparity might be (Korobkin 2003, Plott \& Zieler 2005). Various theories, from the famous loss aversion theory proposed by Kahneman and Tversky (1979), to the theory of subject misconceptions posited by Plott \& Zieler (2005), have all drawn on the extensive body of experimental results and previous research in their attempts to provide an explanation for why the WTA/WTP gap exists. More recently, theories building on the themes of possession, ownership, and attachment have been suggested in an attempt to provide a more in-depth psychological alternative to loss aversion as an explanation for the WTA/WTP disparity (Ariely, Huber, Wertenbroch 2005, Lewis 1997, Dhar \& Wertenbroch 2000, Carmon, Wertenbroch, Zeelenberg 2003). 
The causal processes behind the WTA/WTP disparity cannot be fully understood without first examining the relationship between individuals and their possessions. As noted by psychologist Russell Belk in 1988, an individual's sense of self is defined as the sum of his possessions. That we regard our possessions as part of ourselves is a finding that has been extensively documented (c.f. Van Esterick 1986, Belk 1988). Indeed, possessions have been found to hold a great deal of symbolic meaning for their owners (Csikszentmihalyi \& Rochberg-Halton 1981) and can be used in the maintenance of selfdefinitions (Wicklund \& Gollwitzer 1982) and eventually come to be part of an individual's extended sense of self (Belk 1988).

Radin (1982) has shown that loss of an individual's personal property causes a pain that cannot be relieved simply by the object's replacement. While there are many factors that can create an emotional attachment to one's possessions, (e.g. if the object is received as a gift, or belonged to a deceased family member), there is also evidence that ownership, by itself, can create an emotional connection to an object, as the object is incorporated into the self. Ames (1984) found that feelings of identity invested in owned objects can be quite strong:

"They knew from experience that purchasing a major object would be a significant and momentous occasion... a time of heighten positive emotions and feelings of well-being and importance...they would receive more respect and deference from others, which would, in turn, make them feel better about themselves." (Ames 1984, pg. 30-31)

Additionally, attachment can be formed, not just for material possessions, but also for options (choices) or forgone possibilities (Carmon, Wertenbroch, Zeelenberg 2003). The authors found that attachment to a pair of considered options created a sense of 
ownership in the study's participants, and that loss of one of the options created a feeling of psychological discomfort.

If owning an object contributes to one's sense of self and identity, then an individual's evaluation of their possessions is, in some sense, an evaluation of their own identity (Belk 1988). As a result, an individual's perception of an object will be influenced by whether or not the individual is the owner of that object. For example, individuals have been found to perceive objects they own more favorably than do nonowners (Nuttin 1985, 1987, Beggan 1992). These findings may be able to explain the WTA/WTP disparity, in that, individuals come to regard objects that they own more favorably and consequently assign higher valuations to the objects as a result of ownership. Furthermore, loss of an object could contribute to a diminished sense of self (Belk 1988), thus fostering a reluctance to part with any goods that are considered among one's possessions - again causing individual WTA valuations to exceed individual WTP valuations.

\section{Time, attachment creation, and the WTA/WTP disparity}

In an attempt to elucidate the psychological processes underpinning the WTA/WTP disparity, researchers have begun to explore how the creation of attachment to an object over time can affect an individual's valuations of the object. Strahilevitz and Loewenstein (1998) found that adaptation to the ownership of a good occurs over time and that as the adaptation process progresses, both the value of the good and the attractiveness of the good to the owner increases. Moreover, these higher valuations for object caused by ownership persist even once the good is no longer owned. Strahilevitz 
and Loewenstein (1998) speculated that their results are due in part to the creation and development of attachment with an object coming from familiarity with the object.

Building on Strahilevitz and Loewenstein's (1998) results, Ariely, et al. (2005) proposed an "attachment-based approach" to understanding the WTA/WTP gap. This approach looks at how as an emotional attachment to possessed items increases, reluctance to part with the items also increases, which could contribute to the WTA/WTP disparity:

"A seemingly plausible mechanism to produce the endowment effect [the WTA/WTP gap] is emotional attachment. From this affective perspective, reluctance to give up an item increases as consumers' attachment to the items increases." (Ariely et al. 2005, pg. 135)

It would seem then, from these studies, that there is a temporal component associated with the creation of object attachment that enhances the WTA/WTP disparity. As time from initial ownership increases, object attachment also increases and the effects of ownership intensify as the object is increasingly incorporated into one's identity. However, these theories do not provide a satisfactory explanation for the "instant endowment effect" (Kahneman et al. 1990); that ownership can increase valuations over time does not in and of itself explain how a WTA/WTP gap can manifest immediately upon the bestowal of ownership. The remainder of this chapter provides a theory that may shed light on the relationship between object attachment and the "instant endowment effect". 


\section{Cognitive Investment and the instant endowment effect}

It has been well documented that individuals exhibit a WTA/WTP disparity even for goods that have been given just moments before the valuation takes place (Kahneman et al. 1990). To distinguish this seemingly instant attachment to an object that individuals manifest even after just having been endowed with an object from the longer term effects of prolonged ownership led to Kahneman et al. (1990) labeling the WTA/WTP gap as the “instant endowment effect".

Previous studies have documented that attachment can occur over significant time intervals (Strahilevitz and Loewenstein 1998). However, it has only been assumed that attachment requires the passage of significant time. The author is not aware of previous studies that have examined whether it is possible for a significant measure of attachment to occur within very short time intervals, such as the period of minutes that takes place between bestowal of objects and the reporting of valuations in a typical WTA/WTP gap experiment. For instance, Korobkin writes:

"[A]ttachment seems a far less plausible explanation of the endowment effect in experiments in which subjects are asked to value consumer items just moments after they are randomly given the items. A mug set on a desk in front of an individual just minutes ago seems unlikely to create a greater feeling of attachment than a mug set on the next desk at the same moment. The result that subjects place a higher value on the mug set in front of them might be labeled 'instant attachment,' but to employ this explanation is really to concede that attachment is not the explanatory feature of the endowment effect at all." (Korobkin 2003, pg. 1252) 
Korobkin (2003) apparently views it as self-evident that significant attachment cannot form over a period of minutes as he does not forward any empirical evidence in support of his claim. Korobkin's (2003) reasoning represents a prevalent view of the broader literature. It is typically assumed - without evidence - that no significant measure of attachment can develop within a time period measured in minutes or less.

However, results from other areas of cognitive and social psychology suggest that at least some forms of mental updating can take place essentially instantaneously - over time periods of less than a minute. For instance, the results from attribution theory demonstrate that humans develop assumptions about causal connections immediately upon witnessing novel events or circumstances (Gigerenzer \& Todd 1999, Gilbert 1989, 2002). Similarly, a wide body of research on intuition has shown that humans readily make instantaneous value judgment and that these rapid intuitive evaluations are in many cases superior to evaluations and judgments that develop over longer periods of time (Wilson \& Schooler 1991, Bargh 1997, Zajonc 1998, Paul Slovic et al. 2002, Epstein 2003, Kahneman 2003). In discussing this research, Daniel Kahneman (2003, pg. 1454) writes, "The evidence, both behavioral and neurophysiological, is consistent with the idea that the assessment of whether objects are good (and should be approached) or bad (should be avoided) is carried out quickly and efficiently by specialized neural circuitry."

In light of this extensive body of research demonstrating that at least some forms of mental updating can occur near instantaneously, it should not be taken for granted that object attachment can only occur over prolonged time intervals. Hence, this chapter proposes a theory of cognitive investment as a potential explanation for the WTA/WTP disparity. The theory of cognitive investment states that individuals can develop at least 
some measure of attachment to an object - incorporating the object into the individual's sense of self and identity - immediately upon obtaining ownership of the object.

The theory of cognitive investment claims that individuals develop attachment immediately upon acquiring an object through a process of engaging with the object. This engagement may be either mental or physical (or both) in nature. In either case, engagement helps focus an individual's attention on the object and as a result of which, the individual invests cognitive resources in the object

The connection between engagement, the investment of cognitive resources, and the development of object attachment, is a central theme discussed in the psychological literature on the effects of prolonged ownership. For example, Csikszentmihalyi and Rochberg-Halton (1981) concluded that the effects of ownership result from individuals investing "psychic energy" into objects to which they have directed their efforts, time, and attention and that this investiture leads to the objects becoming part of the individuals' sense of self and identity. Once again, the theory of cognitive investment proposed in this chapter extends on this literature by positing that this investiture of psychic energy can occur nearly instantaneously so as to develop significant object attachment almost immediately upon the bestowal of ownership. The full effects of the engagement caused by ownership may only develop over the passage of longer time intervals, but the theory of cognitive investment claims that at least some measure of engagement and resulting object attachment can occur nearly instantaneously, thus causing the WTA/WTP gap. 


\section{Testing a theory of cognitive investment: Study 2}

Study 2 was designed to examine the theory of cognitive investment through observation of how engagement with a pen affects the values placed on it. In addition, the study also looks at the effect of engaging with an object on non-owner values. If engagement results in the investiture of cognitive resources, then non-owners who have engaged with a pen should value the pen higher than non-owners who did not engage with the pen. The dependent variable in Study 2 was price; the independent variables were ownership and engagement. The two independent variables and the interaction expected between them are discussed in further detail below.

\section{Engagement}

The variable, Engagement, is designed to get participants to cognitively invest in the object they were given. The engagement task contains both a mental and physical engagement aspect, in that participants both used the pen and also answered questions requiring them to think about the pen.

It is predicted that engaging with an object will increase the value the subjects report for the object. Heider (1958) has suggested that ownership can be conceptualized as an association between an object and a person. One of the mediums through which association can be formed is through the use of an object (Furby 1978a, Werner, Brown, \& Damron 1981). As the amount of use increases, one's sense of association with an object should also increase and as a result, one may begin to develop stronger feelings of attachment to the object, which should lead to higher valuations of that object. 
Through engaging with the pen, participants should form a sense of association with it and this, in turn, should invoke an initial phase of attachment to the pen. This initial attachment resulting from engagement will lead to increased valuations of the pen relative to a participant who has not had the opportunity to engage with it.

\section{Ownership}

The variable of ownership consisted of two groups: owners and non-owners of the pen. It is predicted that the owners of the pen will place a higher value on it than will the non-owners. It is important to keep in mind that the purpose of Study 2 is not to disprove the well established fact that owners generally value objects in their possession higher than do non-owners, but rather to illuminate the aspects of ownership that give rise to these higher values (besides the traditional theory of loss aversion). Thus, higher values among owners are not predicted as a novel finding, but rather as a consequence of ownership.

\section{The relationship between ownership and engagement}

It is predicted that engagement with the pen will further increase an owner's valuation of the pen. If engagement increases attachment to an object through cognitive investment, and increased attachment leads to increased association with the object, then it is expected that participants who both own and engage with the pen should value it higher than participants who are told they own the pen, but who are not given the opportunity to engage with it. 
Table 5 below summaries the predictions for Study 2, including the interactions predicted between ownership and engagement.

Table 5. Summary of predictions for Study 2

\begin{tabular}{|cc|}
\hline Situation & $\begin{array}{c}\text { Rank of expected pen } \\
\text { values from highest to } \\
\text { lowest }\end{array}$ \\
\hline Ownership w/ Engagement & $1^{\text {st }}$ \\
No ownership w/ & $2^{\text {nd }}$ \\
Engagement & \\
Ownership w/ No & $3^{\text {rd }}$ \\
Engagement & \\
No ownership w/ No & $4^{\text {th }}$ \\
Engagement & \\
\hline
\end{tabular}

\section{Methods: Study 2}

\section{Participants}

246 undergraduates from the University of Texas at Austin (113 male and 133 female) participated in this study. Participants received extra course credit for their participation. All participants were treated in accordance with the "Ethical Principles of Psychologists and Code of Conduct” (American Psychological Association 2002). 


\section{Materials}

Two booklets were designed, one for each condition: engagement or nonengagement (see Appendices E \& F). The engagement booklet consisted of three questions regarding a pen that had been presented to the participants, each question followed with four to five lines for answer space. The exact instructional set for the engagement forms is as follows:

The 3 questions below pertain to the pen in front of you. Please read each question carefully. You may pick up the pen, write with it, or examine it in any way you see fit.

For each question, try to answer as thoroughly as possible (3-4 sentences each). When you have finished, please close your booklet and turn it over.

The non-engagement booklet consisted of a full color picture of a keychain, followed by three questions regarding the keychain. The instructional set for the non-engagement condition is as follows:

The 3 questions below pertain to the keychain in the picture on the page to the left. Please examine each picture to familiarize yourself with the keychain. Please read each question carefully.

For each question, try to answer as thoroughly as possible (3-4 sentences each). When you have finished, please close your booklet and turn it over. 
The value elicitation sheets used for both conditions were modeled after those used by Strahilevitz and Loewenstein (1998). The instructional set for the value elicitation sheets was altered slightly between the engagement and non-engagement conditions to reflect the ownership or non-ownership condition (Appendices $\mathrm{G} \& \mathrm{H}$ ). The values for the pen ranged from $.05 \phi$ to $\$ 1.50$ in $.05 \phi$ increments. The pens were simple silver ballpoint pens with black ink and a removable top.

\section{Procedure}

Participants $(N=237)$ were randomly assigned to one of the four conditions (owner/non-owner $\mathrm{X}$ engagement/non-engagement/null) prior to the beginning of the session. Within each experimental session, all participants were assigned to the same condition.

Engagement Condition: Participants in the engagement condition were first given the booklet containing questions regarding a pen. Immediately after being given the booklet, the participants were presented with a pen. Those participants in the ownership condition were told that, "this pen is yours, you own it. You may do whatever you like with it and take it home with you at the end of the study. "25 Those in the non-ownership condition were simply presented with a pen that was placed on the desk before each person and told that the questions in the booklet pertained to this pen. Participants in both the ownership and non-ownership conditions were told to use the pen to fill out the

\footnotetext{
25 Previous studies have demonstrated that this is enough to create a feeling of ownership with an object (Plott \& Zeiler 2006).
} 
questions in their booklet. When the participants had finished with the engagement task, the booklets were collected and the value elicitation sheets were handed out.

Non-engagement condition: Participants in the non-engagement condition were given the booklet containing questions about a keychain. Those in the ownership condition were shown the pen and told that later in the condition they would be given the pen and that "the pen is yours to keep, you own it, and may do whatever you like with it and take it home with you at the end of the study." Those participants in the nonownership condition were not given any information about a pen until the value elicitation phase, when they were shown the pen and told that this was the pen referred to in the next task (value elicitation sheet). After the participants had completed the questions booklet, the booklets were collected and the value elicitation sheets handed out. When the participants had filled out the value elicitation forms, the forms were collected and those in the ownership condition received their pens.

Null condition: Participants in the null condition were only given the value elicitation sheet. This condition was designed to see if the mere fact of giving participants any task (i.e. the engagement or non-engagement task) affected the participants' values of the pens. The same procedure used in the other conditions to trigger ownership was also used here.

\section{Results and discussion}

To examine the effects of engagement and ownership on pen values, a $2 \times 3$ ANOVA was used. It was predicted that although ownership should have an effect on pen values, this effect should be strengthened by engagement with the pen. Furthermore, in the non-owner condition, it was expected that engaging with the object would increase 
the pen's valuation relative to the value assigned by an individual in the non-owner, nonengagement condition. The mean values for the pen are presented in Table 6 .

Table 6. Mean pen valuation as a function of Ownership and Engagement

\begin{tabular}{|c|c|c|c|c|}
\hline Ownership & Engagement & $\mathrm{N}$ & Mean & Std. Deviation \\
\hline \multirow{2}{*}{ Owner } & Engage & 40 & $\$ 0.98$ & .3854 \\
\hline & Non-Engage & 43 & $\$ 1.04$ & .3130 \\
\hline \multirow{4}{*}{ Non-Owner } & Null & 37 & $\$ 0.98$ & .3774 \\
\hline & Engage & 41 & $\$ 0.82$ & .4231 \\
\hline & Non-Engage & 39 & $\$ 0.72$ & .3553 \\
\hline & Null & 37 & $\$ 0.69$ & .3620 \\
\hline
\end{tabular}

Initial observation of participants' valuation behavior revealed a clustering of responses around the $.95 \phi$ value in all conditions (see Figure 5, $.95 \phi$ values are indicated in red). After the completion of the study, approximately 25 participants who had marked the $.95 \phi$ value for their pen were informally asked why they had chosen that valuation. The majority of responses indicated that the participants did not necessarily value the pen at that price, but rather that the participants simply did not want to receive change. That is, participants stated that they preferred to keep the pen to receiving "loose change" below the one dollar $\$ 1.00$ value. 
Figure 5. Histogram of pen valuations responses by condition

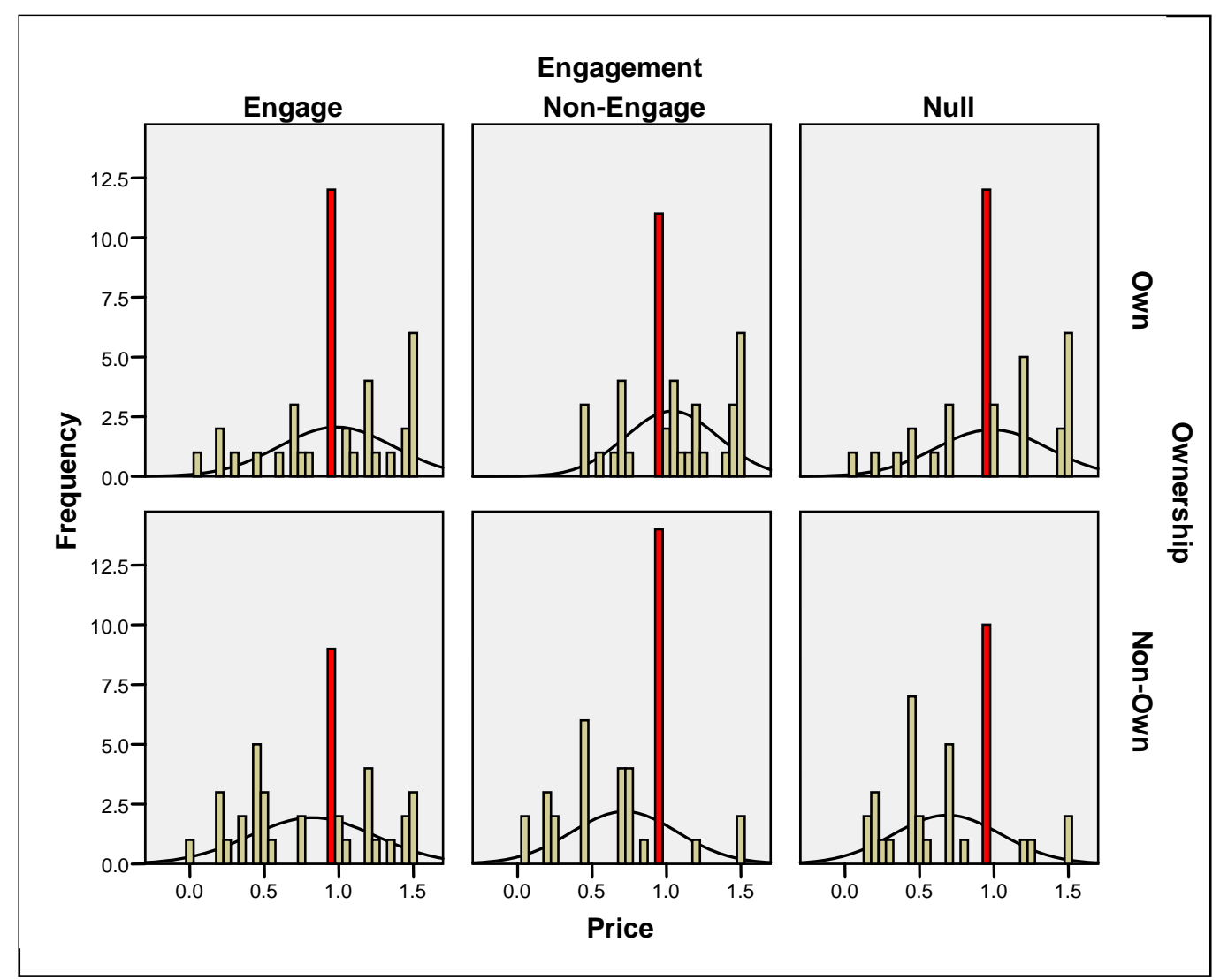


The kurtosis and skewness ratios for the samples were computed to examine the influence of this "loose change effect" on the distribution of the values. It was determined that the distributions could be considered normal (kurtosis \& skewness ratios $< \pm 2$ ).

\section{Test of predictions}

A $2 \times 3$ ANOVA revealed that there was not a significant interaction between the conditions of ownership and engagement $(\mathrm{F}(2,230)=.871$, n.s. $)$, although a graphical comparison of the means for each of the engagement conditions suggests a trend toward an interaction (Figure 6). There was a main effect for ownership $(\mathrm{F}(1,230)=28.27)$ but not for engagement $(\mathrm{F}(2,230)=.678$, n.s. $)$.

\section{Figure 6. Price change as a function of ownership}

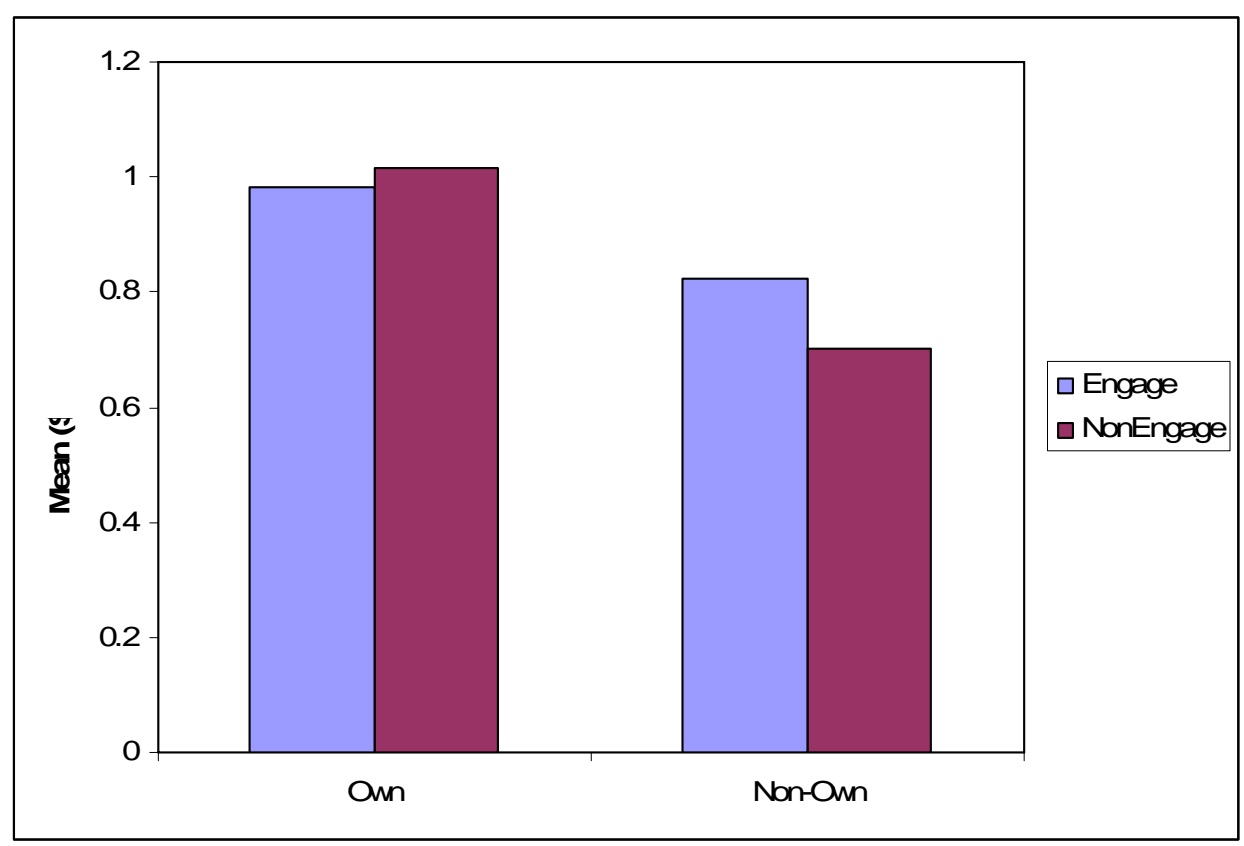


Consistent with the predictions, owners of the pen placed a higher value on the pen $(\mathrm{M}=$ $\$ 1.00)$ than did those individuals who were in the non-owner condition $(\mathrm{M}=\$ 0.74)$. This is not surprising since it was predicted that ownership would affect price insofar as engagement is a part of ownership. However, what was more surprising was the lack of an effect found for the engagement condition. It was predicted that, when ownership was absent, engagement with the object (as a form of pre-ownership) would increase pen values over those of the participants in the non-engagement condition. Visual inspection of chart $\mathrm{X}$ suggests that, although not significant, there is a relationship between engagement and ownership. A number of post hoc analyses were conducted in order to examine the nature of this relationship and are discussed below.

\section{The potential relationship between engagement and ownership}

Across the condition of engagement, the mean values reported for the pens differed as a function of ownership. Contrary to expectations, individuals in the ownership but non-engagement condition reported higher mean values than individuals in the ownership and engagement condition $(\mathrm{M}=\$ 1.04$ versus $\mathrm{M}=\$ 0.98$ respectively). This result was reversed for the individuals in the non-ownership condition; individuals in the non-ownership and engagement condition reported higher mean values $(\mathrm{M}=$ $\$ 0.82)$ than individuals in the non-ownership and non-engagement condition $(\mathrm{M}=\$ 0.72)$ (See Figure 7). 
Figure 7. Mean pen values for Engagement by Ownership

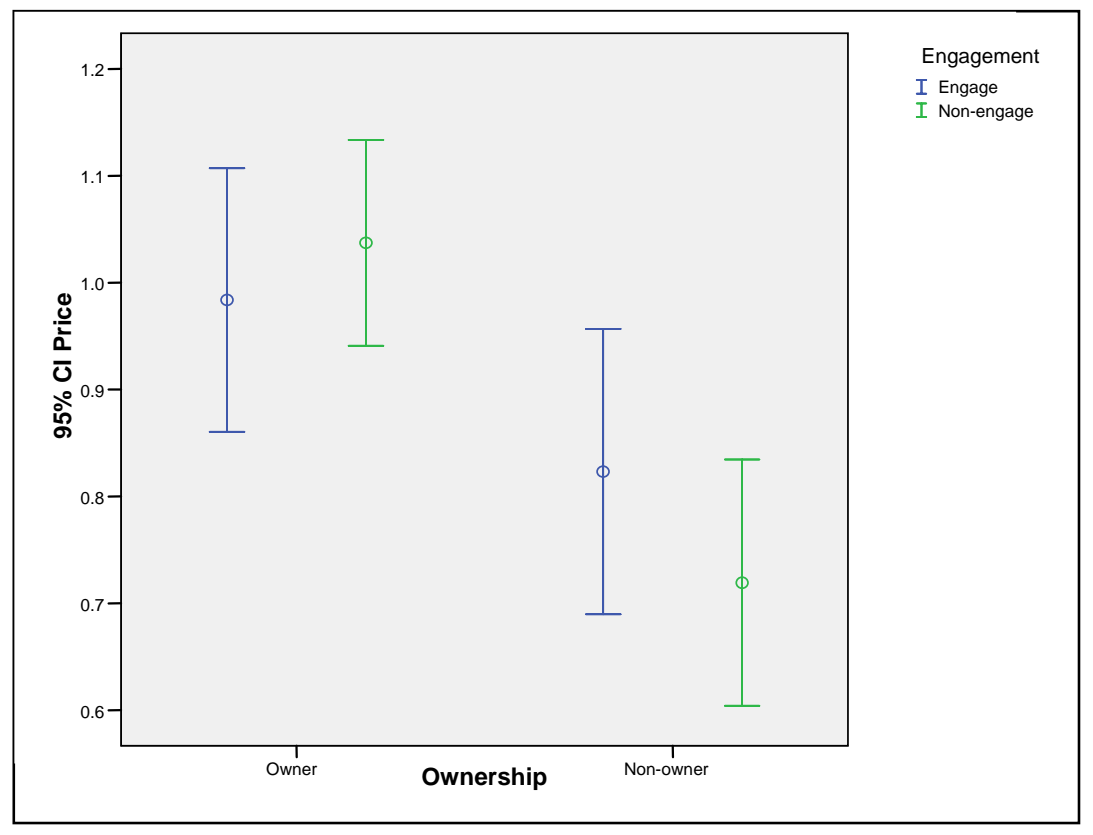

One explanation for this pattern may lie in the nature of the interaction individuals had with the pen. As part of the engagement task, individuals answered three questions relating to the pen they had used. These questionnaire forms were coded for 
overall positive or negative feelings about the pen (i.e. did they like the pen or not, would they like to continue using the pen or not, etc.) and grouped into two groups - positive and negative evaluation.

Figure 8 below displays the number of positive or negative evaluations in the ownership versus non-ownership conditions. Within the owner condition, the ratio of positive responses to negative responses was slightly larger (1:1.4) than was the ratio of positive to negative responses in the non-owner condition (1:1.2). Although this result may just be due to natural variability between the two ownership conditions, it can be speculated that there may be a connection between owning an object and evaluating it in a more positive light.

Figure 8. Number of Positive vs. Negative Evaluations as a function of Ownership

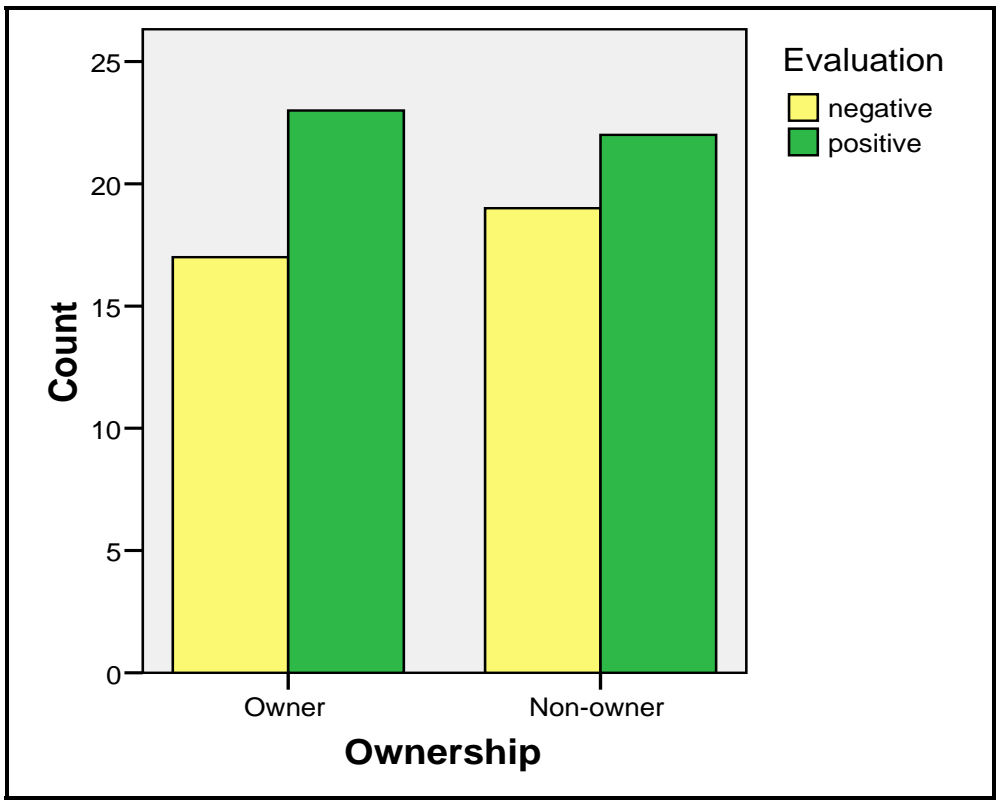


Finally, the prices provided for the pens were compared with the positive/negative evaluations to provide some information regarding the relationship between price and positive/negative evaluations. A comparison of means (Table 7 and Figure 8) shows that - unsurprisingly - owners and non-owners provided lower mean values for their pens if they had given the pen a negative evaluation and higher mean values if they had given the pen a positive valuation.

Table 7. Comparison of mean pen values by evaluation and ownership condition

\begin{tabular}{|cc|c|c|c|}
\hline Evaluation & Ownership & Mean & N & Std. Deviation \\
\hline \multirow{2}{*}{ Negative } & Owner & .835 & 17 & .4245 \\
& Non-owner & .624 & 19 & .4366 \\
& Owner & 1.093 & 23 & .3203 \\
Positive & Non-owner & .995 & 22 & .3323 \\
& Owner & .984 & 40 & .3854 \\
& Non-owner & .823 & 41 & .4231 \\
& Total & .902 & 81 & .4104 \\
\hline
\end{tabular}

Figure 9. Comparison of mean pen values as a function of evaluation 


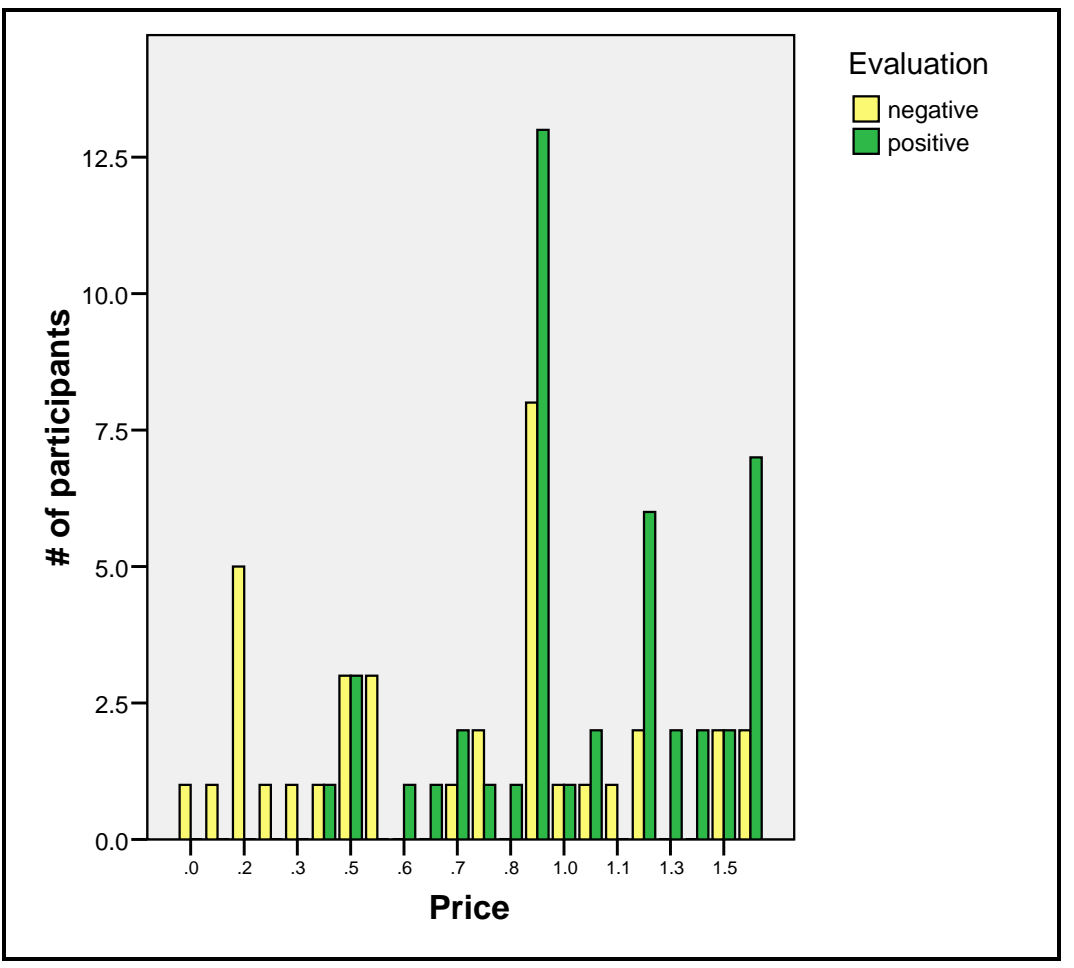

\section{General Discussion, Limitations, and Final Considerations}

Study 2 examined how two conditions, ownership and engagement, affected the value an individual provided for a pen. The results suggest that ownership has a strong influence on value. The owners of the pen had higher mean values than did the nonowners of the pen. The role of engagement is less clear. For example, contrary to the predictions, those participants who both owned and engaged with the pen had lower mean values than owners who did not engage with the pen. However, participants who did not own but engaged with the pen placed a higher value on the pen than participants who both did not own and did not engage with the pen. Although it seems that ownership is an important factor in determining a value, in its absence, the cognitive investment from engagement seems to dispose an individual to place a higher value on the object. 
Further examination of the data revealed that there may be a mediating factor on the engagement condition - the quality of the engagement. Evaluations of the responses regarding the pen suggest that higher values are correlated with a positive versus negative interaction. Participants who gave a positive evaluation had higher mean values for pens than participants who provided negative evaluation. Furthermore, the data suggests that positive evaluation may be tied to ownership condition (i.e. if an individual is assigned to the owner or non-owner condition). Although not significantly different, owners provided more positive evaluations of the pen than did non-owners in Study 2.

Beggan (1998) argues that possessions are an extension of the self and as such will be rendered in a more positive light than a similar, un-owned object. He found that simple possession of an object triggered higher ratings of the object's attractiveness. If this is the case, then it is not surprising that the owners in this study had more positive valuations than the non-owners. However, although ownership and attractiveness were examined in Beggan's study (1998), their effects on object valuation were not measured. Study 2 in this chapter may shed some light on the nature of the relationship between ownership, object value, and quality of the evaluation of the object (i.e. positive or negative).

Future research is needed to examine how the quality of the interaction affects the subsequent valuations of the object in both the presence and absence of ownership. Interaction quality was not originally part of the predictions made for the theory of cognitive investment; however, the post hoc analyses from Study 2 seem to suggest that this factor may be playing an influential role in object valuation. Future studies should include more formal object evaluation measures and attempt to control for the quality of 
the interaction. For example, providing owners with a broken pen, so that the de facto evaluation should be negative, may be one way to control for the interaction quality.

Another area for future exploration is the question of gender effects. Gender information was collected in Study 2, however as gender was not a central factor in the study, no effort was made to control for equal numbers of men and women. A quick examination of the mean values suggests that women are placing a higher value on the pens in all experimental cells. However, as there were different numbers of men and women in each cell, this speculation should be taken lightly.

\section{Limitations}

One of the most serious limitations of Study 2 was the valuation form. Although it was virtually identical to object valuation forms used in pervious studies (Strahilevitz and Lowenstein 1998), the valuation form used in Study 2 had several problematic elements.

First, there was a ceiling effect for the price of the pen. Although the pen retailed for approximately $.88 \notin$, the highest price listed on the form was $\$ 1.50$. It was erroneously thought that this would provide a high enough ceiling, but the responses collected in Study 2 indicate a number of individuals valuing the pen at $\$ 1.50$.

In order to test whether the $\$ 1.50$ values could indicate a ceiling effect, new valuation forms with prices up to $\$ 4.00$ were given to approximately 25 participants. When presented with an opportunity to provide a higher value, a number of participants did so. As such, this supports the observation that the valuation forms were subject to a ceiling effect. 
Secondly, the incremental values used on the valuation form created what I term a "loose change effect", where participants would rather keep the pen up to whole dollar values in order to avoid receiving change in trade. In Study 2, the values on the sheet increased in $.05 \phi$ increments, up to $\$ 1.50$. A number of participants' responses clustered around the $.95 \notin$ value. This valuation response was so ubiquitous that several participants were asked at the end of the study why they had chosen that value. The general response was "to avoid the loose change" or "I didn't want a bunch of change"; participants felt it wasn't worth the effort to trade the pen for, say, $.85 \phi$.

Further speculation on this change problem revealed that the "loose change effect" might be mitigated by using larger increments between the values. For example, the current valuation sheets use increments of a nickel; a better increment may have been a quarter. Quarters generally have greater utility to individuals, in particular the undergraduates who comprised this study, as quarters can be used in a varity of common environments (e.g. laundry machines, vending machines, etc.). For future studies, a valuation sheet with larger increments and an appropriately large value range should be used.

\section{Final Considerations}

Despite the limitations and issues that arose in Study 2, the theory of cognitive investment presents a unique approach to the concept of ownership and how people develop almost instantaneous attachment to objects. It also examines how usage of an object might both intensify ownership and affect an individual's subjective valuation of that object. The idea behind cognitive investment - that devoting cognitive resources to an object may increase feelings of attachment and thus affect the subjective worth of the 
object - contributes to our understanding of the intricate relationship between ownership and valuation. This theory highlights the fact that ownership is a complex psychological process with many elements. This psychological perspective on ownership and value has potential implications for the management of conflicts involving property disputes and other valuation disputes within the realms of law and policy, as well as for research on the WTA/WTP disparity and for the continually growing body of literature on the psychology of ownership. 


\section{Appendix A}

\section{Instructions}

You are a buyer. You will be bargaining with one of the other people in this room. The object you will be bargaining over is the mug on the desk. You are expected to bargain with the seller to determine the price that the mug will sell for. You should treat this situation as you would any serious negotiation.

For the each of the prices listed below, please indicate whether you would buy the mug from your partner at that price.

Please indicate your decision by marking an $\mathrm{X}$ in the appropriate column.

I Will Buy The Mug I Will Not Buy The Mug

If the price is $\$ 0.00$

If the price is $\$ 0.50$

If the price is $\$ 1.00$

If the price is $\$ 1.50$

If the price is $\$ 2.00$

If the price is $\$ 2.50$

If the price is $\$ 3.00$

If the price is $\$ 3.50$

If the price is $\$ 4.00$

If the price is $\$ 4.50$

If the price is $\$ 5.00$

If the price is $\$ 5.50$

If the price is $\$ 6.00$

If the price is $\$ 6.50$

If the price is $\$ 7.00$

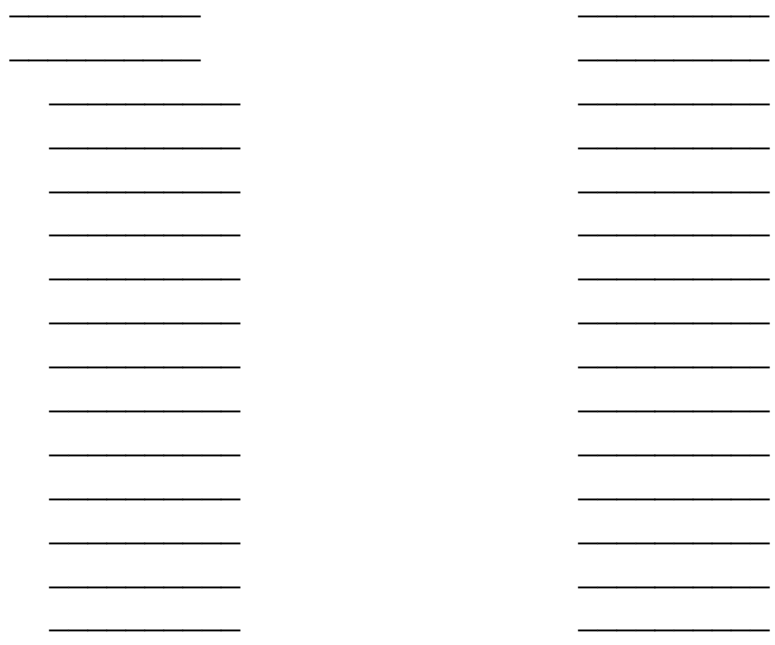




\section{Instructions}

You are a seller. You will be bargaining with one of the other people in this room. The object you will be bargaining over is the mug on the desk. You are expected to bargain with the buyer to determine the price that you will sell the mug for. You should treat this situation as you would any serious negotiation.

For the each of the prices listed below, please indicate whether you would sell the mug to the buyer at that price.

Please indicate your decision by marking an $\mathrm{X}$ in the appropriate column.

\section{Will Sell The Mug I Will Not Sell The Mug}

If the price is $\$ 0.00$

If the price is $\$ 0.50$

If the price is $\$ 1.00$

If the price is $\$ 1.50$

If the price is $\$ 2.00$

If the price is $\$ 2.50$

If the price is $\$ 3.00$

If the price is $\$ 3.50$

If the price is $\$ 4.00$

If the price is $\$ 4.50$

If the price is $\$ 5.00$

If the price is $\$ 5.50$

If the price is $\$ 6.00$

If the price is $\$ 6.50$

If the price is $\$ 7.00$

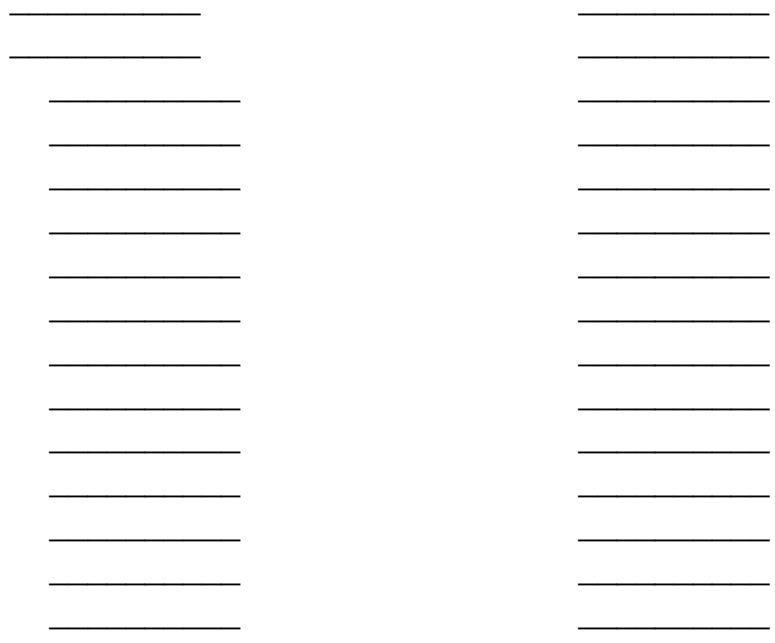




\section{APPENDIX B}

\section{Instructions}

You have the option of buying the mug on the desk.

For each of the possible prices listed below, please indicate whether you wish to:

1) Buy the mug at this price, or 2) Not buy the mug at this price.

We have predetermined a money amount for the mug. The amount is written on a slip of paper in the envelope displayed before you. When everyone has completed their forms, the amount will be revealed.

Please note the following two things:

1) You decision can have no effect on the price actually used because the price has been predetermined.

2) It is in your interest to indicate your true preferences at each of the possible prices below.

Please indicate your decision by marking an $\mathrm{X}$ in the appropriate column.
I Will Buy The Mug
I Will Not Buy The Mug

If the price is $\$ 0.00$

If the price is $\$ 0.50$

If the price is $\$ 1.00$

If the price is $\$ 1.50$

If the price is $\$ 2.00$

If the price is $\$ 2.50$

If the price is $\$ 3.00$

If the price is $\$ 3.50$

If the price is $\$ 4.00$

If the price is $\$ 4.50$

If the price is $\$ 5.00$

If the price is $\$ 5.50$

If the price is $\$ 6.00$

If the price is $\$ 7.50$

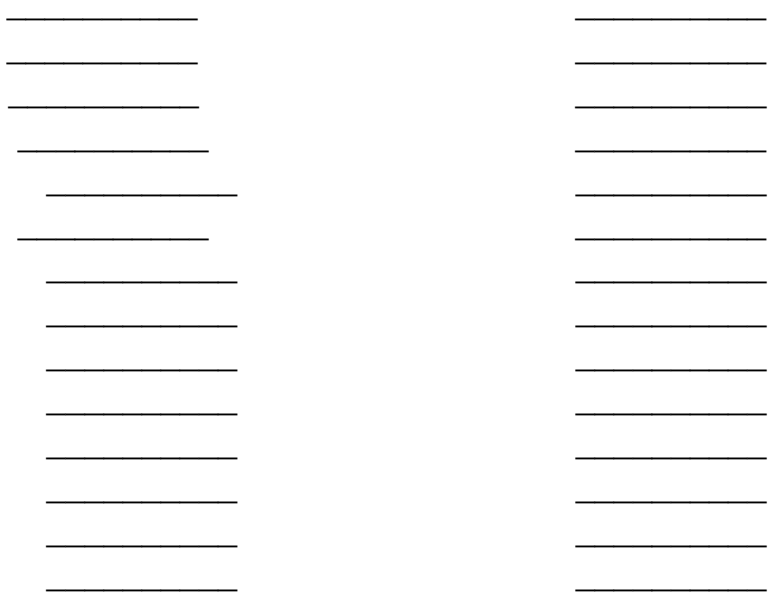


If the price is $\$ 7.00$

\section{Instructions}

You own the mug on the desk. You may choose to sell your mug to the experimenter for an amount of money.

For each of the possible prices listed below, please indicate whether you wish to:

1) Sell your mug at this price, or 2) Not sell your mug at this price.

We have predetermined a money amount for the mug. The amount is written on a slip of paper in the envelope displayed before you. When everyone has completed their forms, the amount will be revealed.

Pleas note the following two things:

1) You decision can have no effect on the price actually used because the price has been predetermined.

2) It is in your interest to indicate your true preferences at each of the possible prices below.

Please indicate your decision by marking an $\mathrm{X}$ in the appropriate column.

\section{Will Sell The Mug I Will Not Sell The Mug}

If the price is $\$ 0.00$

If the price is $\$ 0.50$

If the price is $\$ 1.00$

If the price is $\$ 1.50$

If the price is $\$ 2.00$

If the price is $\$ 2.50$

If the price is $\$ 3.00$

If the price is $\$ 3.50$

If the price is $\$ 4.00$

If the price is $\$ 4.50$

If the price is $\$ 5.00$

If the price is $\$ 5.50$

If the price is $\$ 6.00$

If the price is $\$ 6.50$

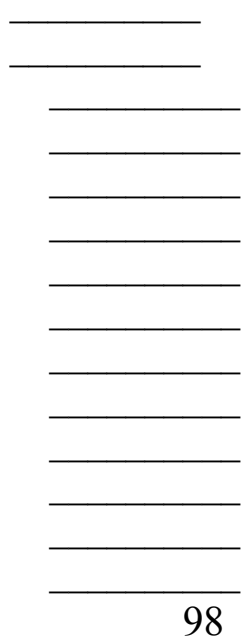


If the price is $\$ 7.00$ 


\section{APpendix C}

\section{Instructions}

You are the owner of the mug on the desk. Please determine a monetary value for the price of your mug.

For each of the possible prices listed below, please your valuation by marking an $\mathrm{X}$ in the appropriate column.

I Value the Mug At

This Price or Higher

If the price is $\$ 0.00$

If the price is $\$ 0.50$

If the price is $\$ 1.00$

If the price is $\$ 1.50$

If the price is $\$ 2.00$

If the price is $\$ 2.50$

If the price is $\$ 3.00$

If the price is $\$ 3.50$

If the price is $\$ 4.00$

If the price is $\$ 4.50$

If the price is $\$ 5.00$

If the price is $\$ 5.50$

If the price is $\$ 6.00$

If the price is $\$ 6.50$

If the price is $\$ 7.00$
I Do Not Value the Mug At This Price

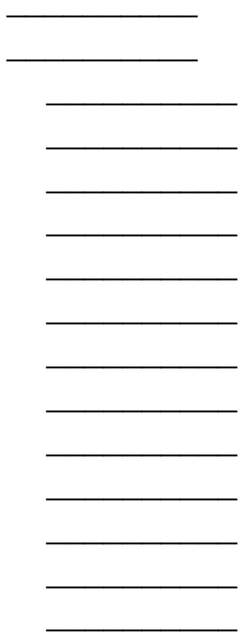

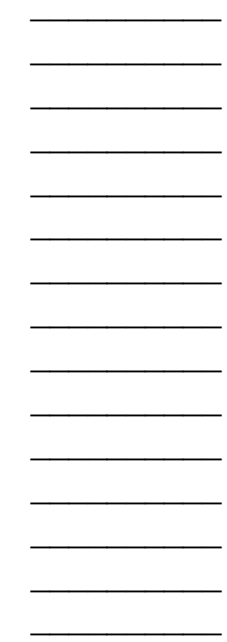




\section{Instructions}

You may become the owner of the mug on the desk. Please determine a monetary value for the price of the mug.

For each of the possible prices listed below, please indicate your valuation by marking an $\mathrm{X}$ in the appropriate column.

I Value the Mug At This Price or Higher

If the price is $\$ 0.00$

If the price is $\$ 0.50$

If the price is $\$ 1.00$

If the price is $\$ 1.50$

If the price is $\$ 2.00$

If the price is $\$ 2.50$

If the price is $\$ 3.00$

If the price is $\$ 3.50$

If the price is $\$ 4.00$

If the price is $\$ 4.50$

If the price is $\$ 5.00$

If the price is $\$ 5.50$

If the price is $\$ 6.00$

If the price is $\$ 6.50$

If the price is $\$ 7.00$
I Do Not Value the Mug At This Price
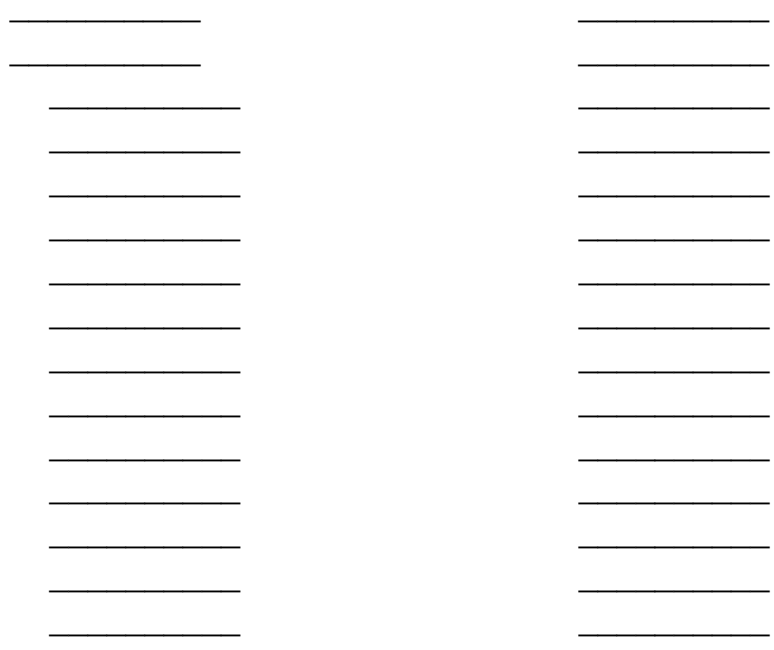


\section{APPENDIX D}

\section{Instructions}

Please assign a value to the mug on the desk.

For each of the possible prices listed below, please indicate your valuation by marking an $\mathrm{X}$ in the appropriate column.

I Value the Mug At

This Price or Higher

If the price is $\$ 0.00$

If the price is $\$ 0.50$

If the price is $\$ 1.00$

If the price is $\$ 1.50$

If the price is $\$ 2.00$

If the price is $\$ 2.50$

If the price is $\$ 3.00$

If the price is $\$ 3.50$

If the price is $\$ 4.00$

If the price is $\$ 4.50$

If the price is $\$ 5.00$

If the price is $\$ 5.50$

If the price is $\$ 6.00$

If the price is $\$ 6.50$

If the price is $\$ 7.00$
I Do Not Value the Mug At This Price

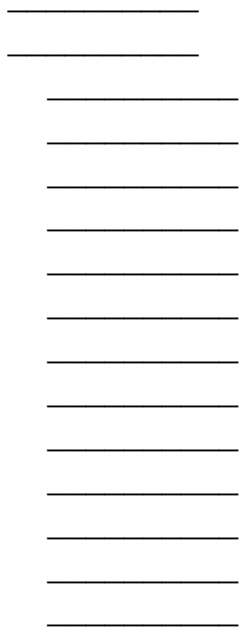

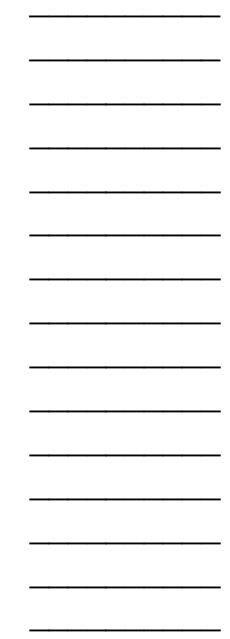




\section{Instructions}

Please assign a value to your mug on the desk.

For each of the possible prices listed below, please indicate your valuation by marking an $\mathrm{X}$ in the appropriate column.

I Value the Mug At This Price or Higher

If the price is $\$ 0.00$

If the price is $\$ 0.50$

If the price is $\$ 1.00$

If the price is $\$ 1.50$

If the price is $\$ 2.00$

If the price is $\$ 2.50$

If the price is $\$ 3.00$

If the price is $\$ 3.50$

If the price is $\$ 4.00$

If the price is $\$ 4.50$

If the price is $\$ 5.00$

If the price is $\$ 5.50$

If the price is $\$ 6.00$

If the price is $\$ 6.50$

If the price is $\$ 7.00$
I Do Not Value the Mug At This Price
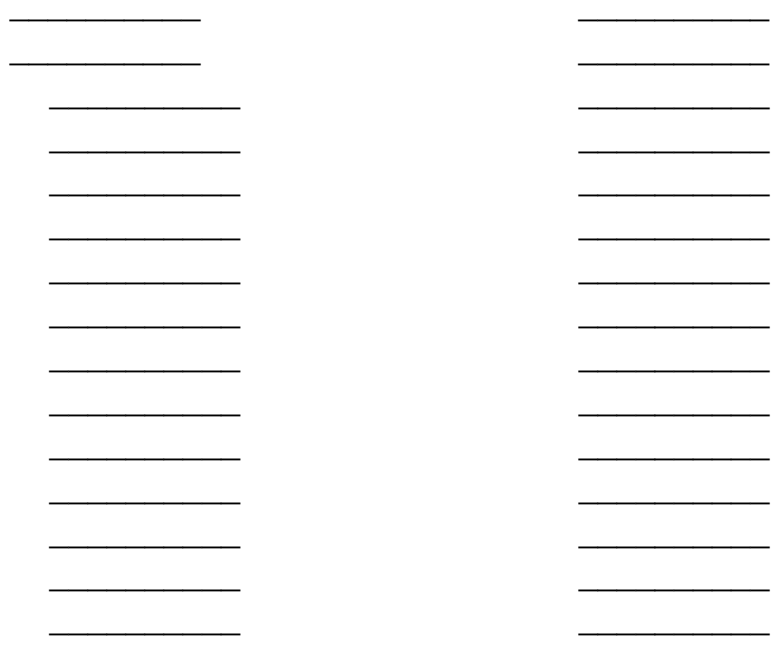
APpendix E

Please answer the following questions:

1. What is your gender? Male __ Female

2. What is your major or program? 


\section{Form A}

The 3 questions below pertain to the pen in front of you. Please read each question carefully. You may pick up the pen, write with it, or examine it in anyway you see fit.

For each question, try to answer as thoroughly as possible (3-4 sentences each). When you have finished, please close your booklet and turn it over.

Q1. How does this pen compare to other pens that you use?

Q2. Think about day-to-day situations in which you use a pen. Would you feel comfortable using this pen in those situations? Why or why not? 
Q3. What features of this pen do you find the most attractive? Why? 
APPENDIX F

Please answer the following questions:

1. What is your gender? Male

Female

2. What is your major or program? 


\section{Form B}

The 3 questions below pertain to the keychain in the picture on the page to the left. Please examine each picture to familiarize yourself with the keychain. Please read each question carefully.

For each question, try to answer as thoroughly as possible (3-4 sentences each). When you have finished, please close your booklet and turn it over.

Q1. How does this keychain compare to other keychains that you use?

Q2. Think about day-to-day situations in which you need to use a keychain. Would you feel comfortable using this keychain in those situations? Why or why not? 
Q3. What features of this keychain do you find the most attractive? Why? 


\section{APPENDIX G}

Please read the following instructions carefully:

You now have the opportunity to trade your pen for some money. Below are a series of lines marked "Keep pen/ Trade it in for \$_". On each line circle whether you would prefer to keep the pen or trade it for the amount of money written on the line. Please circle one or the other for every line.

We have predetermined a money amount for the pens. The amount is written on a slip of paper in the envelope displayed before you. When everyone has completed their forms, the amount will be revealed.

If you specified below that you would prefer to trade the pen in for the money amount we reveal then you will give up the pen and we will give you the money. If you specified that you would prefer to keep the pen over the amount we reveal, then you will keep the pen.

Note that your choice below will not affect the amount written in the envelope. Therefore, it is in your interest to indicate what the pen is truly worth to you.

All trades will take place immediately. 
1. Keep pen / Trade it for $\$ .05$

2. Keep pen / Trade it for $\$ .10$

3. Keep pen / Trade it for $\$ .15$

4. Keep pen / Trade it for $\$ .20$

5. Keep pen / Trade it for $\$ .25$

6. Keep pen / Trade it for $\$ .30$

7. Keep pen / Trade it for $\$ .35$

8. Keep pen / Trade it for $\$ .40$

9. Keep pen / Trade it for $\$ .45$

10. Keep pen / Trade it for $\$ .50$

11. Keep pen / Trade it for $\$ .55$

12. Keep pen / Trade it for $\$ .60$

13. Keep pen / Trade it for $\$ .65$

14. Keep pen / Trade it for $\$ .70$

15. Keep pen / Trade it for $\$ .75$
16. Keep pen / Trade it for $\$ .80$

17. Keep pen / Trade it for $\$ .85$

18. Keep pen / Trade it for $\$ .90$

19. Keep pen / Trade it for $\$ .95$

20. Keep pen / Trade it for $\$ 1.00$

21. Keep pen / Trade it for $\$ 1.05$

22. Keep pen / Trade it for $\$ 1.10$

23. Keep pen / Trade it for $\$ 1.15$

24. Keep pen / Trade it for $\$ 1.20$

25. Keep pen / Trade it for $\$ 1.25$

26. Keep pen / Trade it for $\$ 1.30$

27. Keep pen / Trade it for $\$ 1.35$

28. Keep pen / Trade it for $\$ 1.40$

29. Keep pen / Trade it for $\$ 1.45$

30. Keep pen / Trade it for $\$ 1.50$ 
Please read the following instructions carefully:

You now have the opportunity to take the pen or get some money. Below are a series of lines marked "Take the pen/ Take \$ ." On each line circle whether you would prefer to receive the pen or receive the amount of money written on the line. Circle one or the other on every line.

We have predetermined a money amount for the pens. The amount is written on a slip of paper in the envelope displayed before you. When everyone has completed their forms, the amount will be revealed.

If you specified below that you would prefer to trade the pen in for the money amount we reveal then you will give up the pen and we will give you the money. If you specified that you would prefer to keep the pen over the amount we reveal, then you will keep the pen.

Note that your choice below will not affect the amount written in the envelope. Therefore, it is in your interest to indicate what the pen is truly worth to you.

All trades will take place immediately. 


\section{APPENDiX H}

Please read the following instructions carefully:

You now have the opportunity to get a pen or get some money. Below are a series of lines marked "Get a pen/Get \$_". On each line circle whether you would prefer to receive a pen or receive the amount of money written on the line. Circle one or the other on every line.

We have predetermined a money amount for the pens. The amount is written on a slip of paper in the envelope displayed before you. When everyone has completed their forms, the amount will be revealed.

If you specified below that you would prefer to trade the pen in for the money amount we reveal then you will give up the pen and we will give you the money. If you specified that you would prefer to keep the pen over the amount we reveal, then you will keep the pen.

Please note your choices below will not affect the predetermined money amount. Therefore it is in your best interest to indicate what the pen is truly worth to you.

All trades will take place immediately. 
31. Get a pen / Get $\$ .05$

32. Get a pen / Get $\$ .10$

33. Get a pen / Get $\$ .15$

34. Get a pen / Get $\$ .20$

35. Get a pen / Get $\$ .25$

36. Get a pen / Get $\$ .30$

37. Get a pen / Get $\$ .35$

38. Get a pen / Get $\$ .40$

39. Get a pen / Get $\$ .45$

40. Get a pen / Get $\$ .50$

41. Get a pen / Get $\$ .55$

42. Get a pen / Get $\$ .60$

43. Get a pen / Get $\$ .65$

44. Get a pen / Get $\$ .70$

45. Get a pen / Get $\$ .75$
46. Get a pen / Get $\$ .80$

47. Get a pen / Get $\$ .85$

48. Get a pen / Get $\$ .90$

49. Get a pen / Get $\$ .95$

50. Get a pen / Get $\$ 1.00$

51. Get a pen / Get $\$ 1.05$

52. Get a pen / Get $\$ 1.10$

53. Get a pen / Get $\$ 1.15$

54. Get a pen / Get $\$ 1.20$

55. Get a pen / Get $\$ 1.25$

56. Get a pen / Get $\$ 1.30$

57. Get a pen / Get $\$ 1.35$

58. Get a pen / Get $\$ 1.40$

59. Get a pen / Get $\$ 1.45$

60. Get a pen / Get $\$ 1.50$ 
Please read the following instructions carefully:

You now have the opportunity to trade your pen for some money. Below are a series of lines marked "Keep pen/ Trade it in for \$__. On each line circle whether you would prefer to keep the pen or trade it for the amount of money written on the line. Please circle one or the other for every line.

We have predetermined a money amount for the pens. The amount is written on a slip of paper in the envelope displayed before you. When everyone has completed their forms, the amount will be revealed.

If you specified below that you would prefer to trade the pen in for the money amount we reveal then you will give up the pen and we will give you the money. If you specified that you would prefer to keep the pen over the amount we reveal, then you will keep the pen.

Note that your choice below will not affect the amount written in the envelope. Therefore, it is in your interest to indicate what the pen is truly worth to you.

All trades will take place immediately. 
61. Keep pen / Trade it for $\$ .05$

62. Keep pen / Trade it for $\$ .10$

63. Keep pen / Trade it for $\$ .15$

64. Keep pen / Trade it for $\$ .20$

65. Keep pen / Trade it for $\$ .25$

66. Keep pen / Trade it for $\$ .30$

67. Keep pen / Trade it for $\$ .35$

68. Keep pen / Trade it for $\$ .40$

69. Keep pen / Trade it for $\$ .45$

70. Keep pen / Trade it for $\$ .50$

71. Keep pen / Trade it for $\$ .55$

72. Keep pen / Trade it for $\$ .60$

73. Keep pen / Trade it for $\$ .65$

74. Keep pen / Trade it for $\$ .70$

75. Keep pen / Trade it for $\$ .75$
76. Keep pen / Trade it for $\$ .80$

77. Keep pen / Trade it for $\$ .85$

78. Keep pen / Trade it for $\$ .90$

79. Keep pen / Trade it for $\$ .95$

80. Keep pen / Trade it for $\$ 1.00$

81. Keep pen / Trade it for $\$ 1.05$

82. Keep pen / Trade it for $\$ 1.10$

83. Keep pen / Trade it for $\$ 1.15$

84. Keep pen / Trade it for $\$ 1.20$

85. Keep pen / Trade it for $\$ 1.25$

86. Keep pen / Trade it for $\$ 1.30$

87. Keep pen / Trade it for $\$ 1.35$

88. Keep pen / Trade it for $\$ 1.40$

89. Keep pen / Trade it for $\$ 1.45$

90. Keep pen / Trade it for $\$ 1.50$ 


\section{REFERENCES}

Abelson, R. (1981). Psychological status of the script concept. American Psychologist, vol. 36, 715-729.

Adamowicz, W., Bhardwaj, V., Macnab, B. (1993). Experiments on the Difference between Willingness to Pay and Willingness to Accept. Land Economics, 69, 416427.

Allais, M. (1953). Le comportement de l'homme rationnel devant le risque: critique des postulats et axiomes de l'école Américaine. Econometrica, 21, 503-546.

Ames, Kenneth L. (1984). Material Culture as Nonverbal Communication: A Historical Case Study. American Material Culture: The Shape of Things Around Us. (ed. Edith Mayo) Bowling Green, OH: Bowling Green University Popular Press, 2547.

Andreoni, J., and Vesterlund, L. (2001). Which Is the Fair Sex? Gender Differences in Altruism. Quarterly Journal of Economics 116, no. 1, 293-312.

Ariely, D., Huber, J., \& Wertenbroch, K. (2005). When do losses loom larger than gains? Journal of Marketing Research, 62, 134-138.

, \& Simonson, I (2003). Buying, Bidding, Playing, or Competing? Value Assessment and Decision Dynamics in Online Auctions. Journal of Consumer Psychology, vol. 13, 113-123.

Arlen, J., Spitzer, M., \& Talley, E. (2002). Endowment Effects within Corporate Agency Relationships. Journal of Legal Studies, 31(1), 1-37.

Ayres, I., and Siegelman, P. (1995). Race and Gender Discrimination in Bargaining for a New Car. American Economic Review 85, no. 3, 304-21.

Bar-Hillel, M. \& Neter, E. (1996). Why Are People Reluctant to Exchange Lottery Tickets? Journal of Personality and Social Psychology, 70, 17-27.

Bargh, J. (1997). The Automaticity Of Everyday Life, in Robert S. Wyer, Jr., ed., The Automaticity of Everyday Life: Advances in Social Cognition. Vol. 10. Mahwah, NJ: Erlbaum. pp. 1-61.

Bartlett, F. (1932). Remembering. Cambridge: Cambridge University Press. (1958). Thinking. New York: Basic Books

Beggan, J. (1992). On the Nature of Nonsocial Perception: The Mere Ownership Effect. Journal of Social and Personality Psychology, 62 (2), 229-237.

Beggan, J. \& Brown, E. (1994). Association as a Psychological Justification for Ownership. The Journal of Psychology, 128(4), 365-380. 
Belk, R. (1988). Possessions and the Extended Self. Journal of Consumer Research. 15, $139-168$.

Bettman, J., Luce, M, \& Payne, J. (1998). Constructive consumer choice processes. Journal of Consumer Research, 25, 187-217.

Bernoulli, D (1954). Exposition of a New Theory on the Measurement of Risk (original: 1738). Econometrica, 22, 23-36.

Bicchieri, C (2006). The Grammar of Society. The Nature and Dynamics of Social Norms. New York: Cambridge University Press.

Biddle, J. (1986). Recent Development in Role Theory. Annual Review of Sociology, 1267-1292.

Blondel, S. \& Lévy-Garboua, L. (2006). Cognitive Consistency, the Endowment Effect and The Preference Reversal Phenomenon. Working Paper.

Boyce R., T. Brown, G. McClelland, G. Peterson and W. Schulze (1992). An Experimental Examination of Intrinsic Values as a Source of the WTA-WTP Disparity. American Economic Review 82, 1366-1368.

Brown T., Gregory R. (1999). Why the WTA - WTP disparity matters. Ecological Economics. 28(3), 323-335.

Brown, Thomas C., (2005). Loss aversion without the endowment effect, and other explanations for the WTA-WTP disparity. Journal of Economic Behavior and Organization, 57, 367-379.

Camerer, C. (1995). Individual decision making. In J. Kagel and A. Roth (eds), Handbook of Experimental Economics, Princeton: Princeton University Press.

Carmichael, L. and MacLeod, B. (1996). Territorial bargaining. Mimeo. Queens University, Canada.

Carmon, Z., Wertenbroch, K. Zeelenberg, M. (2003). Option Attachment: When deliberating makes choosing feel like losing. Journal of Consumer Research. 30. 15-29.

Carmon, Z. \& Ariely, D. (2005). Focusing on the Forgone: Why Value Can Appear So Different to Buyers and Sellers. Journal of Consumer Research, 27, 360-370.

Chi, M., Glaser, R. \& Farr, M. (1988). The Nature of Expertise. Hillsdale, NJ: Erlbaum.

Cialdini, R. (1993). Influence: The Psychology of Persuasion. New York: Quill.

Coase, R. (1960). The Problem of Social Cost. 3 Journal of Law and Economics vol. 1. 
Cohen, D, and Knetsch, J. (1992). Judicial Choice and Disparities Between Measures of Economic Values. Osgood Hall Law Review 30.

Coombs, C., \& Avrunin, G. (1977), "Single Peaked Functions and the Theory of Preference". Psychological Review vol. 84 (2), 216-30.

Coursey, D., Hovis, J. and Schulze, W. (1987). The disparity between willingness to accept and willingness to pay measures of value. Quarterly Journal of Economics, 102, 679-690.

Cummings, R.G., Brookshire, D., \& Schulze, W. (1986). Valuing Environment Goods: An Assessment of the Contingent Valuation Method. Totowa, NJ: Rowman and Allanheld.

Csikszentmihalyi, M., \& Rochberg-Halton, E. (1981). The meaning of things: Domestic symbols and the self. Cambridge, England: Cambridge University Press.

Dhar, R. \& Wertenbroch, K. (2000). Consumer Choice between Hedonic and Utilitarian Goods. Journal of Marketing Research, 37. 60-71.

Eckel, C. and Grossman, P. (1998) Are Women Less Selfish Than Men? Evidence from Dictator Experiments. Economic Journal 108, no. 448, 726-35.

Epstein R. (2007). Behavioral Economics: Human Errors and Market Corrections. 73 University of Chicago Law Review 111.

Epstein, S. (2003). "Cognitive-Experiential Self-Theory of Personality." in Theodore Millon and Melvin J. Lerner, eds.: Comprehensive Handbook of Psychology. Vol. 5: Personality and Social Psychology. Hoboken, NJ: Wiley \& Sons, pp. 159-84.

Fiske, S. T. and Taylor, S. E. (1991). Social cognition (2nd edn.). New York: McGraw Hill.

Furby, L. (1978). Sharing: Decisions and Moral Judgments About Letting Others Use One's Posessions, Psychological Reports (43)2, 595-609

Franciosi, R., Kujal P., R. Michelitsch, V. Smith, and G. Deng (1996). Experimental test of the endowment effect. Journal of Economic Behavior \& Organization 30. 213222.

Frank, R. (1988). Passions with Reason. New York: W.W. Norton.

Friedman, D. (2003). Economics and evolutionary psychology. Mimeo. Santa Clara University.

Funnell, E. (2001). Evidence for scripts in Semantic dementia: Implications for theories of semantic memory. Cognitive Neuropsychology, 18(4), 323-341. 
Gal, D. (2006). A Psychological Law of Inertia and the Illusion of Loss Aversion. Judgment and Decision Making, 1, 23-32.

Gigerenzer, G., and Todd, P. (1999). Simple heuristics that make us smart. Oxford: Oxford University Press.

Gilbert, Daniel T. (1989). Thinking Lightly About Others: Automatic Components of the Social Inference Process, in James S. Uleman and John A. Bargh, eds., Unintended Thought. Englewood Cliffs, NJ: Prentice-Hall, pp. 189-211.

Gilbert, Daniel T. (2002). Inferential Correction, in Thomas Gilovich, Dale Griffin and Daniel Kahneman, eds., Heuristics and Biases. New York: Cambridge University Press, pp. 167-184.

Goodpaster, G. (1996). A Primer on Competitive Bargaining. Journal of Dispute Resolution, 325.

Hanemanm, M. (1991). "Willingness to Pay and Willingness to Accept: How Much Can They Differ?". The American Economic Review, 81(3), 635-647.

Harbaugh, W., Krause, K., L. Vesterlund (2001). Are adults better behaved than children? Age, experience and the endowment effect. Economic Letters 70, 175181.

Heberlein, T. \& Bishop, R. (1985). "Assessing the Validity of Contingent Valuation: Three Field experiments". Paper presented at the International Conference on Man's Role in Changing the Global Environment, Venice, Italy.

Heider, F. (1958). The psychology of interpersonal relations. New York: Wiley.

Heifetz, A., Shannon, C. and Spiegel, Y. (2002). What to maximize if you must. Mimeo. University of California, Berkeley.

Heifetz, A., Segev, E., E. Talley (2007). Market Design with endogenous preferences. Games and Economic Behavior vol 58, 121-153.

Herskovits, M.J. (1940). The Economic Life of Primitive People. New York: Alfred A. Knopf. Heyman, J., Orhun Y., and Ariely, D. (2004), "Auction Fever: The Effect of Opponents and Quasi-Endowment on Product Valuations". Journal of Interactive Marketing vol.18 (4), 4-21.

Horowitz, J. \& McConnell, K. (2002). A Review of WTA/WTP studies. Journal of Environmental Economics and Management, 44, 426-47.

Hovencamp, R. (1991). Legal Policy and the Endowment Effect, 20 Journal of Legal Studies vol. 225, 226-34.

Huck, S., Kirchsteiger, G., \& Oechssler, J. (2005). Learning to Like What You HaveExplaining the Endowment Effect. The Economic Journal, 115, 689-702. 
Johnson, E., Gächter, S., A. Herrmann (2006). Exploring the nature of loss aversion. IZA Working Paper No. 2015.

Jolls, C., Sunstein, C., \& Thaler, R. (1998a). A Behavioral Approach to Law and Economics. Stanford Law Review 50:1471-1550.

Kahneman, D. \& Tversky, A. (1984). "Choices, Values, and Frames". American Psychologist, 39(4), 341-50.

, \& Tversky, A. (1979). Prospect theory: An analysis of decision under risk. Econometrica, 47, 263-292.

, Knetsch, J., \& Thaler, R. (1990). Experimental Tests of the Endowment Effect and the Coase Theorem. Journal of Political Economy, 98, 1325-48.

, D. (2003). Maps of Bounded Rationality: Psychology for Behavioral Economics, The American Economic Review, Vol. 93(5), 1449-1475.

Keysar, B. (1994). The illusory transparency of intention: Linguistic perspective taking in text. Cognitive Psychology, 23, 165-208.

Knetsch, Jack L. (1989). The Endowment Effect and Evidence of Nonreversible Indifference Curves. The American Economic Review, 79(5), 1277-1284.

Knez, M. \& Smith, V. (1987). Hypothetical valuations and preference reversals in the context of asset trading, in (A. Roth, ed.), Laboratory Experimentation in Economics: Six Points of View. Cambridge: Cambridge University Press.

Kleine, S., Kleine, R., and C., Allen (1995). "How is a possession me or not me"? Characterizing Types and an Antecedent of Material Possession Attachment. Journal of Consumer Research vol. 22, 327-343.

Koszegi,B., Rabin, M. (2006). A Model of Reference-Dependent Preferences. Quarterly Journal of Economics vol. 121(4), 1133-1166.

Korobkin, R. (2000). A Positive Theory of Legal Negotiation. 88 Geo. L.J. 1789. , \& Ulen,T. (2000). Law and Behavioral Science: Removing the Rationality Assumption from Law and Economics. 88 CAL. L. REV. , (2003). The Endowment Effect and Legal Analysis. Northwestern University Law Review, 97, 1227-1293.

Lamberts, K., and Shanks, D. eds. (1997) Knowledge, Concepts, and Categories. Hove: Psychology Press.

Lamm, H. \& Kayser, E. (1978). An Analysis of Negotiation Concerning the Allocation of Jointly Produced Profit or Loss: The Role of Justice Norms, Politeness, Profit Maximization, and Tactics. $8^{\text {th }}$ International Journal of Group Tensions, 64, 66. 
Leiter, B. \& Weisberg, M. (2006). Why Evolutionary Biology is (So Far) Irrelevant to Law. University of Texas Law Review, Law \& Economics Research Paper no. 81. (Available at SSRN: http://ssrn.com/abstract $=892881$ )

Lerner, J., Small, D., \& Lowenstein, G. (2004). Heart Strings and Purse Strings: Carryover Effects of Emotions on Economic Decisions. Psychological Science, $15,337-341$.

Lewis, E. (1997). Kung Fu Address Books: The Relationship between Pricing and Narrative. Working paper. Department of Social and Decision Sciences. Carnegie Mellon University.

List, J. (2003). Does Market Experience eliminate market anomalies? Quarterly Journal of Economics, Feburary, 41-71.

Loewenstein, G. (1999). Experimental Economics from the Vantage-point of Behavioral Economics, in Economic Journal Controversy Corner: What's the Use of Experimental Economics 109, 25-34.

Loewenstein, G. \& Issacharoff, S. (1994). Source Dependence in the Valuation of Objects. Journal of Behavioral Decision Making, vol. 7, 157-168.

Loomis, J. (1987). Balancing Public Trust Resources of Mono lake and Los Angeles' Water Right: An Economic Approach. Water Resources Research, 23(8). 14491456.

Mandel, D. (2006). Economic Transactions among Friends: Asymmetric Generosity but Not Agreement in Buyers and Sellers Offers. Journal of Conflict Resolution. 50 (4). 584-606.

Mandler, Michael. 2005. Incomplete preferences and rational intransitivity of choice. Games Economic. Behavior 50(2). 255-277.

March, J. G. (1994). A primer on decision-making: How decisions happen. New York: Free Press.

Marshall, J. (1986). Agent's Evaluations and the Disparity of Measures of Economic Loss. 7 Journal of Economic Behavior and Organization vol. 65. 115.

McCaffrey, E., Kahneman, D., and M. Spitzer (1995). Framing the Jury: Cognitive Perspectives on Pain and Suffering Awards. Virginia Law Review, vol. 81(5), 1341-1420.

Mellers, B., \& Ritov, I. (2007). The Relative Magnitude of Pleasure and Pain. Manuscript Under Review.

Morrison, G., (1997). Willingness to pay and willingness to accept: some evidence of an endowment effect. Applied Economics, 29, 411-417. 
Nickerson, R. S. (1999). How we know- and sometimes misjudge what others know: Imputing one's own knowledge to others. Psychological Bulletin, 125, 737-760.

Novemsky, N. \& Kahneman, D. (2005). The Boundaries of Loss Aversion. Journal of Marketing Research, 42, 119-128.

Nuttin, J. (1987). Affective Consequences of Mere Ownership: The Name Letter Effect in Twelve European Languages. European Journal of Social Psychology,17(4), $381-402$.

. (1985). Narcissism beyond Gestalt and awareness: The name letter effect. European Journal of Social Psychology, 15, 353-361.

Ortona, G. \& Scacciati, F. (1992). New experiments on the Endowment Effect. Journal of Economic Psychology, 13, 277-296.

Piaget, J. (1952). The origins of intelligence in children. Norton, New York

Plott, C. \& Zeiler, K. (2005). "The Willingness to Pay-Willingness to Accept Gap, the "Endowment Effect", Subject Misconceptions, and Experimental Procedures for Eliciting Valuations". American Economic Review, 95(3), 530-545.

Plott, C. \& Zeiler, K. (2006). Asymmetries in Exchange Behavior Incorrectly Interpreted as Evidence of Prospect Theory. American Economic Review (forthcoming)

Poindexter, G. (1998) Light, Air, or Manhattanization?: Communal Aesthetics in Zoning Central City Real Estate Development. 78 Boston University Law Review 445, 500 .

Rabin, M. (1998), "Economics and Psychology," Journal of Economic Literature 36(1), $11-46$.

Rachlinski, J., \& Jourden, F. (1998). Remedies and the Psychology of Ownership. Vanderbilt Law Review, 51, 1541-1582.

Radin, M. (1982). Property and Personhood. Stanford Law Review 34.

Richards, J.M., Butler, E. A., \& Gross, J. J. (2003). Emotion regulation in romantic couples: The cognitive consequences of concealing feelings. Journal of Social and Personal Relationships, 20, 599-620.

Robinson, R., Keltner, D., Ward, A., \& Ross, L. (1995). Actual vs. assumed differences in construal: "Naïve realism" in intergroup perception and conflict. Journal of Personality and Social Psychology, 68, 404-417.

, \& Keltner, D. (1996). Much ado about nothing?: Revisionists and traditionalists choose an introductory English syllabus. Psychological Science, 7, $18-24$. 
Roth, G. (2006). Predicting the Gap between Willingness to Accept and Willingness to Pay. unpublished Ph.D. dissertation, University of Munich Graduate School of Economics. Available from ProQuest Dissertation Express: http://www.il.proquest.com/hp/Products/DisExpress.html.

Rumelhart, D., and Norman, D. (1978). Accretion, Tuning, and Restructuring: Three modes of Learning, in J. W. Cotton \& R. L. Klatzky (Eds.), Semantic Factors in Cognition. Hillsdale, NJ: Erlbaum, 37-54.

Rumelhart, D. and Ortony, A. (1977). The representation of knowledge in memory, in eds. Anderson, Spiro, and Montague, Steven's handbook of experimental psychology: Learning and cognition. Hillsdale, NJ: Erlbaum, 99-135.

Samuelson, W., and Zeckhauser, R. (1998). Status Quo Bias in Decision Making. 1 Journal of Risk and Uncertainty vol.7.

Sarbin, T. and Allen V. (1968). Increasing participation in a natural group setting: A preliminary report. Psychological Record vol. 18.

Schank, R.C. (1982a). Dynamic Memory: A Theory of Reminding and Learning in Computers and People. Cambridge: Cambridge University Press.

Schank, R., \& Abelson, R. (1977). Scripts, Plans, Goals and Understanding: an Inquiry into Human Knowledge Structures. Hillsdale, NJ: L. Erlbaum.

Schmidt, U. \& Traub, S. (2003). An Experimental Investigation of the Disparity between WTA and WTP for Lotteries. mimeo.

Shogren, J., Shin, S., Hayes, D., \& Kliebenstein, J. (1994). Resolving Differences in Willingness to Pay and Willingness to Accept. The American Economic Review, 84(1), 255-270.

Schweitzer, M. (2002) Offer-asking price gap and term of possession. Unpublished Paper.

Singh, H. (1991). The disparity between willingness to pay and compensation demanded. Another look at laboratory evidence. Economics Letters, 35, 263-266.

Slovic, P. (1995). The Construction of Preferences. American Psychologist, 50, 364-371.

Slovic, P., Finucane, M., Peters, E., and MacGregor, D. (2002). The Affect Heuristic. in Thomas Gilovich, Dale Griffin, and Daniel Kahneman, eds., Heuristics and Biases. New York: Cambridge University Press, pp. 397-420. 
Solomon, M., Surprenant, C., J. Czepiel, and E. Gutman (1985) A Role Theory

Perspective on Dyadic Interactions: The Service Encounter. Journal of Marketing, 49 (1), 99-111.

Stryker, S., and Statham, A.,(1985). Symbolic Interaction and Role Theory. in G.

Lindzey and E. Aronson (eds.), Handbook of Social Psychology, 3rd Edition. New York:

Random House, 311-378.

Sunstein, C. (1996) Social Norms and Social Roles. 96 Columbia Law Review 903. 943.

Sunstein, C. (1986). Legal Interference with Private Preferences. University of Chicago Law Review 53, 1129-1169.

Strahilevitz, M. \& Loewenstein, G. (1998). The Effect of Ownership History on the Valuation of Objects. Journal of Consumer Research, 25, 276-89.

Thaler, Richard (1980), Toward a Positive Theory of Consumer Choice. Journal of Economic Behavior and Organization, 1, 39-60.

Tversky, A. \& Kahneman, D. (1991). Loss Aversion in Riskless Choice: A ReferenceDependent Model. Quarterly Journal of Economics, 106(4), 1039-61.

, Slovic, P., \& Kahneman, D. (1990). The Causes of Preference Reversal. The American Economic Review, 80(1), 204-217.

Van Boven, L., Loewenstein, G., \& Dunning, D. (2003). Mispredicting the endowment effect: underestimation of owners' selling prices buy buyer's agents. Journal of Economic Behavior and Organization, 51, 351-365.

Van Dijk, E., \& Van Knippenberg, D. (1996). Buying and selling exchange goods: Loss aversion and the endowment effect. Journal of Economic Psychology, 17, 517524.

Van Esterik, P. (1986) Review of 'Distinction'. American Anthropologist vol. 88(2), 456457.

Van de Ven, N., Zeelenberg, M., \& and van Dijk, E. (2005). Buying and selling exchange goods: Outcome information, curiosity and the endowment effect. Journal of Economic Psychology, 26, 459-468.

Von Neumann, J., \& Morgenstern, O. (1947). Theory of games and economic behavior, 2nd ed. Princeton, NJ: Princeton University Press.

Werner, C.M., Brown, B.B., \& Damron, G. (1981). Territorial marking in a game arcade. Journal of Personality and Social Psychology vol. 41, 1094-1104. 
Wicklund, R. \& Gollwitzer, P. (1982). Symbolic Self Completion. HiHsdale, NJ: Lawrence Erlbaum Associates.

Williams, R., (1995). Valuing Natural Environments: Compensation, Market Norms, and the Idea of Public Goods. Connecticut Law Review 27 vol. 365, 455-57.

Wilson, T., \& Gilbert, D. (2005). Affective forecasting: Knowing what to want. Current Directions in Psychological Science, 14, 131-134.

Wilson, T. and Schooler, J. (1991). Thinking Too Much: Introspection Can Reduce the Quality of Preferences and Decisions. Journal of Personality and Social Psychology vol. 60(2), 181-92.

Yen, A. (1990). Restoring the Natural Law: Copyright as Labor and Possession. Ohio State Law Journal vol. 51, 515-559.

Zajonc, R. (1998). Emotions, in Daniel T. Gilbert, Susan T. Fiske, and Gardner Lindzey, eds., Handbook of Social Psychology. 4th Ed, Vol. 1. New York: Oxford University Press, pp. 591-632.

Zhong, C., Loewenstein, J., Murnighan, J. (2007) Speaking the same language: The cooperative effects of labeling in the prisoners' dilemma. Journal of Conflict Resolution. In press. 


\section{Vita}

Amy Elizabeth Coren was born in Fresno, California on August 16, 1979 and is the daughter of Lance and Susan Coren. After graduating from Sierra High School in Tollhouse, CA in 1997, Amy entered the University of California, Berkeley. Amy graduated from UCB with a B.A. in Psychology in May of 2001. Amy entered graduate school at the University of Texas at Austin in August of 2001 to pursue a Ph.D. in Psychology.

Permanent address: 800 W. $38^{\text {th }}$ St. \#1311, Austin, TX 78705

This dissertation was typed by the author, Amy Elizabeth Coren 